\title{
Verification of RESRAD-BUILD Computer Code, Version 3.1
}

\author{
for \\ Argonne National Laboratory \\ Contract No.: 1F-00741
}

March 2003 


\section{TABLE OF CONTENTS}

$\underline{\text { Section }}$

$\underline{\text { Page }}$

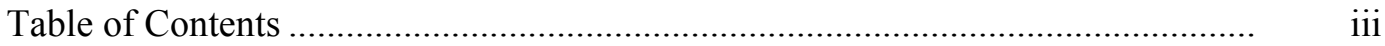

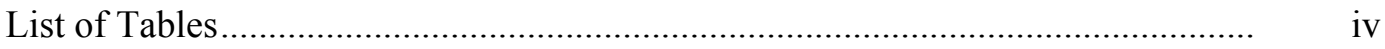

List of Figures ........................................................................................... v

Executive Summary …............................................................................ ES-1

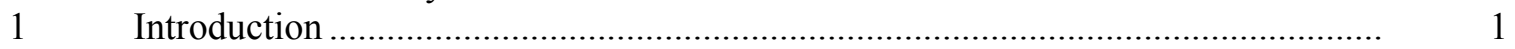

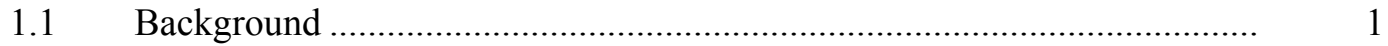

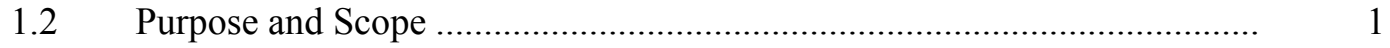

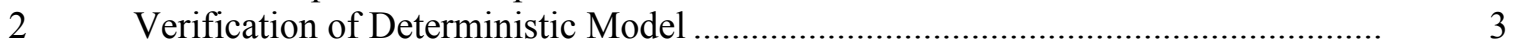

$2.1 \quad$ Database Verification .................................................................................

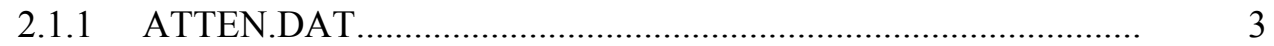

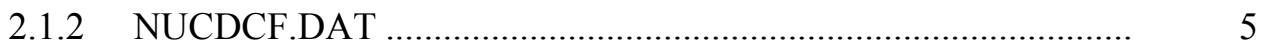

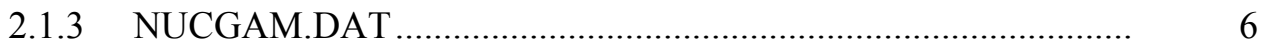

2.1.4 COEFF BD.LIB …........................................................ 7

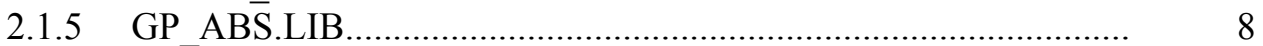

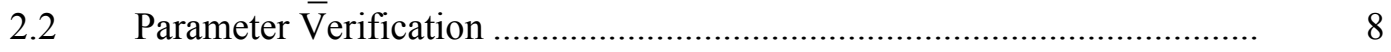

2.2.1 General Observations .......................................................... 10

2.2.2 Time Parameters.................................................................... 11

2.2.3 Building Parameters .............................................................. 13

2.2.4 Receptor Parameters.................................................................... 19

2.2.5 Source Parameters ...................................................................... 25

2.2.6 Shielding Parameters................................................................... 41

2.2.7 Tritium Model Parameters............................................................ 43

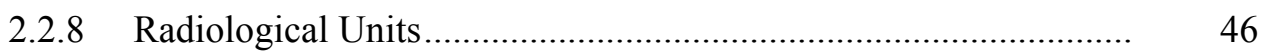

2.2.9 Parameters Not Covered in Appendix J ...................................... 46

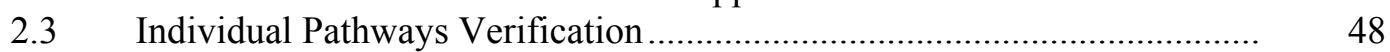

2.3.1 Direct External Gamma Pathway .............................................. 49

2.3.2 Submersion External Gamma Pathway ...................................... 67

2.3.3 Deposition External Gamma Pathway ....................................... 68

2.3.4 Radon Inhalation Pathway ....................................................... $\quad 70$

2.3.5 Other Inhalation Pathway ....................................................... $\quad 72$

2.3.6 Direct Ingestion Pathway ........................................................ $\quad 74$

2.3.7 Indirect Ingestion Pathway ..................................................... $\quad 75$

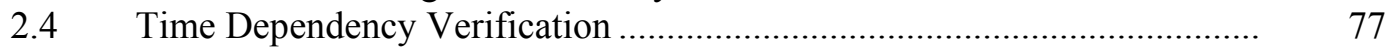

2.5 Multiple-Room Model Verification ...................................................... 78

2.6 Multiple Pathways, Receptors, Sources, Times Verification ....................... 79

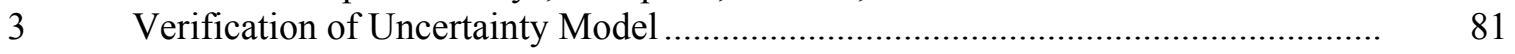

3.1 Verification of Parameter Inputs ....................................................... 81

3.1.1 Time Parameters............................................................... 81

3.1.2 Building Parameters ........................................................... 83

3.1.3 Receptor Parameters.......................................................... 84

3.1.4 Source Parameters ................................................................ 85

3.1.5 Shielding Parameters............................................................. 88

3.1.6 Tritium Model Parameters......................................................... 89

3.2 Input Distribution Verification ............................................................. 101

3.2.1 Selected Parameter Distributions ................................................ 101 
3.2.2 Crystal Ball Results .................................................................. 102

$3.3 \quad$ Output Distribution Verification ............................................................ 102

3.3.1 Input Parameter Distributions ....................................................... 103

3.3.2 Uncertainty Output Tabular Results.............................................. 103

3.3.3 Uncertainty Output Graphic Results ........................................... 105

$4 \quad$ Evaluation of Other Issues ............................................................................. 106

$4.1 \quad$ Consistency ....................................................................................... 106

4.2 User Friendliness ...................................................................................... 107

4.3 Calculation Methodology …………………………………………….... 109

$5 \quad$ Documents Used for Verification........................................................................ 115

\section{List of Tables}

$\underline{\text { Table }} \quad \underline{\text { Page }}$

Table 2-1. Databases and Libraries used by RESRAD-BUILD......................................... 3

Table 2-2. Energy Values for Attenuation Coefficients Used in RESRAD-BUILD (MeV) 4

Table 2-3. Comparison of Mass Attenuation Coefficients for Concrete Reported in ATTEN.DAT and the Radiological Health Handbook ........................................ 5

Table 2-4. List of RESRAD-Build Parameters Accessible through the User Interface ...... 9

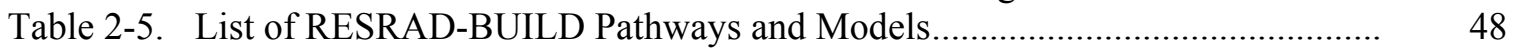

Table 2-6. Source Type and Shield Material Matrix for Point Source............................... 53

Table 2-7. Ratio of RESRAD-BUILD Results to MicroShield Results for Point Source... 55

Table 2-8. Ratio of RESRAD-BUILD Results to MicroShield Results for Line Source.... 55

Table 2-9. Ratio of RESRAD-BUILD Results to MicroShield Results for Infinite Area Source ........................................................................................................ 56

Table 2-10. Ratio of RESRAD-BUILD Results to MicroShield Results for Finite Area Source ................................................................................................... 56

Table 2-11. Ratio of RESRAD-BUILD Results to MicroShield Results for Infinite Volume Source

Table 2-12. Ratio of RESRAD-BUILD Results to MicroShield Results for Finite Volume Source

Table 2-13. Ratio of RESRAD-BUILD to MicroShield Area Factors for Area Source ........

Table 2-14. Ratio of RESRAD-BUILD to MicroShield Area Factors for Volume Source ..

Table 2-15. Ratio of RESRAD-BUILD to MicroShield Source-Material-Dependent Doses

Table 2-16. Ratio of RESRAD-BUILD to MicroShield Doses for Shielded Point Source...

Table 2-17. Ratio of RESRAD-BUILD to MicroShield Doses for Shielded Line Source....

Table 2-18. Ratio of RESRAD-BUILD to MicroShield Doses for Shielded Area Source ...

Table 2-19. Ratio of RESRAD-BUILD to MicroShield Doses for Shielded Concrete Volume Source (Air and Shield Material Buildup Factors) ............................. 65

Table 2-20. Ratio of RESRAD-BUILD to MicroShield Doses for Shielded Concrete Volume Source (Source Material Buildup Factors)........................................... 66

Table 2-21. Verification of Submersion Pathway Results ................................................... 68

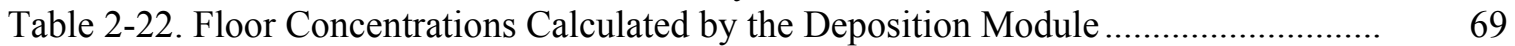

Table 2-23. Verification of Deposition External Gamma Pathway Results .......................... 69

Table 2-24. Verification of Single-Region Radon Volume Source Injection Module ........... 71

Table 2-25. Verification of Multi-Region Radon Volume Source Injection Module ........... 71

Table 2-26. Verification of the Radon Inhalation Module .................................................... 72 


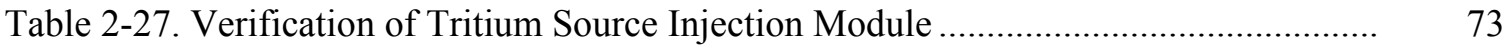

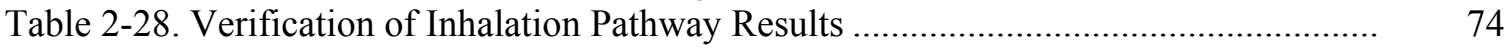

Table 2-29. Verification of Direct Ingestion Pathway Results............................................ 75

Table 2-30. Verification of Indirect Ingestion Pathway Results ........................................... 76

Table 2-31. Verification of Multiple-Room Model Results ................................................... 79

Table 3-1. Parameters, Distributions, and Values Used in Uncertainty Analysis Input Tests 101

Table 3-2. Distribution fits obtained by Crystal Ball using the Kolmogorov-Smirnov Technique.......................................................................................... 102

Table 3-3. Parameters, distributions, and values used in uncertainty analysis output tests 103

Table 3-4. Ratio between RESRAD-BUILD and Crystal Ball Results for Statistical Parameters of Output Distributions

\section{List of Figures}

Figure $\quad \underline{\text { Page }}$

2-1 Source-Receptor Geometries Used to Test the Direct External Gamma Pathway... $\quad 51$ 


\section{Verification of RESRAD-BUILD Computer Code, Version 3.1}

\section{Executive Summary}

RESRAD-BUILD is a computer model for analyzing the radiological doses resulting from the remediation and occupancy of buildings contaminated with radioactive material. It is part of a family of codes that includes RESRAD, RESRAD-CHEM, RESRAD-RECYCLE, RESRADBASELINE, and RESRAD-ECORISK. The RESRAD-BUILD models were developed and codified by Argonne National Laboratory (ANL); version 1.5 of the code and the user's manual were publicly released in 1994. The original version of the code was written for the Microsoft DOS operating system. However, subsequent versions of the code were written for the Microsoft Windows operating system.

The purpose and scope of this report (detailed in Section 1), are to provide an independent review and verification of the RESRAD-BUILD code under the guidance provided by ANSI/ANS-10.41987, Guidelines for the Verification and Validation (V\&V) of Scientific and Engineering Computer Programs for the Nuclear Industry for verification and validation of existing computer programs. This approach consists of an a posteriori $\mathrm{V} \& \mathrm{~V}$ review which takes advantage of available program development products as well as user experience. The purpose, as specified in ANSI/ANS-10.4, is to determine whether the program produces valid responses when used to analyze problems within a specific domain of applications, and to document the level of verification. The culmination of these efforts is the production of this formal Verification Report.

The verification tasks were conducted in three parts and were applied to version 3.1 of the RESRAD-BUILD code and the final version of the user's manual, issued in November 2001 (Yu et al. 2001). These parts include the verification of the deterministic models used in RESRADBUILD (Section 2), the verification of the uncertainty analysis model included in RESRADBUILD (Section 3), and recommendations for improvement of the RESRAD-BUILD user interface, including evaluations of the user's manual, code design, and calculation methodology (Section 4).

Any verification issues that were identified were promptly communicated to the RESRADBUILD development team, in particular those that arose from the database and parameter verification tasks. This allowed the developers to start implementing necessary database or coding changes well before this final report was issued.

The deterministic models in RESRAD-BUILD were verified using a bottoms-up approach to improve task efficiency. Databases that are required to run one or more pathways were verified first. This was followed by verification of input parameters used in the mathematical models to ensure that all were captured in the code. The next step was the verification that mathematical models for individual exposure pathways, as described in the user's manual, were correctly implemented in the code. In addition, the proper implementation of time-dependent calculations was verified. The final step was the integration of the results of the previous steps to verify the proper summation of dose contributions to multiple receptors from multiple sources and pathways at different time intervals. Each of these steps is discussed in greater detail in the Section 2.

No major issues were encountered in verifying the deterministic models. With few exceptions, the database libraries were found to consistent with the literature from which they are derived. Some recommendations are made to improve the error checking routines for many of the input parameters and to correct some minor problems encountered with the line source model. 
The RESRAD-BUILD uncertainty model was verified in three steps. The first step focused the response of the code to inputs made during the parameter verification phase. The second step was to verify that the input data sets produced by the Latin hypercube sampling routine corresponded to the specified statistical distributions. The third step verified the correct distribution of output results following uncertainty simulations.

No major issues were encountered in verifying the uncertainty models when entering parameters within reasonable ranges. However, some problems were encountered when entering parameter values that exceed acceptable ranges, as defined in the deterministic models.

In addition to performing a strict verification of the deterministic and uncertainty calculations performed by RESRAD-BUILD, the following related tasks aimed at improving the code and supporting documentation were conducted in parallel:

- Review of the code, user's manual and other ancillary documentation for consistency.

- Review of the code functions that do not impact the calculations.

- Review of the calculation methodology.

In general, the user's manual was found to be very well written and easy to follow. Most of the time, what was written in the manual was reflected in the code. However, there are some areas, highlighted in Section 4, that could be improved to make the RESRAD-BUILD code and the user's manual a better product. 


\section{Introduction}

\subsection{Background}

RESRAD-BUILD is a computer model for analyzing the radiological doses resulting from the remediation and occupancy of buildings contaminated with radioactive material. It is part of a family of codes that includes RESRAD, RESRAD-CHEM, RESRAD-RECYCLE, RESRADBASELINE, and RESRAD-ECORISK. The RESRAD-BUILD models were developed and codified by Argonne National Laboratory (ANL); version 1.5 of the code and the user's manual were publicly released in 1994. The original version of the code was written for the Microsoft DOS operating system. However, subsequent versions of the code were written for the Microsoft Windows operating system.

The code developers have extensively tested all versions released to the public by ANL, from version 1.5 to the current version 3.1. These internal verification and validation tasks have covered all life-cycle development phases of the software, including the definition, design, coding, integration/testing, installation, and operation/maintenance phases defined in ANSI/ANS10.4-1987, Guidelines for the Verification and Validation of Scientific and Engineering Computer Programs for the Nuclear Industry. As defined in ANSI/ANS-10.4, validation consists of the process of testing a computer program and evaluating the results to ensure compliance with specified requirements, whereas verification consists of the process of evaluating the products of a software development phase to provide assurance that they meet the requirements defined for them by the previous phase.

\subsection{Purpose and Scope}

The purpose of the present verification task (which includes validation as defined in the standard) is to provide an independent review of the latest version of RESRAD-BUILD under the guidance provided by ANSI/ANS-10.4 for verification and validation of existing computer programs. This approach consists of a posteriori $\mathrm{V} \& \mathrm{~V}$ review which takes advantage of available program development products as well as user experience. The purpose, as specified in ANSI/ANS-10.4, is to determine whether the program produces valid responses when used to analyze problems within a specific domain of applications, and to document the level of verification. The culmination of these efforts is the production of this formal Verification Report.

The first step in performing the verification of an existing program was the preparation of a Verification Review Plan. The review plan consisted of identifying:

- Reason(s) why a posteriori verification is to be performed

- Scope and objectives for the level of verification selected

- Development products to be used for the review

- Availability and use of user experience

- Actions to be taken to supplement missing or unavailable development products.

The purpose, scope and objectives for the level of verification selected are described in this section of the Verification Report. The development products that were used for the review and 
any actions that were taken when these items were missing are documented in Section 5 of this report. The availability and use of user experience were limited to extensive experience in performing RESRAD-BUILD calculations by the verification project manager and by participation in the RESRAD-BUILD workshop offered by the code developers on May 11, 2001.

The level of a posteriori verification that was implemented is defined in Sections 2 through 4 of this report. In general, a rigorous verification review plan addresses program requirements, design, coding, documentation, test coverage, and evaluation of test results. The scope of the RESRAD-BUILD verification is to focus primarily on program requirements, documentation, testing and evaluation. Detailed program design and source code review would be warranted only in those cases when the evaluation of test results and user experience revealed possible problems in these areas.

The verification tasks were conducted in three parts and were applied to version 3.1 of the RESRAD-BUILD code and the final version of the user's manual, issued in November $2001(\mathrm{Yu}$ et al. 2001). These parts include the verification of the deterministic models used in RESRADBUILD (Section 2), the verification of the uncertainty analysis model included in RESRADBUILD (Section 3), and recommendations for improvement of the RESRAD-BUILD user interface, including evaluations of the user's manual, code design, and calculation methodology (Section 4).

Any verification issues that were identified were promptly communicated to the RESRADBUILD development team, in particular those that arose from the database and parameter verification tasks. This allowed the developers to start implementing necessary database or coding changes well before this final report was issued. 


\section{Verification of Deterministic Model}

The deterministic models in RESRAD-BUILD were verified using a bottoms-up approach to improve task efficiency. Databases that are required to run one or more pathways were verified first. This was followed by verification of input parameters used in the mathematical models to ensure that all were captured in the code. The next step was the verification that mathematical models for individual exposure pathways, as described in the user's manual, were correctly implemented in the code. In addition, the proper implementation of time-dependent calculations was verified. The final step was the integration of the results of the previous steps to verify the proper summation of dose contributions to multiple receptors from multiple sources and pathways at different time intervals. Each of these steps is discussed in greater detail in the following sections.

\subsection{Database Verification}

The bottoms-up approach includes first verifying that common databases and libraries are correctly implemented in the code. An example of this includes verification that the databases of radionuclide dose conversion factors, half-life, and photon emission energies/intensities have been accurately transcribed from their original sources. Verification of correct data transcription was not limited to a comparison between the data in the user's manual and the code, but was also extended to the original sources from which these data were obtained (e.g., Federal Guidance Reports 11 and 12). Table 2-1 lists the databases and libraries that are included in RESRADBUILD.

Table 2-1. Databases and Libraries used by RESRAD-BUILD

\begin{tabular}{ll} 
File Name & Description \\
\hline ATTEN.DAT & Material attenuation coefficients \\
NUCDCF.DAT & Nuclide dose conversion factors \\
NUCGAM.DAT & Photon emission energies and yields \\
COEFF_BD.LIB & Nuclide photon coefficients for volume sources \\
GP_ABS.LIB & Material buildup factor coefficients
\end{tabular}

Where appropriate, an Excel spreadsheet program was used to enter the radionuclide-specific or material-specific data from the original source. For radionuclide-specific databases, the contribution of short-lived progeny were added to the parent radionuclides based on the definition of principal and associated radionuclides used in RESRAD-BUILD. These values were compared to the values taken from the RESRAD-BUILD database by taking the ratio and identifying any ratios that deviate significantly from the expected ratio of one.

\subsubsection{ATTEN.DAT}

The material attenuation coefficients used for shielding calculations in the external gamma pathway are contained in the file ATTEN.DAT. The file simply lists the attenuation coefficients in 8 blocks containing 26 values each. No material names, energy values, or units are provided. Appendix F of the user's manual does not list these coefficients, but indicates that the units of mass attenuation coefficient are in $\mathrm{cm}^{2} / \mathrm{g}$. Based on the way in which material types are 
displayed in the user's manual, the order in which the material coefficients are arranged is as follows: Concrete, Water, Aluminum, Iron, Copper, Tungsten, Lead, Uranium. The energy values corresponding to the 26 entries for each material are assumed to be in $\mathrm{MeV}$, as shown in Table 2-2.

Table 2-2. Energy Values for Attenuation Coefficients Used in RESRAD-BUILD (MeV)

$\begin{array}{llll}1.0 \mathrm{E}-02 & 1.3 \mathrm{E}-02 & 1.5 \mathrm{E}-02 & 2.0 \mathrm{E}-02 \\ 3.0 \mathrm{E}-02 & 4.0 \mathrm{E}-02 & 5.0 \mathrm{E}-02 & 6.0 \mathrm{E}-02 \\ 8.0 \mathrm{E}-02 & 1.0 \mathrm{E}-01 & 1.5 \mathrm{E}-01 & 2.0 \mathrm{E}-01 \\ 3.0 \mathrm{E}-01 & 4.0 \mathrm{E}-01 & 5.0 \mathrm{E}-01 & 6.0 \mathrm{E}-01 \\ 8.0 \mathrm{E}-01 & 1.0 \mathrm{E}+00 & 1.5 \mathrm{E}+00 & 2.0 \mathrm{E}+00 \\ 3.0 \mathrm{E}+00 & 4.0 \mathrm{E}+00 & 5.0 \mathrm{E}+00 & 6.0 \mathrm{E}+00\end{array}$

$8.0 \mathrm{E}+00 \quad 1.0 \mathrm{E}+01$

With the exception of the entry for $1.3 \mathrm{E}-02 \mathrm{MeV}$, all the other energy values appear to correspond exactly to the energy values reported in Table 5.1, Mass Attenuation Coefficients $\left(\mathrm{cm}^{2} / \mathrm{g}\right)$, of "The Health Physics and Radiological Health Handbook" (RHH; Shleien 1992). Based on a comparison with this reference, it was possible to verify the mass attenuation coefficients for all materials except uranium and for all energy values except $1.3 \mathrm{E}-02 \mathrm{MeV}$.

The mass attenuation coefficient values for 1.3E-02 MeV reported in ATTEN.DAT appear to fall between the values reported for $1.0 \mathrm{E}-02$ and $1.5 \mathrm{E}-02 \mathrm{MeV}$. Therefore, there is a high degree of confidence that the mass attenuation coefficient values at this energy level are correct.

While it was not possible to verify the attenuation coefficients for uranium, these values are of similar magnitudes to the values for lead, the material closest to uranium in terms of atomic number ( $Z=82$ vs. 92$)$. In addition, for all energies at which scattering is the dominant attenuation mechanism, the mass attenuation coefficients for uranium are greater than those for lead, as expected. In addition, the material type is used only as a secondary input to determine the shielding effectiveness; the primary inputs are the shielding density and thickness. Finally, uranium is not a common shielding material for most RESRAD-BUILD applications. Therefore, the inability to verify the uranium mass attenuation coefficients is not critical.

With the exceptions noted above, the coefficients in ATTEN.DAT exactly matched the coefficients listed in Table 5.1 of the RHH for all materials and energies except for the coefficients for concrete at energies between 1.0E-2 and 5.0E-01 MeV. The values in ATTEN.DAT were up to 11 percent higher in this energy range, as shown in Table 2-3. These discrepancies are not critical and are likely due to slightly different assumed compositions of concrete. Such variability can be expected in the different formulations of concrete that are likely to be encountered in actual applications of the RESRAD-BUILD code.

No mass attenuation coefficients for air are listed in ATTEN.DAT. While air is not one of the material types that can be selected by the user, it appears to be used internally by the code to determine the attenuation between otherwise unshielded sources and receptors. The user's manual does not list the mass attenuation coefficients used in the code, and the source code was not reviewed. Therefore, it was impossible to directly verify the correct implementation of mass attenuation coefficients for air. 
Table 2-3. Comparison of Mass Attenuation Coefficients for Concrete Reported in ATTEN.DAT and the Radiological Health Handbook

\begin{tabular}{cccc}
$\begin{array}{c}\text { Energy } \\
(\mathrm{MeV})\end{array}$ & ATTEN.DAT & RHH & Ratio \\
\hline $1.0 \mathrm{E}-02$ & 26.9 & 26.1 & 1.03 \\
$1.3 \mathrm{E}-02$ & 26.9 & $\mathrm{n} / \mathrm{a}$ & $\mathrm{n} / \mathrm{a}$ \\
$1.5 \mathrm{E}-02$ & 8.24 & 8.02 & 1.03 \\
$2.0 \mathrm{E}-02$ & 3.59 & 3.47 & 1.03 \\
$3.0 \mathrm{E}-02$ & 1.19 & 1.12 & 1.06 \\
$4.0 \mathrm{E}-02$ & 0.605 & 0.552 & 1.10 \\
$5.0 \mathrm{E}-02$ & 0.392 & 0.353 & 1.11 \\
$6.0 \mathrm{E}-02$ & 0.295 & 0.266 & 1.11 \\
$8.0 \mathrm{E}-02$ & 0.213 & 0.195 & 1.09 \\
$1.0 \mathrm{E}-01$ & 0.179 & 0.167 & 1.07 \\
$1.5 \mathrm{E}-01$ & 0.144 & 0.138 & 1.04 \\
$2.0 \mathrm{E}-01$ & 0.127 & 0.124 & 1.02 \\
$3.0 \mathrm{E}-01$ & 0.108 & 0.107 & 1.01 \\
$4.0 \mathrm{E}-01$ & 0.0963 & 0.0955 & 1.01 \\
$5.0 \mathrm{E}-01$ & 0.0877 & 0.0872 & 1.01 \\
$6.0 \mathrm{E}-01$ & 0.081 & 0.0806 & 1.00 \\
$8.0 \mathrm{E}-01$ & 0.0709 & 0.0708 & 1.00 \\
$1.0 \mathrm{E}+00$ & 0.0637 & 0.0637 & 1.00 \\
$1.5 \mathrm{E}+00$ & 0.0519 & 0.0519 & 1.00 \\
$2.0 \mathrm{E}+00$ & 0.0448 & 0.0448 & 1.00 \\
$3.0 \mathrm{E}+00$ & 0.0365 & 0.0365 & 1.00 \\
$4.0 \mathrm{E}+00$ & 0.0319 & 0.0319 & 1.00 \\
$5.0 \mathrm{E}+00$ & 0.029 & 0.0289 & 1.00 \\
$6.0 \mathrm{E}+00$ & 0.027 & 0.027 & 1.00 \\
$8.0 \mathrm{E}+00$ & 0.0245 & 0.0245 & 1.00 \\
$1.0 \mathrm{E}+01$ & 0.0231 & 0.0231 & 1.00
\end{tabular}

\subsubsection{NUCDCF.DAT}

The NUCDCF.DAT file contains the following data, primarily dose conversion factors (DCFs), in columnar form for each of the 67 radionuclides in the RESRAD-BUILD database:

- Principle nuclide name

- Principle nuclide decay product (if any)

- Ingestion $\mathrm{DCF}(\mathrm{mrem} / \mathrm{pCi})$

- Inhalation DCF (mrem/pCi),

- Immersion DCF $(\mathrm{mrem} / \mathrm{pCi} / \mathrm{m} 3)$

- Surface contamination DCF (mrem/yr per pCi/m2)

- Volume contamination DCF (mrem/yr per pCi/m3)

- Half life (years)

- Number of photons (if any)

- Nuclide branching ratio (if applicable)

The DCFs for ingestion and inhalation were developed from Federal Guidance Report (FGR) 11 (Eckerman et al. 1988) while the immersion, surface and volume contamination DCFs were 
developed from FGR 12 (Eckerman and Ryman 1993). The source of the half-life was assumed to be FGR 11. The source of the number of photons and nuclide branching ratio data is not specified or readily apparent, but such data are available from reference sources such as the RHH.

To verify the dose conversion factors, the contributions from short-lived associated radionuclides (decay products with half-life less than 180 days) had to be calculated first. The DCFs of any associated radionuclide were added to the DCF of the principal radionuclide that generated them, after accounting for the decay yield. The DCFs derived from the Federal Guidance Reports were then converted to the proper units (from SI to standard units) so that ratios could be taken between the values listed in NUCDCF.DAT and the values used for verification. The ratio for all inhalation and ingestion DCF values, as well as the half-life values, was unity, indicating perfect agreement with the original source. Most of the ratios for the other pathway DCFs were unity, with the exception of some deviation on the order of $2 \%$ or less for Sb-125 (immersion and surface contamination) and Th-229 (immersion, surface and volume contamination). It is possible that such small discrepancies could be due to rounding, but they would not have significant effects on the dose calculations.

Based on the description of the external gamma model in Appendix F of the user's manual, the surface dose factors in this file are not used directly in the calculations. Rather, area sources are treated as volume sources of small thickness $(0.01 \mathrm{~cm})$ with unit density. It is possible that previous versions of the RESRAD-BUILD code made use of contaminated surface DCF values, but if indeed these DCFs are no longer used, a note stating this fact should be added to the file.

\subsubsection{NUCGAM.DAT}

The NUCGAM.DAT file appears to contain a listing of the number of photons, energies, yields, and half-lives for each of the 67 radionuclides in the RESRAD-BUILD database that decays by photon emission. It also appears to list the inhalation, ingestion, and immersion DCFs for some, but not all radionuclides. Several discrepancies were noted in these DCF values (relative to the values reported in NUCDCF.DAT), but the DCFs in NUCGAM.DAT were not formally verified as it appeared that RESRAD-BUILD did not use the DCF values from this file.

Only the data on the number of photons, energies and yields was verified for all photon-emitting radionuclides. The comparison was made using the RHH or ICRP Publication38 (ICRP 1983) as the sources for the original data. The listing for each radionuclide consisted of first the photon energies corresponding to the number of photons (as many as 20 energy groups per radionuclide). The contributions from associated radionuclides, accounting for yield, were included in the verification. In many cases, the photon groups in NUCGAM.DAT did not correspond to the photon groups in the RHH or ICRP 38. This made the verification task very tedious, as certain assumptions had to be made regarding the proper grouping of photons corresponding to the groups in NUCGAM.DAT.

A large number of discrepancies were encountered in verifying the photon energy groups and yields. In many cases, these discrepancies could not be resolved by re-assigning photons to different energy groups. However, such discrepancies do not appear to have any impact on the calculation of external gamma doses in RESRAD-BUILD. The photon energy and yield data used in these calculations appear to be drawn from another file, CEOFF BD.LIB, described in the next section. Therefore, while NUCGAM.DAT was found to contain numerous inconsistencies, this file does not appear to have any use in the current version of RESRAD- 
BUILD and may have been retained from earlier versions of the code. If that is the case, a note should be added to the file to avoid potential sources of confusion.

\subsubsection{COEFF_BD.LIB}

The COEFF_BD.LIB file contains data necessary to perform external dose pathway calculations. The data are listed in columns (for each of 67 radionuclides) as follows:

- Volume contamination DCF for an infinite slab source from FGR 12, in (mrem/yr) per ( $\mathrm{pCi} / \mathrm{g})$, including contributions of any associated decay products

- Fitted parameters $A_{i}, B_{i}, K_{A i}$, and $K_{B i}$ used to calculate depth and cover factors from Table F.1 in the RESRAD-BUILD user's manual

- Number of photon groups $(0,1,2,3$, or 4$)$ that follow

- Energy (in MeV) in each of up to 4 photon groups

- Yield (fraction) of photons in each of photon energy group

- Name of the principle radionuclide and whether it has associated decay products (identified as " $+\mathrm{d} 180 ")$

The volume contamination DCFs had already been verified for the file NUCDCF.DAT, but several DCF values in COEFF_BD.LIB were inconsistent and incorrect. The ratios of the DCFs for $\mathrm{Ce}-144$, Th-229, U-238, and $\mathrm{Pu}-244$ were $0.99,1.01,0.90$, and 3.83. These last two ratios indicate that, for area and volume sources, the direct gamma doses calculated in RESRADBUILD from U-238 would be underestimated by 10 percent, while the doses from Pu- 244 would be overestimated by almost a factor of 4 .

The fitted parameters $A_{i}, B_{i}, K_{A i}$, and $K_{B i}$ were compared to the values in Table $F-5$ of the user's manual and were all found to match with the exception of the $\mathrm{K}_{\mathrm{Ai}}$ value for $\mathrm{Eu}-154$, which was a factor of 10 times higher in Table 5.1 than in COEFF_BD.LIB.

Appendix F of the user's manual indicates that three constraints were put on the four fitting parameters as follows:

- All the parameters are forced to be positive

- $\mathrm{A}+\mathrm{B}=1$

- In the limit source depth, $t_{s}=$ zero; the DCF should match the contaminated surface DCF

The first condition was verified for all radionuclides by visual inspection.

The second condition was verified by summing the $A_{i}$ and $B_{i}$ coefficients when these were nonzero to see whether the result was equal to one. A minor discrepancy was found for U-233, for which the sum was found to be 1.0001. This is likely due to some rounding and should not significantly affect any results.

The third condition was verified by implementing equation F.2 in the user's manual for the cover and depth factor $\left(\mathrm{F}_{\mathrm{CD}}\right)$. This equation makes use of all four fitting parameters, plus the cover and source thickness and densities. In the limit as the volume source approaches zero thickness, the volume source thickness was set to $0.01 \mathrm{~cm}$, the density was set to $1.6 \mathrm{~g} / \mathrm{cm}^{3}$, and the cover thickness and density were set to zero. The $\mathrm{F}_{\mathrm{CD}}$ calculated in this way should approach the ratio 
of contaminated surface to volume DCFs from FGR12, corrected for a $0.000001-\mathrm{cm}$ "thick" surface source. In fact, most of the calculated $F_{C D}$ values were within $2 \%$ of the FGR 12 surfaceto-volume DCF ratios. However, the FGR 12 surface-to-volume DCF ratio calculated for Sm151 was $25 \%$ higher than the calculated $\mathrm{F}_{\mathrm{CD}}$ value. This indicates a possible error in one or more of the fitting parameters $\left(\mathrm{A}_{\mathrm{i}}, \mathrm{B}_{\mathrm{i}}, \mathrm{K}_{\mathrm{Ai}}\right.$, and $\left.\mathrm{K}_{\mathrm{Bi}}\right)$ derived for Sm-151.

\subsubsection{GP_ABS.LIB}

The GP_ABS.LIB contains buildup factor coefficients for all eight material types accessible to RESRAD-BUILD users, plus the coefficients for air and "S as magnesium". The reason for including the coefficients for sulfur is not clear and no explanation is provided in the RESRADBUILD user's manual.

The source for the buildup factor coefficients is also not provided in the user's manual. However, a review of the report External Exposure Model Used in the RESRAD Code for Various Geometries of Contaminated Soil (Kamboj et al. 1998) indicates that the source of the coefficients and the methodology for calculating the buildup factors is based on NUREG-5740 (Trubey 1991). Therefore, the buildup factor coefficients listed in NUREG-5740 were used to verify the buildup coefficients listed in GP_ABS.LIB for air and the eight material types used in RESRAD-BUILD. The coefficients for sulfur were not verified, as there are no explanation provided regarding their applicability to RESRAD-BUILD. All coefficients in GP_ABS.LIB were found to match the values reported in Table 5.1 of NUREG- 5740.

\subsection{Parameter Verification}

After the databases had been verified, all parameters that are normally accessible to the user were examined. The parameter names correspond to the way in which they are listed in the RESRADBUILD input files. The majority of these parameters are described in Appendix J of the RESRAD-BUILD user's manual. A list of these parameters is presented in alphabetical order in Table 2-4 by the name with which they appear in a typical RESRAD-BUILD input file. As noted where appropriate, these names did not always match the name in the user's manual. 
Table 2-4. List of RESRAD-Build Parameters Accessible through the User Interface

\begin{tabular}{|c|c|c|}
\hline Parameter & Descriptive title & $\begin{array}{l}\text { Section in } \\
\text { manual }\end{array}$ \\
\hline AIRFR & Air Release Fraction & J.4.7 \\
\hline AREA & Room Area & J.2.5 \\
\hline BRTRATE & Breathing Rate & J.3.5 \\
\hline DENSIO & Bulk Density (volume source) & J.4.16 \\
\hline DKSUS & Resuspension Rate & J.2.3 \\
\hline DLVL & Receptor Room & J.3.2 \\
\hline DOSE_TIME & Evaluation Time & J.1.4 \\
\hline DRYTḦICK & Dry Zone Thickness (tritium volume source) & J.6.1 \\
\hline DSDEN & Shielding Density & J.5.2 \\
\hline DSTH & Shielding Thickness & J.5.1 \\
\hline $\mathrm{DX}$ & Coordinates of Receptor Location & J.3.3 \\
\hline EFDIF0 & Effective Diffusion Coefficient (volume source) & J.4.19 \\
\hline EMANAO & Radon Emanation Fraction (volume source) & J.4.20 \\
\hline EROSO & Erosion Rate (volume source) & J.4.17 \\
\hline FCONTO & Contaminated Region (volume source) & J.4.14 \\
\hline FTIN & Indoor Time Fraction & J.1.2 \\
\hline $\mathrm{H}$ & Room Height & J.2.4 \\
\hline H3POROSITY & Porosity (tritium volume source) & N/A \\
\hline H3RMVF & $\begin{array}{l}\text { Fraction of Water Available for Evaporation } \\
\text { (tritium volume source) }\end{array}$ & J.6.4 \\
\hline H3THICK & $\begin{array}{l}\text { Wet+Dry Zone Thickness (tritium volume } \\
\text { source) }\end{array}$ & J.6.2 \\
\hline H3VOLFRACT & $\begin{array}{l}\text { Volumetric Water Content (tritium volume } \\
\text { source) }\end{array}$ & J.6.3 \\
\hline HUMIDITY & $\begin{array}{l}\text { Absolute Humidity of Indoor Air (tritium volume } \\
\text { source) }\end{array}$ & J.6.5 \\
\hline INGE1 & Ingestion Rate (direct) & J.4.8 \\
\hline INGE2 & Ingestion Rate (indirect) & J.3.6 \\
\hline LAMBDAT/LINPUT & Building/Room Air Exchange Rate & J.2.6 \\
\hline MTLC & Material Type (shielding) & J.5.3 \\
\hline MTLS & Material Type (source) & J.4.21 \\
\hline ND & Number of Receptors & J.3.1 \\
\hline NREGIOO & Number of Regions & J.4.13 \\
\hline NROOM & Number of Rooms & J.2.1 \\
\hline NS & Number of Sources & J.4.1 \\
\hline NTIME & Number of Times for Calculations & J.1.3 \\
\hline NUCSNAM/NNUCS & $\begin{array}{l}\text { Radionuclide Name/Number of Radionuclides } \\
\text { per Source }\end{array}$ & N/A \\
\hline POINT & Time Integration & J.1.5 \\
\hline POROSO & Porosity (volume source) & J.4.18 \\
\hline Q12/Q21/Q23/Q32/N12/N23 & Flow Rates Between Rooms & $\mathrm{J} .2 .7$ \\
\hline QINPUT & Flow Rate Between the Interior and the Exterior & $\mathrm{J} .2 .8$ \\
\hline RFO & Time of Source Removal (Lifetime) & J.4.10 \\
\hline RMVFR & Removable Fraction of Source & J.4.9 \\
\hline RNUCACT & Radionuclide Concentration/Activity & J.4.12 \\
\hline RRF & Radon Release Fraction & J.4.11 \\
\hline
\end{tabular}


Table 2-4. List of RESRAD-Build Parameters Accessible through the User Interface (Cont'd)

\begin{tabular}{lll}
\multicolumn{1}{c}{ Parameter } & \multicolumn{1}{c}{ Descriptive title } & \multicolumn{1}{c}{$\begin{array}{c}\text { Section in } \\
\text { manual }\end{array}$} \\
\hline SAREA & Area (or Length) of Source & $\mathrm{J} .4 .6$ \\
SDIR & Source Direction & $\mathrm{J} .4 .4$ \\
SLVL & Source Room & $\mathrm{J} .4 .2$ \\
STYPE & Source Type (Geometry) & $\mathrm{J} .4 .3$ \\
SX & Coordinates of Source Location & $\mathrm{J} .4 .5$ \\
THICK0 & Thickness (volume source) & $\mathrm{J} .4 .15$ \\
TITLE & Case Title & $\mathrm{N} / \mathrm{A}$ \\
TTIME & Exposure Duration & $\mathrm{J} .1 .1$ \\
& & \\
TWGHT & Receptor Time Fraction & $\mathrm{J} .3 .4$ \\
& & $\mathrm{~J} .7 .1$ \\
U_activity & Radiological Activity & $\mathrm{J} .2 .2$ \\
UD & Deposition Velocity & $\mathrm{J} .7 .2$ \\
U_dose_unit & Radiological Dose & $\mathrm{N} / \mathrm{A}$
\end{tabular}

Any default parameter values displayed in the user interface were compared with the value reported in both the user manual and in the parameter help screens of the user interface. In addition to the defaults, the code was tested by running cases with upper- and lower-bound values for each parameter, as specified in the parameter help screen or user's manual, or tested using extremely small or large parameter values where no bounds are specified.

The code was tested to determine whether (and how) the user interface rejects inappropriate inputs for each parameter. Examples of this include testing parameter values outside of the specified range or alphanumeric inputs entered when only numeric inputs are acceptable. The manner in which the code handles conflicting parameter values was verified. Examples of such conflicts include co-located sources/receptors and shielding thickness exceeding the sourcereceptor distance. In addition, certain parameters and their units may depend on the presence, absence and/or values of other parameters. These dependencies were also tested to ensure they were handled correctly by the user interface and generated a valid input file.

The parameter test results were documented by using a Input Parameter Verification Checklist form. When test results indicated a problem, any relevant RESRAD-BUILD input and output files were saved. To maintain consistency throughout the review process, the checklist form was designed with a variety of input options. Where appropriate, the reviewer responded by selecting an option from pull-down menus, marking one or more checkboxes or entering values and comments directly into the checklist form.

\subsubsection{General Observations}

Parameter-specific observations are listed in detail for each parameter in the CD-ROM appendix to this report and are summarized in Sections 2.2.2 through 2.2.9 for each parameter grouping defined in Appendix J of the user's manual. This section summarizes some responses to user actions that are common to a large number of parameters. 


\section{Response to entry of inappropriate or out-of-bound values}

Entering an inappropriate value (e.g., alphanumeric or out of bounds) for most parameters requiring typed user input, followed by an attempt to go to another parameter results in the following error message:

$X$ not set appropiately.

Where $X$ would be replaced by the code name of the paramters, such as AIRFR or UD. This is the correct way to handle such an input error. However, if the user simply tries to run the code IMMEDIATELY following an unacceptable entry, the code will attempt to run but will report the following error before crashing:

Run-time error '5': Invalid procedure call or argument

The output that is generated in most cases uses the previous (or default) value of parameter $X$, rather than the inappropriate value. The reason for this is that the user is not allowed to exit the "Details" window by pressing OK or Cancel without first entering a valid value for the parameter. However, in some cases the code actually computes spurious results using the out-of-bound values. These exceptions are noted in the parameter-specific discussions.

\section{Response to entry of very small or very large values}

Many parameters are defined with input fields that allow the entry of numerical values that are equal to (or slightly greater than) zero or are unbounded (i.e. the upper bound is "infinity"). This leads to untrapped errors when the entered values are either very small or very large. In some, but not all, cases, entering a very small value such as 1E-99 resulted in that value being set to zero by the code. However, this is not always the case. For example, in the case of volume source density, DENSI0, the smallest density accepted without error in the default case is $1 E-45$. Any smaller non-zero numbers cause the code to crash, with errors such as:

Cannot Open Error file "F77L3.EER", error \# 6

Entering very large numbers (e.g., greater than $1 \mathrm{E}+31$ for DENSI0) results in the following error message:

Cannot Open Error file "F77L3.EER", error \#4 (or \#104)

These errors are due to the computer limitiations for handling very large or very small numbers. While extreme values are unlikely to be entered by users, the user interface could be improved by incorporating error trapping for such extreme values and limiting the range of values to physically realistic extremes.

\subsubsection{Time Parameters}

\section{TTIME}

The general observations apply to this parameter for extreme and out-of-bound values. 
The user's manual specifies that the exposure duration can be any value greater than zero. A value of zero should result in zero dose (or be rejected as invalid by the code). However, while it is accepted by input field, the code does not execute properly, either running indefinitely (stuck in "Beginning Calculations") or resulting in the following error message:

Cannot Open Error file "F77L3.EER", error \# 6.

The solution to this is to prevent the user from entering a value of zero.

Additional problems related to the execution of the uncertainty analysis module are reported in Section 3.1.1.

\section{FTIN}

The general comments apply to the indoor fraction parameter for out-of-bound values.

The code does not normally accept out-of-bound values for the indoor fraction, which can range from 0 to 1, inclusive. However, if the user simply tries to run the code IMMEDIATELY following an unacceptable entry, such as ' 2 ', the code will initiate a run, but will report the following error before crashing:

\section{Run-time error '5': Invalid procedure call or argument}

In addition, a full output report is actually generated for the run. The last page of the report indicates that the Receptor Doses Received for the Exposure Duration are $1.85 \mathrm{E}+01$ and $1.62 \mathrm{E}+01$ for year 0 and year 1 , respectively. This is four times the default result and is mathematically consistent with a fourfold increase in the indoor time fraction (from a default of 0.5 to 2), but is inconsistent with the defined bounds for this parameter.

The solution to this is to prevent the user from entering a value in excess of the bounding values, and trapping such an error before allowing the program to execute.

Additional problems related to the execution of the uncertainty analysis module are reported in Section 3.1.1.

\section{NTIME}

No errors were found in the way that the code processes the number of times for calculations.

\section{DOSE TIME}

The parameter name for the beginning times for each calculation is referred to as TIME in Appendix J, but is listed as DOSE_TIME in the input file.

Entering ' 0 ' or a negative number as a year is not accepted and the input field disappears (the same effect as hitting the 'remove' button). This is only a nuisance issue, since the code automatically calculates the dose at time zero. Entering a number in excess of the upper bound does not result in a warning, but the code simply replaces the large number with the upper bound value.

The solution to this would be for the code to issue a formal warning to the user that the value that is being entered is out-of-bounds. 


\section{POINT}

No errors were found in the way that the code processes the maximum number of integration points.

The space allocated for the parameter name is left blank in Appendix J of the user's manual, but the name given to the maximum number of integration points is POINT in the input file.

Running a test on the default case resulted in convergence after selecting only 2 points. Increasing the exposure duration by a factor of 10 resulted in convergence after selecting only 3 points. Since many cases will rapidly converge, specifying somewhere in the output file how many points were actually needed to achieve convergence would provide useful information.

\subsubsection{Building Parameters}

\section{NROOM}

The parameter name for the number of rooms is listed in the user's manual as "NROOMS" but in the code input it is listed as "NROOM."

With the default input file in memory, the following actions were performed in the Building Parameters input panel: Press "Air Flow" button; Select 2 for "Number of Rooms"; Press "Air Flow" button; Select 3 for "Number of Rooms"; Press "Air Flow" button. This sequence of actions caused three "Room Details" windows to open up on the screen, one for the one-, one for the two-, and one for the three-room models. This has the potential to cause confusion, as the user may choose a different number of rooms, but forget to cancel the inappropriate "Room Details" window. Inappropriate data may still be present on the screen, possibly covered by a larger sized window. Each of the three windows was found to accept user input even when only one would have been appropriate based on the current selection for the number of rooms.

The solution to this is to not allow multiple "Room Detail" windows to appear. Show only the "Room Detail" window for the selected number of rooms.

\section{$\underline{\text { UD }}$}

The general observations apply to the deposition velocity parameter for extreme and out-of-bound values.

If the user simply tries to run the code IMMEDIATELY following an unacceptable entry, such as '- 1 ', the code will initiate a run, but will report the following error before crashing:

\section{Run-time error '5': Invalid procedure call or argument}

In addition, a full output report is actually generated for the run, with spurious results. The following dose summary is produced for the default case at time zero:

Receptor External Deposition Immersion Inhalation Radon Ingestion $1 \quad 4.62 \mathrm{E}+00 \quad 5.23 \mathrm{E}-06 \quad * * * * * * * * \quad * * * * * * * * \quad 0.00 \mathrm{E}+00 \quad 1.89 \mathrm{E}-06$ 
Note that the calculated deposition dose with UD $=-1$ is actually higher than the maximum deposition dose of 4.84E-6 for the default case at time zero obtained with UD $=1 \mathrm{E} 37$.

The solution to this is to prevent the user from entering a value in excess of the bounding values, and trapping such an error before allowing the program to execute.

Additional problems related to the execution of the uncertainty analysis module are reported in Section 3.1.2.

\section{DKSUS}

The general observations apply to the resuspension rate parameter for extreme and out-of-bound values.

If the user simply tries to run the code IMMEDIATELY following an unacceptable entry, such as '-1', the code will initiate a run, but will report the following error before crashing:

\section{Run-time error '5': Invalid procedure call or argument}

In addition, a full output report is actually generated for the run, with spurious results. The following dose summary is produced for the default case at time zero:

Receptor External Deposition Immersion Inhalation Radon Ingestion

$$
1 \quad 4.62 \mathrm{E}+00 \quad * * * * * * * * \quad 8.27 \mathrm{E}-09 \quad 8.09 \mathrm{E}-07 \quad 0.00 \mathrm{E}+00 \quad * * * * * * * *
$$

The solution to this is to prevent the user from entering a value in excess of the bounding values, and trapping such an error before allowing the program to execute.

Additional problems related to the execution of the uncertainty analysis module are reported in Section 3.1.2.

\section{$\underline{\mathbf{H}}$}

The general observations apply to the room height parameter for extreme and out-of-bound values.

It is possible to run the code with the "Room details" window still open, but any changes made to the room height(s) will not be accepted and the code will run using the previous values. This is the case with all other user-input parameters in the "Room details" window, as well as for all other input windows requiring an "OK/Cancel" response from the user.

The solution to this is for the code to request that the user either confirm or cancel any changes made in open windows prior to running the code.

Additional problems related to the execution of the uncertainty analysis module are reported in Section 3.1.2.

\section{AREA}

The parameter name for the room area is listed in the user's manual as "A" but in the code input it is listed as "AREA." 
The general observations apply to the room area parameter for extreme and out-of-bound values.

Additional problems related to the execution of the uncertainty analysis module are reported in Section 3.1.2.

\section{LAMBDAT/LINPUT}

The general observations apply to the air exchange rate parameters for extreme and out-of-bound values.

The user's manual indicates that the air exchange parameter value must be greater than zero. A value of zero should indeed result in problems with the air pathways because there would be a constant buildup of airborne material over time and no steady state could be achieved. Therefore, it should be rejected as invalid by the code. However, a value of zero is accepted without warning in the input field, but the code does not execute properly, resulting in the following error message:

Cannot Open Error file "F77L3.EER", error \# 3.

Additional problems related to the execution of the uncertainty analysis module are reported in Section 3.1.2.

\section{Q12/Q21/Q23/Q32/N12/N23}

If values of any intra-room airflow values are inconsistent with the air flow rates between the rooms and the outside, this inconsistency will be highlighted by a red outflow field. The user must then modify one or more of the airflow parameter values until a consistent airflow configuration is achieved. However, in many cases it is possible to enter inconsistent values that are within acceptable parameter bounds with no warning from the code prior to running the scenario.

In the default 3-room model, entering ANY number other than the default for Q23 and running the code results in the following error message:

Physically inconsistent Building air model

Please review air flow and try again

Also, entering ANY value for Q23 and/or Q32 will change the default values of Q12 and Q21 from zero to some unpredictable (and possibly negative) value.

The user interface will accept a value of zero between all rooms as well as a very large number $(1 \mathrm{E}+99)$.

In the 2-room model, the code accepts, but does not execute correctly, when zero is entered for Q12, Q21 or both, resulting in the following error message:

Physically inconsistent Building air model

Please review air flow and try again 
The same problem occurs when either Q23 or Q32 are set to zero in the 3-room model. This is not an acceptable response, since it should be possible to specify airflow from one room into another, but no return airflow.

When both Q23 and Q32 are set to zero in the 3-room model, and the outside airflow is changed to 72 (as in the 1-room default scenario) the code runs correctly, yielding the same output as the 1-room model. However, upon re-entering the "Room Details" window, both Q23 and Q32 are changed from zero to $2.8421709430404 \mathrm{E}-14$.

The lowest accepted value for Q12 and Q21 for the default 2-room model is 1E-5. A value of 1E6 or smaller results in the following error message:

\section{Physically inconsistent Building air model}

Please review air flow and try again

Any number greater than 1E-12 entered for Q12 in the default 3-room model will result in Q12 being reset to zero. However, the code will accept and retain extremely small numbers (e.g., 1E99) entered for Q21. The smallest value for Q32 that will not result in an error message is 1E-6. As indicated above, it was not possible to determine the smallest acceptable value for Q23 or Q32, since any value will generate an error message or change the default values for Q12 and Q21. Entering any value for the airflows between Rooms 2 and 3 will change the default airflows from zero to some unpredictable (and possible negative) value.

In the 2-room model, it is possible to set Q12 to 1E99, but the Room 1 outflow field becomes negative (with a red background). However, setting Q21 to 1E99 then causes the airflows out of Rooms 1 and 2 to be calculated as zero. This is physically impossible, since the airflow out of the building must equal the total airflow into the building of $144 \mathrm{~m} 3 / \mathrm{h}$ (84 into Room 1 and 60 into Room 2). Attempting to run the code results in the following error message:

\section{Physically inconsistent Building air model}

Please review air flow and try again

The highest acceptable intra-room airflows for the default 2-room model is Q12=Q21 = 1E17. However, this results in changes in the flows to the outside from Rooms 1 and 2 of 80 and 64 $\mathrm{m} 3 / \mathrm{h}$, from 84 and $60 \mathrm{~m} 3 / \mathrm{h}$, respectively. The highest intra-room airflows that do not change the default flows from Rooms 1 and 2 to the outside are Q12=Q21 = 1E16.

As with the 2-room model, it is possible to set all intra-room airflow paramters to 1E99, but the flows to the outside from all 3 rooms are set to zero. Attempting to run the code results in the following error message:

Cannot Open Error file "F77L3.EER", error \# 104

The highest intra-room airflows that do not change the default flows from Rooms 1, 2, and 3 to the outside are Q12=Q21=Q23=Q32=1E16. Higher values, such as 1E17 and 1E18 change the outflow values so that the net building inflow and outflow is not zero, which is physically impossible. However, the code accepts these values, appears to run correctly and DOES NOT report an error. When inspecting Page 3 of RESRADB.RPT, these outflows are reported at their default values, and are not consistent with the values shown in the "Room Details" window. 
Setting a value of zero airflow between rooms $(\mathrm{Q} 12=\mathrm{Q} 21=0$ and/or $\mathrm{Q} 23=\mathrm{Q} 32=0)$ should isolate adjacent rooms and not allow the movement of contaminants between these rooms. Currently this approach does not work due to the problems encountered with setting these parameters to zero.

Resolution is required for problems encountered with re-calculations of the values of Q12, Q21, Q23, and/or Q32, as well as changes in the values of airflows from the rooms to the outside after the user clicks on the OK button in the "Room Details" window. Modify the interface to check that the input values are within the acceptable range before saving the input file and starting calculations. Allow zero air flows between adjacent rooms. Allow uncertainty analysis, but implement checks to ensure that the selected range of parameter values is consistent with their deterministic limits.

\section{QINPUT}

While the building outdoor inflow and outflow parameters are defined as Q10, Q01, Q 20, Q02, Q30, and Q03 in the user's manual, they are collectively identified as QINPUT in the input file.

The interface will accept a value of zero in all rooms as well as a very large number (1E+99). If all QINPUT values are set to zero in a 2- or 3-room model, the code calculates a value of LAMBDAT $=0$. This value of zero causes problems with the air pathways because there would be a constant buildup of airborne material over time and no steady state could be achieved. Therefore, such combinations should be rejected as invalid by the code. Indeed, while a value of all zeros is accepted by the interface, the code does not execute properly, resulting in the following error message:

Cannot Open Error file "F77L3.EER", error \# 6.

In the 3-room model, a Room 2 inflow of zero was accepted (all other values were left at their defaults), and the code appears to run without problems. However, upon re-entering the "Room Details" window, both directions of airflow between rooms 1 and 2 are changed from the defaults of zero to -3.19744231092045E-14. Clicking on either of these fields and attempting to re-exit the "Room Details" window or moving to another parameter results in the following error message:

q12 not set appropiately, or q21 not set appropiately

The code accepts, but does not execute correctly when a zero inflow rate is entered for Room 3 instead of Room 2, resulting in the following error message:

\section{Physically inconsistent Building air model \\ Please review air flow and try again}

In addition, the airflow between rooms 1 and 2 is changed by the code from the defaults of zero to 3.19744231092045E-14 (note the positive sign, which does not cause the same error messages for Q12 or Q21 as encountered in the previous test). This is not an acceptable responses, since a zero flow rate from the outside into any of the rooms (Room 3 in this case) is consistent with modeling a basement with no direct airflow connection to the outside. In addition, a zero flow rate between Rooms 1 and 2 should not cause a problem, since one may wish to model a source in Room 2 affecting a receptor in Room 1 (direct external pathway only from Source 2), while at the same 
time allowing a receptor in Room 3 to be exposed to both direct external and air pathways from the same source. Note that adding a second receptor in Room 3 and moving the source from the default location in Room 1 to Room 2 did not resolve this problem.

Setting the Room 1 inflow rate to zero, with all other fields in the 3-room "Room Details" window left at their defaults, results in the following error message:

Cannot Open Error file "F77L3.EER", error \# 3

If such situations cause computational problems in the 3-room model, at the very least the default airflows between Rooms 1 and 2 should be changed from zero to some other value, and the user should not be allowed to enter zero simultaneously in both these fields. This restriction should probably also be extended to the airflows between Rooms 2 and 3. As indicated above, however, such restrictions impose undue limitations on the choice of realistic exposure scenarios.

The smallest inflows that would be accepted and properly executed in the 2-room default scenario are 1E-14 into Room 1 and zero into Room 2. However, after clicking OK to exit the "Room Details" window, the code changes the user-input Room 1 inflow from 0 to $1.008 \mathrm{E}-14$, and the Room 1 outflow is re-calculated as 1.1E-14. Reversing the flow rates causes the user-input Room 1 inflow to be changed by the code from 0 to $7.99999999999997 \mathrm{E}-17$, while the calculated flow out of room 2 changes from $1 \mathrm{E}-14$ to $1.1 \mathrm{E}-14$.

The smallest inflow that is accepted and properly executed in the 3-room default scenario is $1 \mathrm{E}-5$ into Room 1. However, after clicking OK to exit the "Room Details" window, the code changes the Room 1 inflow 9.99999987527644E-06. Changing the Room 2 inflow to any number other than the default of 60 causes the airflows between Rooms 1 and 2 to change from their default of zero to some other value. In some cases these values are negative and cause the same error messages for Q12 or Q21 as encountered in previous tests. The same problem occurs when attempting to change the Room 3 inflows to any value other than the default.

The interface will accept a large number such as $1 \mathrm{E}+99$, but the code does not execute properly, either running indefinetely (stuck in "Beginning Calculations) or resulting in the following error message:

Cannot Open Error file "F77L3.EER", error \# 104 (or \#4).

By trial and error, it was determined that the largest inflow into Room 1 that would be accepted and properly executed by the default 2 - or 3-room scenario was $1 \mathrm{E}+38$.

The upper limit for the inflow into Room 2 is accepted and properly executed by the default 2room scenario was $1 \mathrm{E}+4$. A larger value $(1 \mathrm{E}+5)$ is accepted, but results in the following error message after attempting to run the code:

Physically inconsistent Building air model

Please review air flow and try again

Upon review of the "Room Details" window, Q12 and Q21 are changed by the code from their default values of 30 to the inappropriate values of -1000 , and Room 1 displays an air exchange rate of -10 . 
As noted previously, any non-default input for the flow into Room 2 or Room 3 (with all other parameters at default values) results in automatic changes to the Q12, Q21, Q23, and Q32 values from their default values. Therefore, it is not possible to verify the maximum Room-2 or Room-3 inflow rate for the 3-room model.

Resolutions to these issues are similar to those discussed in the previous section regarding the flows between rooms.

\subsubsection{Receptor Parameters}

\section{$\underline{\mathrm{ND}}$}

The code appears to be defining the parameter as the numeric number assigned to each receptor, not the total number of receptors as stated in the user's manual. Although this may not actually be inconsistent, it is somewhat confusing.

When more than one receptor is added, and then one or more receptors are removed, the interface will not automatically re-number the receptors. As an example, the following sequence is followed:

- 9 receptors are added (for a total of 10 receptors)

- The $\mathrm{x}$ coordinate for Receptors 1-10 is set to equal the receptor number

- Receptor 2 is selected and removed

- Receptor 4 is selected and removed

- Receptor 5 is selected

- 1 receptor is added

Upon removing Receptors 2 and 4, the receptor location drop-down menu box, the shielding parameter table and the graphic display list Receptors 1-10, with Receptors 2 and 4 missing from the sequence. However, once the file is run/saved, the receptor location numbers in the input file and output report are automatically re-numbered as Receptor 1-8, with the parameters for Receptor 3 now assigned to the previously deleted Receptor 2, Receptor 5 --> Receptor 3, Receptor 6 now assigned to previously deleted Receptor 4, Receptor 7 ---> Receptor 5, ---, and Receptor 10 --> Receptor 8 . This is a potential source of confusion. It may not be immediately obvious to the user that the receptor was successfully removed, since the interface does not automatically re-number the receptor locations once a receptor is removed until the saved file is loaded back into memory (unless, of course, the receptor location numbers being removed are at the end of the list).

After Receptors 2 and 4 are removed, adding one receptor back results in this receptor being assigned the number 2, but the parameter values associated with this new Receptor 2 are not the same as the parameters assigned to the original Receptor 2; they are the same as the currently selected receptor number (in this case, Receptor 5). This is another potential source for confusion, since the user may not realize that the values associated with this receptor number will probably differ from the values originally entered. If the interface automatically renumbers the sequence of receptors each time one is removed, then the user may recognize that Receptors 2 and 4 in the original listing have been "permanently" removed. 
A less critical issue is the order in which the 10th receptor location appears in the pull-down box. It is placed between Receptors 1 and 2. The logical location in the box would be at the end of the list (after Receptor 9).

There should be a faster way to select the number of receptors than adding or removing one at a time through the main menu bar, which is not intuitive and involves a sequence of two mouse clicks. One way to accomplish this would be to provide add and remove buttons in the "Receptor Parameters" window or in the graphic "Display" window. It would also be advisable to be able to delete a specific receptor number and have the interface automatically re-number the receptors, since this is done anyway when the file is saved and run. Finally, the 10th receptor location listed in the drop-down menu box should appear at the end of the listing, not between Receptors 1 and 2. One possible approach would be to create a table (similar a combination of the shielding table and the evaluation time table) listing all Receptor properties, including the add/remove buttons, possibly a copy parameters button, and an automatic re-arrangement of remaining receptors each time one is deleted.

\section{DLVL}

Contrary to what is stated in the Help Screen, the receptor room is not used by the Direct External pathway. The exposure from Direct External is independent of the receptor room. The user's manual states that the air pathways are affected by this parameter but not the direct gamma radiation pathway.

The following sequence is tested, starting with the default case:

- The 3-room model is selected

- 5 more receptors are added

- Receptors 2 and 3 are assigned to Rooms 2 and 3, respectively

- Receptors 4, 5, and 6 are assigned to Rooms 1, 2, and 3, respectively

- Receptor 3 is selected

- The number of rooms is changed to 2

At this point, the room assigned to Receptor 3 changes from Room 3 to Room 1, but the room assigned to Receptor 6 changes from Room 3 to Room 2. If, however, any receptor other than Receptors 3 or 6 is selected, and the number of rooms is changed from 3 to 2 rooms, the room assigned to Receptor 3 changes from Room 3 to Room 2 (as is the case for Receptor 6). This treatment is inconsistent since the room number change appears to depend in part on whether an affected receptor location is selected.

Note that restoring the problem back to a 3-room model does not automatically restore any prior Room 3 assignments that had been re-assigned by the code. That is, Receptors 3 and 6 remain in their re-assigned rooms (Rooms 2 or 1 ).

Resolutions to these issues include correcting the text in the Help Screen to exclude Direct External as a pathway that is affected by this parameter. Correct the problem observed when changing the number of rooms (NROOM) from 3 to 2 by ensuring a consistent treatment of the room into which receptors previously assigned to Room 3 are re-assigned. One way to accomplish this would be to warn the user that the room number change affects the location of one or more receptors. The code could then request whether the affected receptor(s) should be re- 
assigned to another room, giving a choice between Room 1 or 2 if moving from a 3- to a 2-room model, or whether the affected receptor(s) should be deleted.

\section{$\underline{\text { DX }}$}

While there are no explicit upper or lower bounds specified for the coordinates, the code imposes an effective bound at around $+/-1 \mathrm{E}+6$. Attempting to enter an exponent between 7 and 69 (larger exponents cannot be entered) causes the code to immediately crash after reporting the following error message:

\section{Run-time error '6': Overflow}

While it is unlikely that a receptor would ever be located so far from the origin $(>1,000 \mathrm{~km})$, a user may wish to use large distances to suppress the direct external pathway from a source.

As pointed out in the description, it is up to the user to ensure that the receptor is not co-located with a source (all source types), and is not on the same line (line source) or plane (area/volume sources) of a source. However, the code does not provide an explicit limit on how close to a point, line, or plane a source and receptor may be located. When the source and receptor are "too close" the code behaves in different ways depending on the source type and/or the distances between source and receptor. It is also possible to place a receptor outside of the plane, but "inside" of a volume source. These issues are addressed as part of the extreme/out-of-bounds values tests below.

Locating the receptor in the center of a cylindrical volume source does not result in an error message, but the results are physically inconsistent. Using the default volume source $(15-\mathrm{cm}$ thick, $36 \mathrm{~m}^{2}$ area, on plane normal to $\mathrm{x}$ direction) located at $(0,0,0)$, the receptor location was changed to be either $7.5 \mathrm{~cm}$ INSIDE the center of the volume source $(-0.075,0,0)$ or $7.5 \mathrm{~cm}$ outside the plane of and along the centerline of the source $(0.075,0,0)$. In both cases the results were identical: a dose of 7.03 mrem from the direct external pathway at time zero.

There are no such volumetric space considerations for the remaining source types. However, there are implicit proximity limits imposed by the code that go beyond the stated exclusion of receptors from the same point, line or plane coordinates as a source. For the remaining tests, the receptor is moved increasingly closer to the origin, where the center of the source is located.

The $\mathrm{X}$ coordinate of the receptor is moved at ever-decreasing distances from the default volume source along the $\mathrm{x}$ axis ( $\mathrm{y}$ and $\mathrm{z}$ receptor coordinates set to zero). The following direct external doses are calculated at time zero:

$\mathrm{X}(\mathrm{m})$ Dose (mrem)

$1 \mathrm{E}-1 \quad 6.97$

1E-2 7.35

$1 \mathrm{E}-3 \quad 7.72$

1E-4 6.98

1E-5 7.08

1E-6 7.11

1E-7 7.12

1E-8 7.12

For the default volume source case, the "contact-dose" distance therefore appears to be $1 \mathrm{E}-7 \mathrm{~m}$. The higher doses at $1 \mathrm{E}-2$ and $1 \mathrm{E}-3 \mathrm{~m}$ are most likely due to integration or convergence issues. 
The default source type is changed from volume to area and the receptor is placed at everdecreasing distances from the source along the $\mathrm{x}$ axis ( $\mathrm{y}$ and $\mathrm{z}$ receptor coordinates set to zero). The following direct external doses are calculated at time zero:

$\begin{array}{lc}\mathrm{X}(\mathrm{m}) & \text { Dose }(\mathrm{mrem}) \\ 1 \mathrm{E}-1 & 6.44 \mathrm{E}-5 \\ 1 \mathrm{E}-2 & 1.06 \mathrm{E}-4 \\ 1 \mathrm{E}-3 & 1.43 \mathrm{E}-4 \\ 1 \mathrm{E}-4 & 1.31 \mathrm{E}-4 \\ 1 \mathrm{E}-5 & 1.17 \mathrm{E}-4 \\ 1 \mathrm{E}-6 & 1.18 \mathrm{E}-4 \\ 1 \mathrm{E}-7 & 1.18 \mathrm{E}-4\end{array}$

For the default area source case, the "contact-dose" distance therefore appears to be 1E- $6 \mathrm{~m}$. The higher doses at 1E-3 and 1E-4 are most likely due to integration or convergence issues, as indicated by the long times required to complete a simple run.

The default source type is changed from volume to line, with the direction set to $\mathrm{z}$. The receptor is placed at ever-decreasing distances from the source along the $\mathrm{x}$ axis ( $\mathrm{y}$ and $\mathrm{z}$ receptor coordinates set to zero). The following direct external doses are calculated at time zero:

$\mathrm{X}(\mathrm{m})$ Dose (mrem)

1E-1 9.24E-5

1E-2 9.29E-4

1E-3 9.31E-3

1E-4 9.31E-2

$\ddot{1 E}-19 \quad \ddot{9} 32 \mathrm{E}+13$

Any distance smaller than $1 \mathrm{E}-19$ results in the following error message:

Cannot Open Error file "F77L3.EER", error \# 3 (or \#36), or

Physically inconsistent source and receptor locations

Please review locations and try again

The default source type is changed from volume to point. The receptor is placed at everdecreasing distances from the source along the $\mathrm{x}$ axis ( $\mathrm{y}$ and $\mathrm{z}$ receptor coordinates set to zero). The following direct external doses are calculated at time zero:

$\begin{array}{lc}\mathrm{X}(\mathrm{m}) & \text { Dose }(\mathrm{mrem}) \\ 1 \mathrm{E}-1 & 2.96 \mathrm{E}-4 \\ 1 \mathrm{E}-2 & 2.97 \mathrm{E}-2 \\ 1 \mathrm{E}-3 & 2.97 \mathrm{E}+0 \\ 1 \mathrm{E}-4 & 2.97 \mathrm{E}+2 \\ 1 \mathrm{E}-5 & 2.97 \mathrm{E}+4 \\ . . & . . \\ 1 \mathrm{E}-19 & 2.97 \mathrm{E}+32\end{array}$

Any distance smaller than 1E-19 results in the following error message: 
Cannot Open Error file "F77L3.EER", error \# 4, or

Physically inconsistent source and receptor locations

Please review locations and try again

Of course, the increases in dose as a function of decreasing distance follow the inverse square (for point source) or inverse linear (for line source) law as expected. However, the smallest distance is also governed by the combination of source activity, external gamma dose factor and the limits on how large a number can be handled by the code.

The results of the extreme value tests conducted on the receptor coordinates are consistent with the tests conducted on the source coordinates.

The code should be modified to limit uppper and lower coordinate values, as well as place limits on small numbers. This would reduce the potential generation of the error messages described above. Modify the code to check that a receptor is not located INSIDE a volume source by comparing volume source thickness with the location of the receptor.

It is recommended that uncertainty analysis be enabled for this parameter. This would be extremely useful if the position of a receptor may change during the exposure duration. It would allow the user to model a single receptor at multiple locations within a room without requiring the use of multiple receptor locations and time fractions. A potential application would be in estimating doses from decontaminating large area or volume sources, which require the worker to be at different locations along the source over time.

\section{TWGHT}

The parameter name for the receptor time fraction in the user's manual is listed as "TWIGHT" but in the code it is "TWGHT." The description for the receptor time fraction in the user's manual, stating that the user can input a value greater than one, is not consistent with the code. The user's manual specifies the range of the parameter as $>0$, whereas the code and help screen bound the upper value at 1 (the code also allows a value of zero, but this effectively sets the dose to zero). The discussion of collective dose in the user's manual is consistent with the specified lack of an upper bound, but since the input values can not be greater than 1 for each receptor, there is no way to use this feature in the current version of the code.

If the user simply tries to run the code IMMEDIATELY following an unacceptable entry, such as '2', the code will attempt to run but will report the following error before crashing:

\section{Run-time error '5': Invalid procedure call or argument}

In addition, a full output report is actually generated for the run. The last page of the report indicates that the Receptor Doses Received for the Exposure Duration are 9.23 and 8.09 for year 0 and year 1, respectively. This is two times the default result and is mathematically consistent with a twofold increase in the receptor time fraction (from 1 to 2), but is inconsistent with the defined bounds for this parameter.

It is recommended that the upper bound be increased to a reasonable value consistent with a realistic number of exposed receptors so that collective dose calculations may be performed. In addition, this parameter should be eligible for uncertainty analysis since indoor occupancy may be subject to considerable variability. 


\section{BRTRATE}

The general observations apply to the breathing rate parameter for extreme and out-of-bound values.

Since the user's manual claims that this parameter controls the dose to a receptor from both particulate and radon inhalation pathways, Ra-226 was selected as the source radionuclide instead of the default Co-60. While the code correctly suppressed the particulate inhalation pathway (zero dose) when the breathing rate was set to zero, the radon inhalation was not changed from the default dose of 2.27 mrem for year zero. This concern is addressed in more detail as part of the radon model verification.

The practical upper bound, from trial-and-error running the default case, appears to be 1E38 (see Extreme Test results). However, the upper bound of the breathing rate should be set at a much lower value to reflect the physiological limits of this parameter. In addition, by setting the value of this parameter sufficiently high, it may be possible to calculate an inhalation of activity that exceeds the source inventory, resulting in a gross mass-balance error.

If the user simply tries to run the code IMMEDIATELY following an unacceptable entry, such as '-1', the code will attempt to run but will report the following error before crashing:

\section{Run-time error '5': Invalid procedure call or argument}

In addition, a full output report is actually generated for the run, with spurious results. The following dose summary is produced for the default case (with a Ra-226 source) at time zero:

Receptor External Deposition Immersion Inhalation Radon Ingestion

$$
1 \quad 3.44 \mathrm{E}+00 \quad 5.55 \mathrm{E}-07 \quad 6.24 \mathrm{E}-09 \quad * * * * * * * * \quad 2.27 \mathrm{E}+00 \quad 1.51 \mathrm{E}-05
$$

Recommendations include revising the radon pathway model to incorporate the user-input breathing rate. Limit the upper bound of the parameter to a value that is physiologically possible. Provide a mass balance test to ensure that the inhaled activity does not exceed the activity in the source.

Additional problems related to the execution of the uncertainty analysis module are reported in Section 3.1.3.

\section{INGE2}

The general observations apply to the indirect ingestion rate parameter for extreme and out-ofbound values. The practical upper bound, from trial-and-error running the default case, appears to be 1E38. However, the upper bound of the deposited material ingestion rate should be set at a much lower value to reflect the physiological limits of this parameter. In addition, by setting the value of this parameter sufficiently high, it may be possible to calculate an ingestion of activity that exceeds the source inventory, resulting in a gross mass-balance error.

If the user simply tries to run the code IMMEDIATELY following an unacceptable entry, such as '-1', the code will attempt to run but will report the following error before crashing:

\section{Run-time error '5': Invalid procedure call or argument}

In addition, a full output report is actually generated for the run, with spurious results. The following dose summary is produced for the default case at time zero: 


\section{Receptor External Deposition Immersion Inhalation Radon Ingestion $1 \quad 4.62 \mathrm{E}+00 \quad 6.31 \mathrm{E}-07 \quad 7.20 \mathrm{E}-09 \quad 7.04 \mathrm{E}-07 \quad 0.00 \mathrm{E}+00 \quad * * * * * * * *$}

Recommendations include limiting the upper bound of the parameter to a value that is physiologically possible. A simplistic solution would be to perform a mass balance test to ensure that the ingested activity does not exceed the activity in the deposited source. A better solution may be to include the indirect ingestion rate as a removal mechanism (sink) for the indoor air model.

Additional problems related to the execution of the uncertainty analysis module are reported in Section 3.1.3.

\subsubsection{Source Parameters}

\section{NS}

The code appears to be defining the parameter as the numeric number assigned to each source, not the total number of sources as stated in the user's manual. Although this may not actually be inconsistent, it is somewhat confusing.

When more than one source is added, and then one or more sources are removed, the interface will not automatically re-number the sources. As an example, the following sequence is followed:

- 9 sources are added (for a total of 10 sources)

- The $\mathrm{x}$ coordinate for Sources 1-10 is set to equal the source number

- $\quad$ Source 2 is selected and removed

- $\quad$ Source 4 is selected and removed

- Source 5 is selected

- 1 source is added

Upon removing Sources 2 and 4, the source location drop-down menu box, the shielding parameter table and the graphic display list Sources 1-10, with Sources 2 and 4 missing from the sequence. However, once the file is run/saved, the source location numbers in the input file and output report are automatically re-numbered as Source 1-8, with the parameters for Source 3 now assigned to the previously deleted Source 2, Source 5 --> Source 3, Source 6 now assigned to previously deleted Source 4, Source 7 ---> Source 5, ---, and Source 10 --> Source 8 . This is a potential source of confusion. It may not be immediately obvious to the user that the source was successfully removed, since the interface does not automatically re-number the source locations once a source is removed until the saved file is loaded back into memory (unless, of course, the source location numbers being removed are at the end of the list).

After Sources 2 and 4 are removed, adding one source back results in this source being assigned the number 2, but the parameter values associated with this new Source 2 are not the same as the parameters assigned to the original Source 2; they are the same as the currently selected source number (in this case, Source 5). This is another potential source for confusion, since the user may not realize that the values associated with this source number will probably differ from the values originally entered. If the interface automatically renumbers the sequence of sources each time 
one is removed, then the user may recognize that Sources 2 and 4 in the original listing have been "permanently" removed.

A less critical issue is the order in which the 10th source location appears in the pull-down box. It is placed between Sources 1 and 2. The logical location in the box would be at the end of the list (after Source 9).

There should be a faster way to select the number of sources than adding or removing one at a time through the main menu bar, which is not intuitive and involves a sequence of two mouse clicks. One way to accomplish this would be to provide add and remove buttons in the "Source Parameters" window or in the graphic "Display" window. It would also be advisable to be able to delete a specific source number and have the interface automatically re-number the sources, since this is done anyway when the file is saved and run. Finally, the 10th source location listed in the drop-down menu box should appear at the end of the listing, not between Sources 1 and 2. One possible approach would be to create a table (similar a combination of the shielding table and the evaluation time table) listing all Source properties, including the add/remove buttons, possibly a copy parameters button, and an automatic re-arrangement of remaining sources each time one is deleted.

\section{SLVL}

Contrary to what is stated in the Help Screen, the source room is not used by the Direct External pathway. The exposure from Direct External is independent of the source room. The user's manual states that the air pathways are affected by this parameter but not the direct gamma radiation pathway.

The following sequence is tested, starting with the default case:

- The 3-room model is selected

- 5 more sources are added

- Sources 2 and 3 are assigned to Rooms 2 and 3, respectively

- Sources 4, 5, and 6 are assigned to Rooms 1, 2, and 3, respectively

- $\quad$ Source 3 is selected

- The number of rooms is changed to 2

At this point, the room assigned to Source 3 changes from Room 3 to Room 1, but the room assigned to Source 6 changes from Room 3 to Room 2. If, however, any source other than Sources 3 or 6 is selected, and the number of rooms is changed from 3 to 2 rooms, the room assigned to Source 3 changes from Room 3 to Room 2 (as is the case for Source 6). This treatment is inconsistent since the room number change appears to depend in part on whether an affected source location is selected.

Note that restoring the problem back to a 3-room model does not automatically restore any prior Room 3 assignments that had been re-assigned by the code. That is, Sources 3 and 6 remain in their re-assigned rooms (Rooms 2 or 1 ).

Resolutions to these issues include correcting the text in the Help Screen to exclude Direct External as a pathway that is affected by this parameter. Correct the problem observed when changing the number of rooms (NROOM) from 3 to 2 by ensuring a consistent treatment of the room into which sources previously assigned to Room 3 are re-assigned. One way to accomplish 
this would be to warn the user that the room number change affects the location of one or more sources. The code could then request whether the affected source(s) should be re-assigned to another room, giving a choice between Room 1 or 2 if moving from a 3- to a 2-room model, or whether the affected source(s) should be deleted.

\section{STYPE}

No errors were found in the way that the code processes the source type.

\section{SDIR}

In the input file, the parameter values for source direction are stored as SDIR=SDIR(1),---, SDIR(i),---, SDIR(NS-1), SDIR(NS), where SDIR(i) is expressed as an integer between 1 and 3, inclusive. $X=1, Y=2, Z=3$. The input file saves the direction of a point source as 1 (default), 2 or 3, depending on the direction selected for any other source type previously assigned to that source number. While this direction number is meaningless for a point source, it is a possible source of confusion for advanced users that might inspect the input file. A more appropriate way to handle point source direction in the input file may be to assign SDIR $=0$ for a point source. However, this would add a layer of complexity, since reverting from point to other source type would result in having to reset SDIR for that source to either X (1), Y (2), or Z (3). Note that keeping the non-zero point-source direction in the input file would not be a source of confusion to users that do not inspect the input file: this parameter becomes unavailable and invisible in the GUI for a point source, and the code runs fine as is.

\section{$\underline{\text { SX }}$}

The following text should be added for consistency with the receptor coordinates Help Screen and the user's manual: "The coordinates of the source location are used only to calculate direct external exposure; the user must ensure that the source is not on the plane of a receptor so as not to violate this assumption in the calculation of external exposure."

Similar issues arise with both receptor and source placements, since the code calculates the distance between source and receptor based on their relative coordinates and directions. As with the discussion on the receptor coordinates, there are implicit proximity limits imposed by the code that go beyond the stated exclusion of receptors from the same point, line or plane coordinates as a source. For the remaining tests, the receptor is located at the origin, and the centers of each source are moved increasingly closer to the origin.

The $\mathrm{X}$ coordinate of the default volume source is moved at ever-decreasing distances from the receptor along the $\mathrm{x}$ axis ( $\mathrm{y}$ and $\mathrm{z}$ receptor coordinates set to zero). The following direct external doses are calculated at time zero:

$\begin{array}{lc}X(m) & \text { Dose (mrem) } \\ \text { 1E-1 } & 6.97 \\ 1 E-2 & 7.35 \\ 1 E-3 & 7.72 \\ 1 E-4 & 6.98 \\ 1 E-5 & 7.08 \\ 1 E-6 & 7.11 \\ 1 E-7 & 7.12 \\ 1 E-8 & 7.12\end{array}$


For the default volume source case, the "contact-dose" distance therefore appears to be $1 \mathrm{E}-7 \mathrm{~m}$. The higher doses at $1 \mathrm{E}-2$ and $1 \mathrm{E}-3 \mathrm{~m}$ are most likely due to integration or convergence issues.

The default source type is changed from volume to area and the source is placed at everdecreasing distances from the receptor along the $\mathrm{x}$ axis ( $\mathrm{y}$ and $\mathrm{z}$ receptor coordinates set to zero). The following direct external doses are calculated at time zero:

$\mathrm{X}(\mathrm{m})$ Dose (mrem)

1E-1 6.44E-5

$1 \mathrm{E}-2 \quad 1.06 \mathrm{E}-4$

$1 \mathrm{E}-3 \quad 1.43 \mathrm{E}-4$

$1 \mathrm{E}-4 \quad 1.31 \mathrm{E}-4$

$1 \mathrm{E}-5 \quad 1.17 \mathrm{E}-4$

1E-6 1.18E-4

1E-7 1.18E-4

For the default area source case, the "contact-dose" distance therefore appears to be $1 \mathrm{E}-6 \mathrm{~m}$. The higher doses at 1E-3 and 1E-4 are most likely due to integration or convergence issues, as indicated by the long times required to complete a simple run.

The default source type is changed from volume to line, the source direction is changed to $\mathrm{z}$, and the source is placed at ever-decreasing distances from the receptor along the $\mathrm{x}$ axis $(\mathrm{y}$ and $\mathrm{z}$ receptor coordinates set to zero). The following direct external doses are calculated at time zero:

$\mathrm{X}(\mathrm{m})$ Dose (mrem)

1E-1 9.24E-5

1E-2 9.29E-4

1E-3 9.31E-3

$1 \mathrm{E}-4 \quad 9.31 \mathrm{E}-2$

..

$1 \mathrm{E}-19 \quad 9.32 \mathrm{E}+13$

Any distance smaller than $1 \mathrm{E}-19$ results in the following error message:

Cannot Open Error file "F77L3.EER", error \# 3 (or \#36), or

Physically inconsistent source and receptor locations

Please review locations and try again

The default source type is changed from volume to point. The source is placed at ever-decreasing distances from the receptor along the $\mathrm{x}$ axis ( $\mathrm{y}$ and $\mathrm{z}$ receptor coordinates set to zero). The following direct external doses are calculated at time zero:

$\mathrm{X}(\mathrm{m})$ Dose (mrem)

1E-1 2.96E-4

1E-2 2.97E-2

$1 \mathrm{E}-3 \quad 2.97 \mathrm{E}+0$

$1 \mathrm{E}-4 \quad 2.97 \mathrm{E}+2$

$1 \mathrm{E}-5 \quad 2.97 \mathrm{E}+4$

..

$1 \mathrm{E}-19 \quad 2.97 \mathrm{E}+32$ 
Any distance smaller than $1 \mathrm{E}-19$ results in the following error message:

Cannot Open Error file "F77L3.EER", error \# 4,or

Physically inconsistent source and receptor locations

Please review locations and try again

Of course, the increases in dose as a function of decreasing distance follow the inverse square (for point source) or inverse linear (for line source) law as expected. However, the smallest distance is also governed by the combination of source activity, external gamma dose factor and the limits on how large a number can be handled by the code.

The results of the extreme value tests conducted on the source coordinates are consistent with the tests conducted on the receptor coordinates.

The code should be modified to limit upper and lower coordinate values, as well as place limits on small numbers. This would reduce the potential generation of the error messages described above. Modify the code to check that a receptor is not located INSIDE a volume source by comparing volume source thickness with the location of the receptor.

It is recommended that uncertainty analysis be enabled for this parameter. This would be extremely useful if the position of the source may change during the exposure duration, as would be the case during gradual removal of a source during decontamination. By correlating source area (or length) and source/receptor coordinates, it would possible to model a source that is decreasing over time and whose center is moving in space.

\section{SAREA}

If the selected source type is "line", the Help Screen displays the text for the area, not the length, when this parameters is highlighted and the help button is pressed.

The general observations apply to the source length/area parameter for extreme and out-of-bound values. In addition, entering the lower bound of zero area or length is accepted by the interface, but running the code results in the following error message:

Cannot Open Error file "F77L3.EER", error \# 6

The exception to the above statement is when the user enters a tritium volume source. In that case, the code runs and reports a dose of zero.

The smallest area or length that is accepted by the interface and will not cause an error in the default case is $1 \mathrm{E}-3 \mathrm{~m}^{2}$ (volume source), $1 \mathrm{E}-5 \mathrm{~m}^{2}$ (area source), or 1E-45 m (line source).

The largest area or length that is accepted by the interface and will not cause an error in the default case is $1 \mathrm{E}+14 \mathrm{~m}^{2}$ (volume and area source) or $1 \mathrm{E}+19 \mathrm{~m}$ (line source). However, the largest length for a line source that does not result in a $" * * * * * * "$ being reported for the direct external dose at time zero is $1 \mathrm{E}+4 \mathrm{~m}$. 
Entering an extremely small or large value for the source area or length results in one of the following error messages, depending on the magnitude of the value entered and/or the source type selected:

Cannot Open Error file "F77L3.EER", error \# 6 (or \#16, or \#4, or \#104)

The input file reports the source area or length as follows: SAREA = SAREA(1), ---, SAREA(i), ---, SAREA(NS-1), SAREA(NS), where SAREA(i) the source area or length, depending on the ith source type. The input file saves the length of a point source as the source area or length previously assigned to that source number. While this area/length is meaningless for a point source, it is a possible source of confusion for advanced users that might inspect the input file. A more appropriate way to handle point source area/length in the input file may be to assign $\mathrm{SAREA}=0$ for a point source. However, this would add a layer of complexity, since reverting from point to other source type would result in having to reset SAREA for that source to a nonzero entry. Note that keeping the non-zero point-source area/length in the input file would not be a source of confusion to users that do not inspect the input file; this parameter becomes unavailable and invisible in the interface for a point source, and the code runs fine as is.

Additional problems related to the execution of the uncertainty analysis module are reported in Section 3.1.4.

\section{AIRFR}

The general observations apply to the air release fraction parameter for out-of-bound values.

Additional problems related to the execution of the uncertainty analysis module are reported in Section 3.1.4.

\section{INGE1}

The general observations apply to the direct ingestion rate parameter for extreme and out-ofbound values.

To test this parameter, the deposited material (indirect) ingestion rate was set to zero.

In the default case (volume source), the upper bound appears to be $1 \mathrm{E}+39 \mathrm{~g} / \mathrm{h}$. However, the upper bound of the direct ingestion rate from a volume source should be set at a much lower value to reflect the physiological limits of this parameter (i.e., maximum human mass ingestion rate). In addition, by setting the value of this parameter sufficiently high, it may be possible to calculate an ingestion of source material and activity that greatly exceeds the source inventory, resulting in a gross mass-balance error.

For all other sources, the ingestion rate is calculated as a fraction of the source ingested per hour. The upper bound of the direct ingestion rate appears to be $1 \mathrm{E}+38 / \mathrm{h}$ for non-volume sources. As with the volume source, this upper bound is still extremely high, but not for physiological limitations since there is no ingestion of mass, just a "massless" fraction of the source activity. Setting this maximum ingestion rate for a point source of $1 \mathrm{pCi} \mathrm{Co}-60$ results in a calculated dose of $2.82 \mathrm{E}+36 \mathrm{mrem}$ during the exposure duration. Since the ingestion dose factor for Co-60 is $2.69 \mathrm{E}-5 \mathrm{mrem} / \mathrm{pCi}$, ingesting the entire source would result in an ingestion dose that is 41 orders of magnitude lower than the dose calculated by the code using the maximum direct ingestion rate. 
One way to resolve these issues is to limit the upper bound of the parameter to a value that is physiologically possible. A simplistic solution would be to perform a mass balance test to ensure that the activity ingested by all receptors does not exceed the activity in the source. A better solution may be to include the direct ingestion rate as a source removal mechanism (as is done with the removal rate, erosion rate and radioactive decay mechanisms).

The direct ingestion dose from tritium in a volume source is always zero, regardless of how high the ingestion rate and/or erosion rate are set. However, the indirect ingestion dose is not affected (unless the deposition velocity has been set to zero). This is not a problem for all other source types. The only way to enable the direct ingestion of tritium in a volume source is to set the water fraction available for evaporation to a value less than the default of 1 , but it is not realistic that a receptor not be permitted to ingest "evaporable" water in a source prior to the evaporation having occurred.

Additional problems related to the execution of the uncertainty analysis module are reported in Section 3.1.4.

\section{RMVFR}

The general observations apply to the removable fraction parameter for out-of-bound values.

Additional problems related to the execution of the uncertainty analysis module are reported in Section 3.1.4.

\section{$\underline{\text { RF0 }}$}

The parameter name is identified as SLIFE in the user's manual, but is listed as RF0 in the input file.

The general observations apply to the source lifetime parameter for extreme and out-of-bound values. In addition, while the value of zero is accepted by the interface, running the default area source with this lifetime results in the following error message:

Cannot Open Error file "F77L3.EER", error \# 3

However, a value of zero would be physically consistent with a "puff" release of the source, but the code would have to be modified to account for such non-steady state source release.

The smallest and largest numbers that are accepted and executed with a default non-volume source are $1 \mathrm{E}-38$ and $1 \mathrm{E}+33$, respectively. However, entering an extremely small value for the time of source removal results in unrealistically high doses from any of the air pathways. For example, running the default point source with $1 \mathrm{pCi}$ of Co-60 and a source release lifetime of $1 \mathrm{E}-38 \mathrm{~d}$ results in an inhalation dose of $2.36 \mathrm{E}+30 \mathrm{mrem}$. This is much higher than the maximum possible dose of $2.19 \mathrm{E}-04$ mrem that a receptor could incur from instantly inhaling the ENTIRE source.

In addition to the typical error messages incurred after entering extreme values, when a number between $1 \mathrm{E}+34$ and $1 \mathrm{E}+38$ is entered, the following error message is generated:

Beginning Calculations Abnormal program termination: Illegal instruction $C S: E I P=000 F h: 00004354 h$ 
In the input file, the times of source removal are reported in pairs as follows: RF0 $(1,1)=$ lifetime of Source 1, followed below by $\operatorname{RF} 0(1,2)=0$, . This sequence is repeated for all source numbers, with RF0(i,2) always equal to 0 , where $\mathrm{i}$ is the source number. The reason for having this second RF0 entry for each source is not immediately apparent, since it is independent of the actual time of source removal assigned to each source. The input file saves time of source removal of a volume source as the default of 365 or the values selected for any other source type previously assigned to that source number. While this time of source removal is meaningless for a volume source, it is a possible source of confusion for advanced users that might inspect the input file. A more appropriate way to handle a volume source removable fraction in the input file may be to assign RF0 $=0$ for a volume source. Note that keeping the default volume-source time of source removal in the input file would not be a source of confusion to users that do not inspect the input file: this parameter becomes unavailable and invisible in the interface for a volume source, and the code runs fine as is.

Additional problems related to the execution of the uncertainty analysis module are reported in Section 3.1.4.

\section{$\underline{\text { RRF }}$}

The general observations apply to the radon release fraction for out-of-bound values.

Additional problems related to the execution of the uncertainty analysis module are reported in Section 3.1.4.

\section{RNUCACT}

The general observations apply to the radionuclide activity/concentration parameter for extreme and out-of-bound values.

The code should indicate when a selected radionuclide has long-lived progeny and give the user the option to add all long-lived progeny to the input window (within the 10 nuclide limit). The initial concentration can be set to zero, but the user would be allowed to enter a non-zero concentration for one or more progeny. This would make the input of radionuclides more consistent with the RESRAD code and may save the user some data entry time. Also, the uncertainty analysis module should be available for this parameter to reflect any uncertainties in the measured values of individual radionuclides in each source.

\section{NREGI0}

The Help Screen states that "All releases from the source, other than that of radon, are assumed to occur from region 1." This should actually be written as "All releases from the source, other than that of radon, are assumed to start from region 1 and move to posterior regions as the anterior regions are removed due to erosion." There should be some additional help regarding the release of radon and tritium.

The input file reports the number of regions per source as follows: NREGIO0 $=$ NREGIO0(1),---, NREGIO0(i),---, NREGIO0(NS-1), NREGIO0(NS), where NREGIO0(i) is the number of regions in the $i$ th source. The input file saves the number of regions of a non-volume source as the default of 1 or the value selected for the volume source previously assigned to that source number. While this number of regions is meaningless for a non-volume source, it is a possible 
source of confusion for advanced users that might inspect the input file. A more appropriate way to handle the number of regions in the input file may be to assign NREGIO0 $=0$ for a nonvolume source, but this would require the code to revert back to the default number of regions if the user changes the non-volume source back to a volume source. Note that keeping the number of regions for a non-volume source in the input file would not be a source of confusion to users that do not inspect the input file: this parameter becomes unavailable and invisible in the GUI for a non-volume source, and the code runs fine as is.

There is a serious flaw in the way that the code calculates the direct external dose from a volume source. While this flaw is not entirely dependent on the number of regions that are selected, it is accentuated in sources with multiple regions.

The cylindrical volume source modeled in RESRAD-BUILD must have two planar surfaces bounding the source. The coordinates used to locate the source correspond to the center of the planar surface that is closest to the origin. The region immediately "behind" this surface is defined as Region 1. "Behind" is defined as the region of space from the surface closest to the origin in the direction of the second planar surface, which is furthest away from the origin. Note that this region of space is undefined when the source is located at the origin, but is taken to be the region of space in the positive direction. The problem arises when receptors are placed at opposite sides of a volume source. If two receptors are on placed on the source centerline, equidistant but in opposite directions from the center of the first planar surface that defines the source location, it follows that one of these receptors should receive a higher direct external dose than the other. For example, if a $15-\mathrm{cm}$ thick volume source is located at the origin in the $\mathrm{x}$ direction, the user might consider two receptors, Receptor 1 located at $(-1,0,0)$ and Receptor 2 located at $(1,0,0)$, to be equidistant from the source. However, this would not be the case, since the finite thickness of the source means that some of the source volume would be closer to one of the receptors by an amount equal to the source thickness. The $15-\mathrm{cm}$ thick source at the origin occupies the space in the positive $\mathrm{x}$ direction; to be truly equidistant from this source, Receptor 2 would have to be located at $(1.15,0,0)$. However, the code does not consider the space occupied by the source in calculating the direct external dose. The calculated direct external doses to the receptors that are equidistant from the origin, but on opposite sides of the source, are the same.

Multiple regions further complicate matters, since now receptors on opposite sides of the volume source may be exposed to different internal shielding geometries. Consider the previous example, but instead of a single-region source select two regions, each 15-cm thick. Regardless of which region is selected as the one containing the contamination, it follows that the dose to two equidistant receptors on opposite sides of the source volume should be different. It also follows that the dose to the receptor on the side of the source containing the contaminated region should be higher than the dose to the receptor equally distant from the side of the source containing the uncontaminated region. Using the previous example, but adding a second region to the source (contamination in Region 1) results in the dose to receptor 1 being higher than the dose to receptor 2. This is consistent with the fact that receptor 1 is on the side of the contaminated region, whereas receptor 2 is shielded by the uncontaminated region of the source. Selecting Region 2 as the location of the contamination simply flips the doses to the two receptors. However, the dose to Receptor 2 in this case should be higher than what the dose to Receptor 1 was in the first case, since the contaminated region is now $30 \mathrm{~cm}$ closer to Receptor 2 than was the case for Receptor 1 when the contamination was located in Region 1. This is not the case, and the doses to the receptors on the unshielded side of the source are actually the same as the doses reported for the single region source. 


\section{FCNT0}

When a volume source is set up for more than one region, it is possible to select a contaminated region other than the default Region 1 . However, if the user later decides to change the number of regions in that volume source to a number smaller than the previously selected contaminated region, the code will accept this change without warning the user. Upon inspection of the wall region parameters, all the radio buttons above each region appear to be unchecked (i.e., no contaminated region appears to be selected). Running the code with no contaminated region checked results in the following error message:

Cannot Open Error file "F77L3.EER", error \# 16

The code should be modified so that a warning is issued to the user (and/or reset the contaminated region) prior to exiting the "Details for Source \# $\mathrm{i}$ " window if a reduction in the number of wall regions results in the inadvertent "removal" of the contaminated region.

\section{THICKO}

The general observations apply to the source region thickness parameter for extreme and out-ofbound values. In addition, a value of zero thickness is accepted by the interface in the default case (1-region volume source), but causes the following error message:

Cannot Open Error file "F77L3.EER", error \# 6

This is true even for the thickness of a region in a multi-region source that does not contain the contamination and is located "behind" the contaminated region (e.g., 3-region source with contamination in Region 2, non-zero thickness in Regions 1 and 2, and zero thickness in Region 3). The correct response for the code should be to either warn the user that zero is inappropriate, or accept zero thickness as a way to remove individual regions (similar to what is done for the unsaturated zone thicknesses in the RESRAD code).

The smallest thickness that is accepted in the default case is 1E-43. However, the direct external dose is reported to be zero for any thickness less than 1E-20. The air pathway doses, excluding radon, and the direct ingestion pathway are not affected by the differences in thickness of an extremely thin source, even though inhalation or ingestion of the entire source inventory would be incapable of producing the calculated dose. For example, a source whose area is $36 \mathrm{~m}^{2}$, is 1E$20 \mathrm{~cm}$ thick and $2.4 \mathrm{~g} / \mathrm{cc}$ dense, contaminated with $1 \mathrm{pCi} / \mathrm{g}$ of CO- 60 , contains $8.6 \mathrm{E}-17 \mathrm{pCi}$. The inhalation dose factor for CO-60 is $2.19 \mathrm{E}-4 \mathrm{mrem} / \mathrm{pCi}$, resulting in a maximum dose of $1.9 \mathrm{E}-20$ mrem if the entire source is inhaled. However, the reported inhalation dose is $7.83 \mathrm{E}-9 \mathrm{mrem}$. To test the sensitivity of the source thickness to the air pathways calculations, 10 one-region volume sources are defined. The following thicknesses (with all other parameters at their default values) result in the following inhalation doses calculated at time zero: 


$\begin{array}{lc}\text { Thickness (cm) } & \text { Dose (mrem) } \\ 1 \mathrm{E}-1 & 7.04 \mathrm{E}-7 \\ 1 \mathrm{E}-2 & 7.04 \mathrm{E}-7 \\ 1 \mathrm{E}-3 & 7.04 \mathrm{E}-7 \\ 1 \mathrm{E}-4 & 7.04 \mathrm{E}-7 \\ 1 \mathrm{E}-5 & 7.04 \mathrm{E}-7 \\ 1 \mathrm{E}-6 & 8.55 \mathrm{E}-8 \\ 1 \mathrm{E}-7 & 7.83 \mathrm{E}-9 \\ 1 \mathrm{E}-8 & 7.83 \mathrm{E}-9 \\ 1 \mathrm{E}-9 & 7.83 \mathrm{E}-9 \\ 1 \mathrm{E}-10 & 7.83 \mathrm{E}-9\end{array}$

Since the erosion rate controls the material removal rate from the source, increasing or decreasing the value of this parameter will also change the source thickness at which the minimum air pathway doses occur. The impact of such changes is discussed in erosion rate parameter checklist.

Very large thicknesses are accepted by the code, but a maximum thickness of $1 \mathrm{E}+25 \mathrm{~cm}$ can be entered in the default case without an error message.

Additional problems related to the execution of the uncertainty analysis module are reported in Section 3.1.4.

\section{DENSIO}

The general observations apply to the source density parameter for extreme and out-of-bound values. In addition, a value of zero density is accepted by the interface in the default case (1region volume source), but causes the following error message:

Cannot Open Error file "F77L3.EER", error \# 6

This is true even for the density of a region in a multi-region source that does not contain the contamination and is located "behind" the contaminated region (e.g., 3-region source with contamination in Region 2, non-zero density in Regions 1 and 2, and zero density in Region 3). The correct response for the code should be to warn the user that zero is inappropriate.

The smallest density that is accepted in the default case is 1E-45. However, the direct external dose is reported to be zero for any density less than $1 \mathrm{E}-20$.

Very large densities are accepted by the code, and a maximum density of $1 \mathrm{E}+31$ can be entered in the default case without an error message. Physically, the material density cannot exceed that of the densest material typically available. For most practical cases, that is the density of uranium metal. The RESRAD code uses a maximum density of $22.5 \mathrm{~g} / \mathrm{cc}$ (and this is the stated limit in the user's manual). NOTE: as the material density for a contaminated region is increased, the direct external dose approaches a maximum value, while the air pathways and direct ingestion pathways continue to increase proportionally to the increase in density. This is the expected behavior, since the concentration is expressed in activity per unit mass, and the source mass increases proportionally to the density. At higher densities, the external dose from the increased inventory is countered by additional self-shielding of the source mass. 
Additional problems related to the execution of the uncertainty analysis module are reported in Section 3.1.4.

\section{EROSO}

The general observations apply to the source erosion rate parameter for extreme and out-of-bound values.

When both the "Details for Source i" and the "Wall Region Parameters" windows are still on the screen, it is possible to select a different source number, add/remove radon precursors, change the source type and/or change the number of regions in a volume source. While the "Details.." window reflects any changes made to either number of regions, source type or source number, the "Wall Region Parameters" window does not keep up with these changes unless the user first exits and then re-enters this window. This may be a source of confusion if the user inadvertently forgets to exit this screen before modifying or moving on to another source. This could result in incorrect wall region parameters being assigned to a source.

The solution to this would be to require the user to exit or confirm the values in the "Wall Regions Parameter" window prior to selecting a new source, changing the source type, adding/removing radon precursors, or changing the number of wall regions.

The erosion rate for a tritium source will result in a dose even when the Wet+Dry zone thickness $=$ Dry zone thickness, as long as the volume fraction available for evaporation is less than 1 . There is no apparent limit to the volume of bound tritium that could be removed, since the normal thickness parameter (THICK0) for a volume source does not apply in this case. Also, the erosion rate has no apparent impact on the time-dependent values of the Dry/Wet+Dry zone thicknesses. It is conceivable that the removal of surface layers could occur at a rate that is greater than the evaporation rate used in the model to remove the tritium from the source.

Additional problems related to the execution of the uncertainty analysis module are reported in Section 3.1.4.

\section{POROSO}

In the Help File for the porosity, the range is indicated as being 0 to 1 INCLUSIVE. A value of zero will cause the code to crash and a value of 1 is physically impossible. The correct phrase should be "not inclusive." The user's manual also should be edited to specify that 0 and 1 are not included in the range.

The general observations apply to the source porosity parameter for extreme and out-of-bound values. In addition, a value of zero is accepted by the interface, but attempting to run the code results in the following error message:

Cannot Open Error file "F77L3.EER", error \# 3

An error occurs regardless of whether the region of the source with zero porosity is contaminated or not. In the latter case, the error message is:

Cannot Open Error file "F77L3.EER", error \# 6 
Zero porosity should be accepted by the code to allow the user to suppress the radon pathway. This is how one might model a volume source region to simulate an impermeable barrier. In addition, the code should be able to calculate the diffusion of radon out of a multi-region source when one side of the region containing the contamination is sealed but the other is not.

For a 1-region source, the smallest value for the porosity that does not result in an error message is $1 \mathrm{E}-38$. However, even such a low porosity value does not change the default radon dose of 2.27 mrem from a Ra-226 source, indicating a possible problem with the calculation.

The smallest value for a 2-region source that does not result in an error message is $1 \mathrm{E}-45$ when it is applied to the non-contaminated region. Not unrealistically small values of porosity applied to the contaminated Region 2 of a 2-region source result in spurious results for the radon inhalation dose at time zero, as indicated below:

Porosity Dose

$\begin{array}{ll}1 \mathrm{E}-1 & 2.27 \mathrm{E}+0 \\ 1 \mathrm{E}-2 & 2.27 \mathrm{E}+0 \\ 1 \mathrm{E}-3 & 2.27 \mathrm{E}+0 \\ 1 \mathrm{E}-4 & 2.21 \mathrm{E}+0 \\ 1 \mathrm{E}-5 & 2.71 \mathrm{E}+0 \\ 1 \mathrm{E}-6 & 6.86 \mathrm{E}+0 \\ 1 \mathrm{E}-7 & * * * * * * * * \\ 1 \mathrm{E}-8 & 1.48 \mathrm{E}+2 \\ 1 \mathrm{E}-9 & 1.13 \mathrm{E}+0 \\ 1 \mathrm{E}-10 & 1.13 \mathrm{E}+0\end{array}$

At very small values of porosity, the results are even more extreme (e.g., a radon inhalation dose of $1.35 \mathrm{E}+21$ with a porosity of $1 \mathrm{E}-27)$. The smallest value that does not result in an error message is $1 \mathrm{E}-31$, but the reported radon inhalation dose is $1.11 \mathrm{E}+25$.

The above results are highly dependent on which of the two regions is selected to contain the contamination. If Region 1, rather than Region 2 as tested above, contains the contamination, the dose does not change from the default value of 2.27 , regardless of the porosity value used in Region 1.

Similar spurious results are observed when a third region is added, with the contaminated region now bounded by the two uncontaminated regions.

Setting the porosity in the default 1-region source to the upper bound value of 1 does not change the radon inhalation dose from the default of $2.27 \mathrm{mrem}$, which is a suspect result. A porosity of 1 is equivalent to vacuum, so any region with a porosity of 1 could not contain any material, contaminated or otherwise. This value should be rejected by the code.

The material density and porosity are closely linked properties. Logically, any material cannot be very dense and very porous at the same time. There should be a correlation function between density and porosity which should be checked and the code should provide warnings if the user exceeds these realistic bounds.

In addition to the usual error messages encountered with extreme values, in a 1-region source, entering a number between $1 \mathrm{E}-39$ and $1 \mathrm{E}-45$ results in the following error message: 
Phar Lap fatal err 10049: Ran out of stack buffers.

It is important to resolve the problem that is causing spurious output to be generated at very low or very high values of porosity. In addition, the codes should compare the material densities and porosities in each region to ensure that the user has entered values that are within realistic constraints. The algorithm that uses the porosity to calculate the radon diffusion needs to be checked, since radon doses appear to be very insensitive to changes in this parameter.

Additional problems related to the execution of the uncertainty analysis module are reported in Section 3.1.4.

\section{EFDIF0}

The range for the effective diffusion coefficient in the user's manual places an upper bound on the value of 1.1E-5, but neither code nor Help Screen specify this. In fact, the default value of 2E-5 lies outside of this range.

The general observations apply to the radon effective diffusion coefficient for extreme and outof-bound values. In addition, a value of zero is accepted by the interface, but attempting to run the code results in the following error message:

\section{Cannot Open Error file "F77L3.EER", error \# 3}

This error occurs regardless of whether the region of the source with zero effective diffusion coefficient is contaminated or not. A zero effective diffusion coefficient should be accepted by the code to allow the user to suppress the radon pathway. This is how one might model a volume source region to simulate an impermeable barrier. In addition, the code should be able to calculate the diffusion of radon out of a multi-region source when one side of the region containing the contamination is sealed but the other is not.

The smallest value for the effective diffusion coefficient that does not result in an error message is $1 \mathrm{E}-11$ for a one- or two-region source. Once more, this limiting value is independent of whether the region contains the contamination or not. However, the default radon dose does not change when a very low effective diffusion rate is entered in the uncontaminated region of a tworegion source. Some problems arise when a 3-region source is set up with the contamination in Region 2. In this case, the smallest effective diffusion coefficient in the two outer regions that will not cause the code to report an error message or a radon dose of $* * * * * *$ ' is $1 \mathrm{E}-9$.

Large values of effective diffusion coefficients may result in several different problems. These problems are reported in the following two tests.

The first test consists of the default single-region source with a large effective diffusion coefficient. As a baseline, the default effective diffusion coefficient $(0.00002)$ results in a radon dose of 2.27 mrem. Increasing the diffusion coefficient should result in a higher radon dose, but this is not the case. The following doses are calculated by the code at time zero using the following values for effective diffusion coefficient (EDC): 


$\begin{array}{ll}\mathrm{EDC} & \text { Dose (mrem) } \\ 1 \mathrm{E}+1 & 2.27 \\ 1 \mathrm{E}+2 & 2.27 \\ 1 \mathrm{E}+3 & 2.25 \\ 1 \mathrm{E}+4 & 2.21 \\ 1 \mathrm{E}+5 & 2.46 \\ 1 \mathrm{E}+6 & 2.73 \\ 1 \mathrm{E}+7 & 1.70 \\ 1 \mathrm{E}+8 & 9.44 \mathrm{E}-11 \\ 1 \mathrm{E}+9 & 9.44 \mathrm{E}-11 \\ 1 \mathrm{E}+10 & 9.44 \mathrm{E}-11\end{array}$

The dose of 9.44E-11 is reported for effective diffusion coefficients as large as $1 \mathrm{E}+31$, beyond which the code reports an error message. The response of the code to large effective diffusion coefficients is inconsistent with the expected response, since the dose appears to first decrease slightly, then increase slightly, and finally drop dramatically to a limiting value as the effective diffusion coefficient is increased by factors of ten. This limiting value is the contribution from the RA-226 that is eroded from the surface and will depend on the erosion rate (it will be zero if the erosion rate is set to zero).

The second test consists of a two-region volume source, with the contamination in Region 2. Increasing the effective diffusion coefficient in Region 1 (all other parameters at default) results in the following doses:

$$
\begin{array}{ll}
\mathrm{EDC} & \text { Dose (mrem) } \\
1 \mathrm{E}+1 & * * * * * * * \\
1 \mathrm{E}+2 & 1.13 \\
1 \mathrm{E}+3 & 1.13 \\
1 \mathrm{E}+4 & 3.58 \mathrm{E}+4 \\
1 \mathrm{E}+5 & * * * * * * * \\
1 \mathrm{E}+6 & 1.13 \\
1 \mathrm{E}+7 & * * * * * * * \\
>1 \mathrm{E}+7 & \text { Error message }
\end{array}
$$

Increasing the effective diffusion coefficient in the uncontaminated side of the source only should not affect the radon dose to a receptor to such an extreme and erratic extent. It is interesting to note that the most common dose that appears in the previous table is $1.13 \mathrm{mrem}$. This happens to be half of the dose to a receptor from the default 1-region source. It appears that the code is not able to correctly calculate the diffusion of radon across the boundary between Regions 2 and 1 when the diffusion rate in Region 1 is much larger than the diffusion rate in Region 2.

Radon precursors that are far up the decay chain (e.g., CM-252) may not be present in sufficient activities in the source to generate much radon immediately following time zero. This results in the radon dose being shown as '*******' in the output report. There is no explanation given for this display. The user should be either warned that the radon dose is too small, or the radon dose should simply be set to zero under these circumstances.

Additional problems related to the execution of the uncertainty analysis module are reported in Section 3.1.4. 


\section{EMANAO}

The radon emanation fraction is applicable only to the region that contains the contamination. However, in a multi-region source, the interface displays input fields for the radon emanation fraction even for those regions that are not contaminated. Entering any value between the lower and upper bounds in these fields has no effect on the calculation.

The general observations apply to the radon emanation fraction for extreme and out-of-bound values.

Additional problems related to the execution of the uncertainty analysis module are reported in Section 3.1.4.

\section{MTLS}

The input file reports the source material type as follows: MTLS = MTLS (1),---, MTLS (i),---, MTLS (NS-1), MTLS (NS), where MTLS (i) is the material type of the ith source. The source material is identified by an integer between 1 and 8 , inclusive. Concrete $=1$, water $=2$, aluminum $=3$, iron $=4$, copper $=5$, tungsten $=6$, lead $=7$, uranium $=8$. The input file saves the source material type of a non-volume source as the default of 1 or the value selected for the volume source previously assigned to that source number. While this source material type is meaningless for a non-volume source, it is a possible source of confusion for advanced users that might inspect the input file. A more appropriate way to handle source material type in the input file may be to assign MTLS $=0$ for a non-volume source, but this would require the code to revert back to the default source material type if the user changes the non-volume source back to a volume source. Note that keeping the source material type for a non-volume source in the input file would not be a source of confusion to users that do not inspect the input file: this parameter becomes unavailable and is invisible in the interface for a non-volume source, and the code runs fine as is.

A symbol is used to represent the last six source material types. This is inconsistent with the full names that are used to identify the material types when defining external shielding properties.

To test each material type, these steps are followed starting with the default case:

- Add 7 sources for a total of 8 sources, all located at $(0,0,0)$

- Leave the material type for Source 1 at Concrete (1)

- Change the material type (but not thickness or density) for Sources 2-8 to water (2), aluminum (3), iron (4), copper (5), tungsten (6), lead (7), and uranium (8), respectively

The resulting direct external doses from each source at time zero are:

$$
\begin{array}{cccccccc}
1 & 2 & 3 & 4 & 5 & 6 & 7 & 8 \\
4.62 \mathrm{E}+00 & 4.56 \mathrm{E}+00 & 4.75 \mathrm{E}+00 & 4.51 \mathrm{E}+00 & 4.50 \mathrm{E}+00 & 3.43 \mathrm{E}+00 & 3.14 \mathrm{E}+00 & 2.80 \mathrm{E}+00
\end{array}
$$

As expected, the material with the most effective self-shielding is uranium, but the lower effectiveness of aluminum (which has a higher atomic number) relative to water and concrete needs to be investigated. 


\subsubsection{Shielding Parameters}

\section{DSTH}

The general observations apply to the shielding thickness parameter for extreme and out-of-bound values. In addition, if the user simply tries to run the code IMMEDIATELY following an unacceptable entry, such as '-1', the code will attempt to run but will report the following error before crashing:

\section{Run-time error '5': Invalid procedure call or argument}

A full output report is actually generated for the run, with spurious results. The direct external dose at time zero is reported to be $4.64 \mathrm{mrem}$, which is greater than the default dose with no shielding of $4.62 \mathrm{mrem}$.

Physically, the shielding thickness between a receptor and source pair cannot exceed the distance separating the two (in the direction normal to the source). However, it is possible to enter a value greater than $100 \mathrm{~cm}$ for the default case, where the receptor is located $1 \mathrm{~m}$ from the source (along the $\mathrm{x}$ axis). Any amount of shielding thickness that exceeds this distance has the effect of reducing the direct external dose to levels that are not physically possible. The code does not provide any warning alerting the user of this inconsistency.

When a non-zero parameter is entered for the shielding thickness, it appears on a yellow background in the "Source Receptor Table" window. This is inconsistent with the table legend, which shows the shielding thickness as having a blue background.

The "Shielding Parameters" window shows the active Source\#/Receptor\#. Since the receptor parameters are above and the source parameters are below, this order may lead to confusion and the proper order should be Receptor\#/Source\#. There is also an inconsistency in the name of the "Source/Receptor Table" window. The receptor numbers are listed on the left, while the source numbers are listed on the top, going towards the right. The window title should be renamed as "Receptor/Source Table"

Additional problems related to the execution of the uncertainty analysis module are reported in Section 3.1.5.

\section{DSDEN}

The general observations apply to the shielding density parameter for extreme and out-of-bound values.

The effective upper bound in the default case (with zero shielding thickness) is $1 \mathrm{E}+35$. Larger values are accepted, but result in error messages. Physically, the shielding density cannot exceed that of the densest material typically available for shielding. For most practical cases, that is the density of uranium metal. The RESRAD code uses a maximum density of $22.5 \mathrm{~g} / \mathrm{cc}$, which is also the upper bound listed in the user's manual.

To verify the effect of very large shield densities (but less than 1E+35), a small (but non-zero) shielding thickness was introduced. This had the expected effect of reducing the direct external dose to zero. 
To verify the lower bound of the density range, a non-zero shielding thickness $(10 \mathrm{~cm})$ is entered, keeping concrete as the shield material. After running the problem with the default density, the density is reduced by one order of magnitude for each step, with the following results for the direct external dose:

Density (g/cc) Dose (mrem)

2.4E-0 $\quad 0.976$

$2.4 \mathrm{E}-1 \quad 3.98$

$2.4 \mathrm{E}-2 \quad 4.38$

$2.4 \mathrm{E}-3 \quad 4.41$

$2.4 \mathrm{E}-4 \quad 4.40$

$2.4 \mathrm{E}-5 \quad 4.40$

This dose of 4.40 mrem does not change for densities approaching perfect vacuum (1E-99 g/cc). Reducing the shield thickness to $1 \mathrm{~cm}$ produces a maximum direct external dose of $4.59 \mathrm{mrem}$, regardless of the density. The default direct external dose (zero shield thickness) is 4.62.

Therefore, there appears to be an error in the way the code handles the combination of shielding thickness and density. The above differences in the maximum direct external doses are quite significant. The direct external dose from a shielded source should equal the dose from the unshielded source (zero thickness) when the density approaches zero, regardless of the shield thickness that is entered by the user. NOTE: this issue appears to affect only the volume and area sources. For point and line sources, the direct external doses from unshielded and shielded sources are equivalent as the shield density approaches zero.

Additional problems related to the execution of the uncertainty analysis module are reported in Section 3.1.5.

\section{MTLC}

To test each material type, these steps are followed starting with the default case:

- Change the source type to "point"

- Change the receptor location to $(0,0,1)$

- Add 7 receptors for a total of 8 receptors, all located at $(0,0,1)$

- Change the shielding thickness to $1 \mathrm{~cm}$ between all 8 receptors and Source 1

- Leave all densities at $2.4 \mathrm{~g} / \mathrm{cc}$

- Leave the shielding material for Receptor 1 at Concrete (1)

- Change the shielding material for Receptors 2-8 to water (2), aluminum (3), iron (4), copper (5), tungsten (6), lead (7), and uranium (8), respectively 
The resulting direct external dose to each receptor at time zero is:

$\begin{array}{cl}\text { Source: } 1 & \\ \text { Receptor } & \text { External } \\ 1 & 2.86 \mathrm{E}+06 \\ 2 & 2.87 \mathrm{E}+06 \\ 3 & 2.87 \mathrm{E}+06 \\ 4 & 2.83 \mathrm{E}+06 \\ 5 & 2.83 \mathrm{E}+06 \\ 6 & 2.73 \mathrm{E}+06 \\ 7 & 2.70 \mathrm{E}+06 \\ 8 & 2.65 \mathrm{E}+06\end{array}$

As expected, the material with the greatest efficiency per unit mass is uranium. To determine the impact of buildup factors over several mean free paths, the shielding thickness is increased from 1 to $100 \mathrm{~cm}$, with the following results at time zero:

$\begin{array}{cc}\text { Source: } 1 & \\ \text { Receptor } & \text { External } \\ 1 & 7.58 \mathrm{E}+01 \\ 2 & 2.38 \mathrm{E}+01 \\ 3 & 1.19 \mathrm{E}+02 \\ 4 & 1.26 \mathrm{E}+02 \\ \text { Source: } & 1 \\ \text { Receptor } & \text { External } \\ 5 & 1.45 \mathrm{E}+02 \\ 6 & 1.63 \mathrm{E}+01 \\ 7 & 5.83 \mathrm{E}+00 \\ 8 & 1.15 \mathrm{E}+00\end{array}$

As expected, the differences are now much more dramatic due to the greater amount of buildup occurring in a thick shield. Water, despite having the lowest average $Z$ value, appears to be a much more effective shield in this case compared to all other materials except the last three (tungsten, lead, and uranium). While this is not necessarily a problem, it warrants further investigation into the relationships between attenuation and buildup.

\subsubsection{Tritium Model Parameters}

\section{DRYTHICK}

The user's manual does not specify the name of this parameter. The second paragraph of the Help Screen is duplicated for both the Dry zone thickness and the Wet+Dry zone thickness. This text describing the tritium volume source model should be deleted from these parameters' Help Screens and instead should be cross-referenced through a link from the Help Screens of all the parameters that are used in the tritium volume source model.

The general observations apply to the Dry zone thickness parameter for extreme and out-ofbound values. Entering a value greater than the current value of the Wet+Dry zone thickness and attempting to go to another parameter results in the following error message:

Wet and Dry zone thickness cannot be less than Dry zone thickness 
This is the correct way to handle such an input error. However, trying to run the code results in the usual Run-time error report. Note that if the Wet+Dry zone thickness is zero and the Dry zone thickness in non-zero, no error message is generated but the resulting dose will be zero.

Additional problems related to the execution of the uncertainty analysis module are reported in Section 3.1.6.

\section{H3THICK}

The Help Screen description should be made consistent with the actual input parameter definition (i.e., provide help on Wet+Dry zone thickness, not the Wet zone thickness, which is not the actual parameter used).

The general observations apply to the Wet+Dry zone thickness parameter for extreme and out-ofbound values and the specific observations are similar to those made for the dry zone thickness.

Additional problems related to the execution of the uncertainty analysis module are reported in Section 3.1.6.

\section{H3VOLFRACT}

The general observations apply to the volumetric water content parameter for extreme and out-ofbound values.

It is possible for the user to enter a moisture content that exceeds the porosity, but is still less than or equal to 1 . This is physically impossible, as indicated in the Help Screen and user's manual, but no warning is issued. A good solution to this problem would be to re-define the parameter as a fraction of the pore space, and not of the bulk material. That way, the volumetric water content would always be less than or equal to the porosity. A better name for such a parameter would be "pore water fraction" or "pore water content."

Recommendations for improvements include warning the user if the volumetric water content exceeds the porosity (as is currently done for the Wet+Dry zone thickness and the Dry zone thickness) or re-define the parameter as the fraction of pore space that is occupied by water.

Additional problems related to the execution of the uncertainty analysis module are reported in Section 3.1.6.

\section{H3RMVF}

The general observations apply to the water fraction available for vaporization parameter for outof-bound values.

Additional problems related to the execution of the uncertainty analysis module are reported in Section 3.1.6.

\section{HUMIDITY}

The general observations apply to the humidity parameter for extreme and out-of-bound values. 
A very large humidity value is accepted by the code, despite the limitation of $100 \mathrm{~g} / \mathrm{m} 3$ indicated in the user's manual. A maximum humidity of $1 \mathrm{E}+38$ can be entered in the default case without an error message. However, such large values are physically impossible. The absolute humidity cannot exceed the carrying capacity of the air at normal building temperatures; the maximum value is not much higher than the default humidity. Condensation will remove any excess water vapor from the air.

Additional problems related to the execution of the uncertainty analysis module are reported in Section 3.1.6.

\section{H3POROSITY}

The user's manual does not list this parameter. Note: this porosity parameter is distinct from the porosity parameter used to define a multi-region volume source (POROS0). This should be clearly indicated in the Help Screen. In addition, the reference to a region and the link to the definition of a region are inappropriate in this case, since there is only one region that can be defined for a tritium volume source. A cautionary note should be included that the porosity cannot be less than the volumetric water content.

The general observations apply to the tritium volume source porosity parameter for extreme and out-of-bound values.

It is possible for the user to enter a porosity that is less than the volumetric water content, but is still greater than zero. This is in conflict with the requirement that the volumetric water content be less than the porosity. As indicated previously, a good way to resolve this issue is to re-define the volumetric water content as the fraction of the available pore space, and not the fraction of the bulk volume.

Setting the porosity to the upper bound value of 1 is equivalent to vacuum, so any region with a porosity of 1 could not contain any material (unless the material is entirely water). This value should be rejected by the code.

The material density and porosity are closely linked properties. Logically, any material cannot be very dense and very porous at the same time. There should be a correlation function between density and porosity which should be checked and the code should provide warnings if the user exceeds these realistic bounds.

Additional problems related to the execution of the uncertainty analysis module are reported in Section 3.1.6.

\section{WALL DENSITY}

The user's manual does not list this parameter. Note: this density parameter is distinct from the density parameter used to define a multi-region volume source (DENSI0). This should be clearly indicated in the Help Screen. In addition, the reference to a region and the link to the definition of a region are inappropriate in this case, since there is only one region that can be defined for a tritium volume source.

The general observations apply to the tritium volume source density parameter for extreme and out-of-bound values. 
A value of zero is accepted by the interface, and a non-zero dose is calculated for the default case at time zero (1.19E-04 mrem). A zero density is not physically possible, and is incompatible with a tritium concentration expressed as activity per unit mass (rather than per unit volume).

Very large densities are accepted by the code, and a maximum density of $1 \mathrm{E}+31$ can be entered in the default case without an error message. Physically, the material density cannot exceed that of the densest material typically available. For most practical cases, that is the density of uranium metal. The RESRAD code uses a maximum density of $22.5 \mathrm{~g} / \mathrm{cc}$. However, since a volume source containing tritium has to be porous, the upper bound density will likely be even lower and closer to the typical densities of concrete materials.

The material density and porosity are closely linked properties. Logically, any material cannot be very dense and very porous at the same time. There should be a correlation function between density and porosity which should be checked and the code should provide warnings

Additional problems related to the execution of the uncertainty analysis module are reported in Section 3.1.6.

\subsubsection{Radiological Units}

\section{$\underline{U}$ activity}

Changing the radiological units for activity is effective only for the duration of the current RESRAD-BUILD session. Closing and then opening RESRAD-BUILD causes the units to revert to the default (pCi). Having to reset the units can become tedious for users that run the code using exclusively SI units or units other than the defaults.

One possible solution would be to display a dialog box asking the user if he/she wishes to save the current activity units as the defaults (if these are different from the current saved defaults) upon exiting RESRAD-BUILD.

\section{$\underline{U}$ dose unit}

Changing the radiological units for dose is effective only for the duration of the current RESRAD-BUILD session. Closing and then opening RESRAD-BUILD causes the units to revert to the default (mrem). Having to reset the units can become tedious for users that run the code using exclusively SI units or units other than the defaults.

One possible solution would be to display a dialog box asking the user if he/she wishes to save the current dose units as the defaults (if these are different from the current saved defaults) upon exiting RESRAD-BUILD.

\subsubsection{Parameters Not Covered in Appendix $\mathrm{J}$}

Several parameters were not described in Appendix J of the user's manual. Two of these parameters, H3POROSITY and WALL_DENSITY, are similar to the parameters POROS0 and DENSI0, but apply only to the tritium volume source model. The verification of these two parameters is discussed in Section 2.2.7. Other parameters not covered in the manual are TITLE and NUCSNAM/NNUCS. The verification of these parameters is discussed below. 


\section{TITLE}

The HELP Screen specifies that upper bound for the case title to be a 70-character alphanumeric title. The following dummy 70-character alphanumeric title was entered to test the upper bound:

123456789a123456789b123456789c123456789d123456789e123456789f123456789g

This title was correctly reported in the input file, but the output file truncated the last 30 characters.

A dummy 71-character alphanumeric title was accepted and correctly reported in the input file, despite the 70-character limitation reported in the help screen. However, as in the upper-bound test, the output file displayed only the first 40 characters.

These issues can be resolved by allowing a 0-70 character title to be fully displayed in the output file and incorporating an error-checking routine to ensure that the 70-character limit is not exceeded by the user in the entry screen.

\section{NUCSNAM/NNUCS}

The code behaved as expected following a battery of the following four tests:

(1) Add more than 10 radionuclides to a source

(2) Remove all radionuclides from a source

(3) Add tritium to a volume source containing other radionuclides

(4) Add other radionuclides to a volume source with tritium

Test (1) results in the following warning:

'Sorry, cannot have more than 10 radionuclides in a source. Please add a new source to put the additional radionuclides'

Test (2) results in the following warning:

'A source must contain at least one radionuclide'

Test (3) resulted in the following warning:

'Please delete all other radionuclides before adding tritium'

Test (4) resulted in the following warning:

'Please delete tritium before adding other radionuclides'

In all cases where tritium is included in a source, the following warning is issued:

'Please note that the deposition velocity is the same for all radionuclides. Please see deposition velocity help for further details.' 


\subsection{Individual Pathways Verification}

This portion of the verification task was an extension of the previous task. The Input Parameter Verification Checklist served as a means to identify the pathways that are affected or could be suppressed/activated depending on the parameter value. While RESRAD-BUILD does not allow the user to suppress individual pathways, setting to zero a number of parameters that affect the other pathways can accomplish the same result. Going through this process had the additional advantage of identifying different ways of suppressing pathways. Table 2-5 shows the individual pathways that were tested. Several of these pathways share radionuclide release and transport models, which are indicated in Table 2-5. These common models were constructed individually on a spreadsheet based on the equations contained in the user's manual. Where applicable, these common models were linked to generate a complete, source-to-receptor pathway model. This permitted a single solution to be obtained for each model, which could then be shared among those pathways that have these models in common. For example, the Deposition External and Indirect Ingestion pathways share the Source Injection, Indoor Air Quality, and Deposition model. The only differences between these two pathways are the dose conversion factors and consumption/occupancy rates. This model was linked to the Source Injection model. The output from the Indoor Air Quality Model was then used as input to other "downstream" models such as the Radon Dose model or the Deposition model. The spreadsheets for the individual pathway models were linked to the various contributing models. When dictated by the complexity of the pathway model, other methods were used. For example, the direct external dose from a shielded volume source was set up using an industry-standard code such as MicroShield (Grove 1996). While it is recognized that this amounts to benchmarking, it is a reasonable and effective verification method when the industry-standard code itself has been extensively verified and validated. The limitations of the MicroShield methodology were noted, particularly in areas where it differed significantly from the methodology used in RESRAD-BUILD.

Table 2-5. List of RESRAD-BUILD Pathways and Models

Pathway

Direct External

Submersion External

Deposition External

Radon Inhalation

Other Inhalation

Direct Ingestion

Indirect Ingestion
Description: Models(s)

External gamma from point, line, area and volume source: Shielding Model

External gamma from submersion in contaminated air: Source Injection Model/Indoor Air Quality Model

External gamma from surfaces contaminated by deposition: Source Injection Model/Indoor Air Quality Model/Deposition Model

Inhalation of radon and short-lived progeny: Radon Diffusion Model (volume source)/Indoor Air Quality Model/Progeny Equilibrium Model/Radon Dose Model Inhalation of particulates and tritium: Source Injection Model/Indoor Air Quality Model/Tritium Release Model (volume source) Ingestion of contaminated material directly from the source Ingestion of material from surfaces contaminated by deposition: Source Injection Model/Indoor Air Quality Model/Deposition Model 
For this task, all parameters that affected the outcome of a particular pathway model were examined as a group. A reasonable number of scenarios were constructed for each exposure pathway in RESRAD-BUILD, using default or other reasonable parameters when the defaults were not appropriate.

The sources in the base-case scenarios included several radionuclides with a wide range of dose impacts and transport properties. The verification cases included a representative set of alpha, beta and gamma emitters, as well as any radionuclides with special transport and exposure properties (e.g., tritium and radon). For some pathways, multiple scenarios were assessed. For example, potential scenarios involving the direct gamma exposure pathway were verified for each source type (point, line, area, and volume), with or without shielding, and using different shielding materials and density. Similarly, multiple scenarios were used to verify the calculation of air pathway doses when one, two, or three rooms are selected, with sources in one room and receptors in another.

The individual pathway models were also verified qualitatively by entering extreme (or bounding) values for each model parameter to determine its impact on the overall calculation (see Section 2.2). The purpose of this strategy was to uncover potential errors in the implementation of the model equations. An example is the detection of potential "divide-by-zero" or "overflow" errors that would not arise under "normal" conditions.

An evaluation was prepared for each pathway, outlining the models and scenarios that were tested, the radionuclides and parameter values used in each scenario, the result of the tests, and any discrepancies between the test results and the output generated by RESRAD-BUILD.

The pathway verification was initially set up to test the results for time zero, with no provision for radioactive decay or physical removal of the source material (other than to generate an airborne source term). The verification of time-dependent calculations is discussed in Section 2.4.

The spreadsheet model and comparison files used in the verification of the RESRAD-BUILD pathways, as well as any RESRAD-BUILD and MicroShield input and output files, are included in the CD-ROM appendix to this report.

\subsubsection{Direct External Gamma Pathway}

The direct external gamma pathway required extensive review and verification relative to the other five pathway models. While the calculation models used in RESRAD-BUILD were not reproduced in a spreadsheet, the models were tested by comparison with an industry-standard external gamma source and shielding model, MicroShield 5.0. MicroShield 5.0 is a point-kernel shielding code that has been rigorously verified. Appendix F of the RESRAD-BUILD user's manual indicates that the area and material factors used in RESRAD-BUILD are derived using the point-kernel method. Therefore any benchmarking of RESRAD-BUILD results against MicroShield results under similar assumptions and conditions can serve to evaluate the accuracy of the calculations in RESRAD-BUILD.

As indicated in Section 2.1.4, the primary radionuclide specific parameters used in the direct external gamma pathway models have been simplified to allow for more efficient dose calculations. For example, a maximum of four energy groups is used by RESRAD-BUILD for point and line sources, whereas MicroShield incorporates the unabridged energy groups from ICRP 38. In addition, MicroShield uses the point kernel method to break a line, area, or volume 
source into segments to compute the attenuation along the trajectory from the source element through any shielding, and integrates the contribution at the receptor location from this large number of "point" sources. RESRAD-BUILD uses analytical expressions and approximations for source and shielding geometries, including the use of a depth-and-cover factor, area factor, and source-receptor offset factor. The use of such expressions becomes less accurate for complex shielded sources, with a receptor positioned at a location offset from the source axis. In addition, RESRAD-BUILD and MicroShield use different methods to calculate the buildup factor.

Therefore, it was expected that RESRAD-BUILD and MicroShield would yield the best matches for an unshielded point source containing a high-energy gamma emitters at locations closest to the receptor. The greatest discrepancies were expected in the comparison of shielded volume sources with offset receptor locations farther from the source. While discrepancies do not necessarily indicate that RESRAD-BUILD is improperly calculating the doses based on the simplified external gamma model, they do point out to inaccuracies and limitations inherent in this method.

\section{Source - Receptor Geometries}

Figure 2-1 illustrates the source-receptor geometries used to define each scenario for each source type. For each source type, four receptor locations were selected relative to the source centered at the origin of the coordinate system. The four receptors were located at $(1,0,0),(10,0,0),(1,1,0)$, and $(10,10,0)$. These coordinates were chosen to test the effects of moving the receptor along and away from the source centerline (except for the point source geometry where there is no offset). These geometries were tested in the absence and presence of shielding materials of varying thickness and material type. For volume sources, both external and internal shielding configurations were tested. Internal shields were created in RESRAD-BUILD using a volume source with two regions and assigning the contamination to the second region, effectively making the first region a shield.

The line source was made to be 1-m long, and the area and volume sources each had a surface area of $1 \mathrm{~m}^{2}$; the contaminated region of the volume source was set to $10 \mathrm{~cm}$. Since RESRADBUILD uses an area factor to scale the doses from finite sources, additional cases were run with both codes to evaluate doses from area and volume sources of "infinite" area. The ratio of finite/infinite area results was then used as a measure of the "effective" area factor calculated for MicroShield and RESRAD-BUILD sources. 

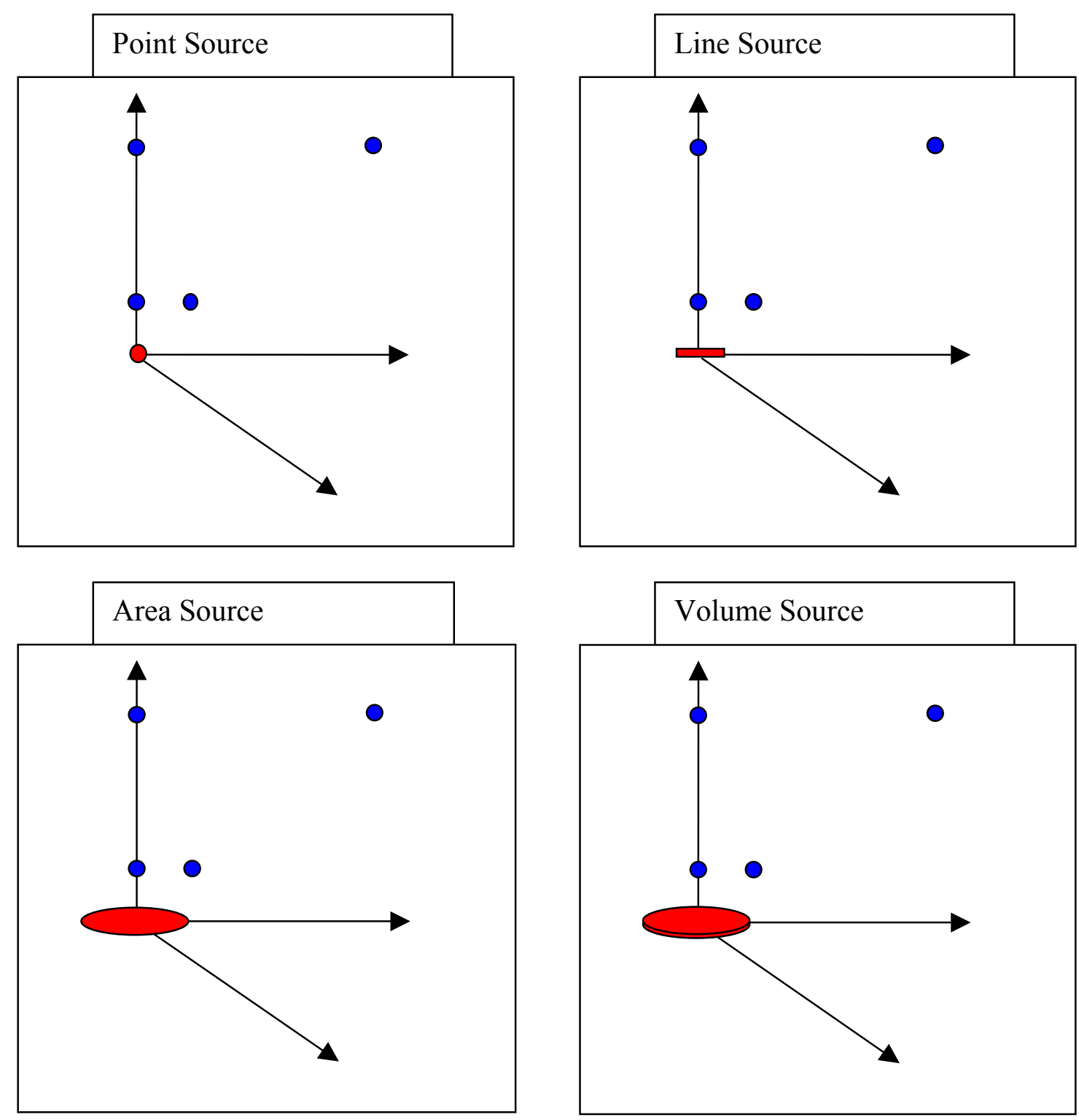

Figure 2-1. Source-Receptor Geometries Used to Test the Direct External Gamma Pathway

\section{Radionuclide Selection and Activity}

Ten radionuclides were selected for testing based on the following considerations:

- C-14 First photon emitter in the list of radionuclides in the COEFF_BD file.

- Co-60 Photon emitter with 1 photon in the COEFF_BD file.

- Sr-90 Photon emitter with the lowest yield in the COEFF_BD file.

- Ag-110m Photon emitter with the highest yield in the COEFF_BD file.

- Cs-137 Photon emitter with 2 energies in the COEFF_BD file.

- Ra-226 Photon emitter with 4 energies in the COEFF_BD file.

- Th-228 Photon emitter with the highest energy in the COEFF_BD file. 
- Np-237 Photon emitter with 3 energies in the COEFF_BD file.

- $\mathrm{Pu}-239$ Photon emitter with the lowest energy in the COEFF_BD file.

- Cf-252 Last photon emitter in the list of radionuclides in the COEFF_BD file.

These criteria cover the full spectrum of possible combinations, and the results from any other of the photon-emitting radionuclides considered in RESRAD-BUILD will be bounded by this list.

Appropriate unit activities or concentrations were entered for each source type within RESRADBUILD. For the point and line sources created in MicroShield, the default energy-group data were replaced with the four-group energy spectra in the COEFF_BD file, and the source activities were scaled to reflect the photon emission frequencies for each energy group per unit activity or concentration. Since RESRAD-BUILD does not use the four-group energy spectra for the area and volume sources, the MicroShield source activities were entered exactly as they were entered in RESRAD-BUILD.

\section{Receptor Occupancy Factor}

The time parameters in the RESRAD-BUILD code were set so that a receptor is exposed to the source for one hour. In addition, the number of points for decay and ingrowth calculations was set to 1 (no decay). This facilitated the comparison with the MicroShield results, which are given in $\mathrm{mrem} / \mathrm{h}$.

\section{Shielding Materials and Dimensions}

All eight shielding materials available in RESRAD-BUILD were tested for cases involving shields. The density of each shield was set to its default physical density. The shielding thickness was selected considering the shield density and the photon energies emitted by source in order to avoid excessive or inadequate attenuation factors. For two radionuclides, Co-60 and $\mathrm{Pu}-239$, all eight materials were tested for all four source types. The other eight radionuclides were tested with two source materials, using different materials for each source type, to ensure that each possible radionuclide/shield material combination was tested. Table 2-6 presents a source type and shield material matrix indicating the material types and densities as well as the shield thickness used in each source and radionuclide combination. The blank cells in Table 2-6 indicate combinations that were not tested.

In addition to the shielded source cases, tests were run to determine the impact of changes to the source material type and density on the doses from an unshielded volume source. For these tests, the source material and radionuclide combinations were selected in accordance with the same material/radionuclide matrix for the volume source as listed in Table 2-6. 
Verification of RESRAD-BUILD, Version 3.1

Table 2-6. Source Type and Shield Material Matrix for Point Source

Source Material and Material Density $\left(\mathrm{g} / \mathrm{cm}^{3}\right)$

Type and

\begin{tabular}{ccccccccc} 
Nuclide & Concrete & Water & Aluminum & Iron & Copper & Tungsten & Lead & Uranium \\
\hline 2.4 & 1 & 2.7 & 7.87 & 8.96 & 19.3 & 11.35 & 19.1
\end{tabular}

Point

C-14

Co-60

Sr-90

Ag-110m

Cs-137

Ra-226

Th-228

Np-237

Pu-239

Cf-252

Shielding Thickness $(\mathrm{cm})$

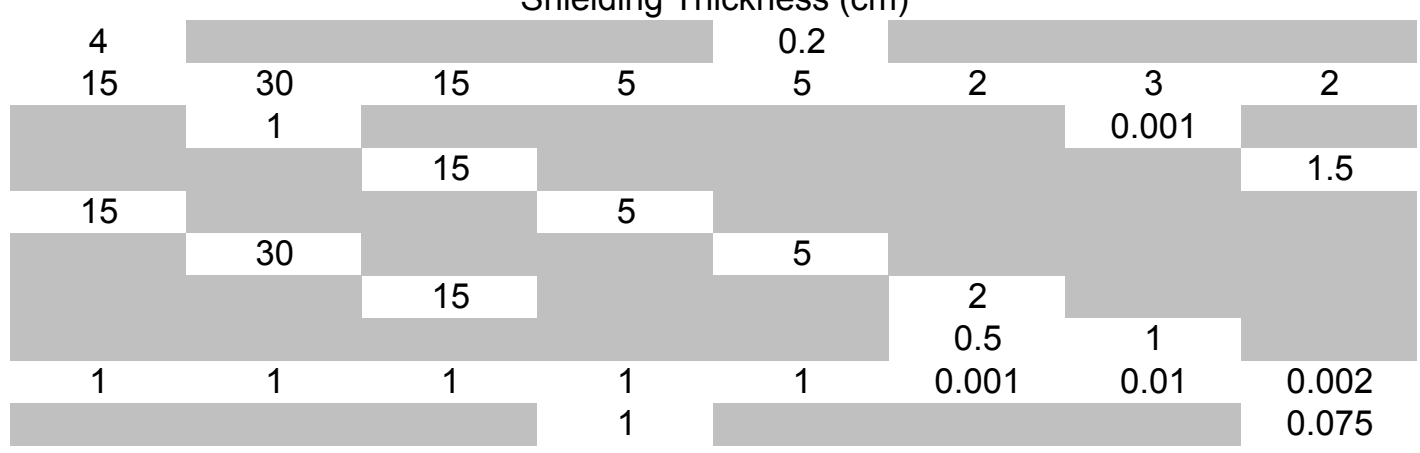

Line

C-14

Co-60

Sr-90

Ag- $110 \mathrm{~m}$

Cs-137

Ra-226

Th-228

Np-237

Pu-239

Cf-252

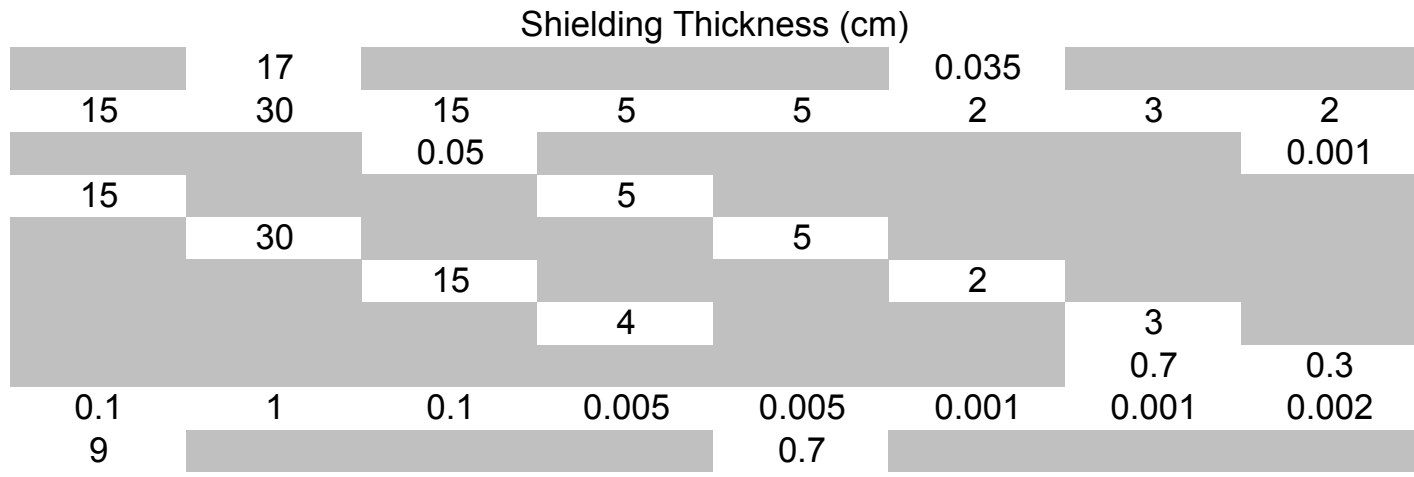

Area

C-14

Co-60

Sr-90

Ag- $110 \mathrm{~m}$

Cs-137

Ra-226

Th-228

Np-237

Pu-239

Cf-252

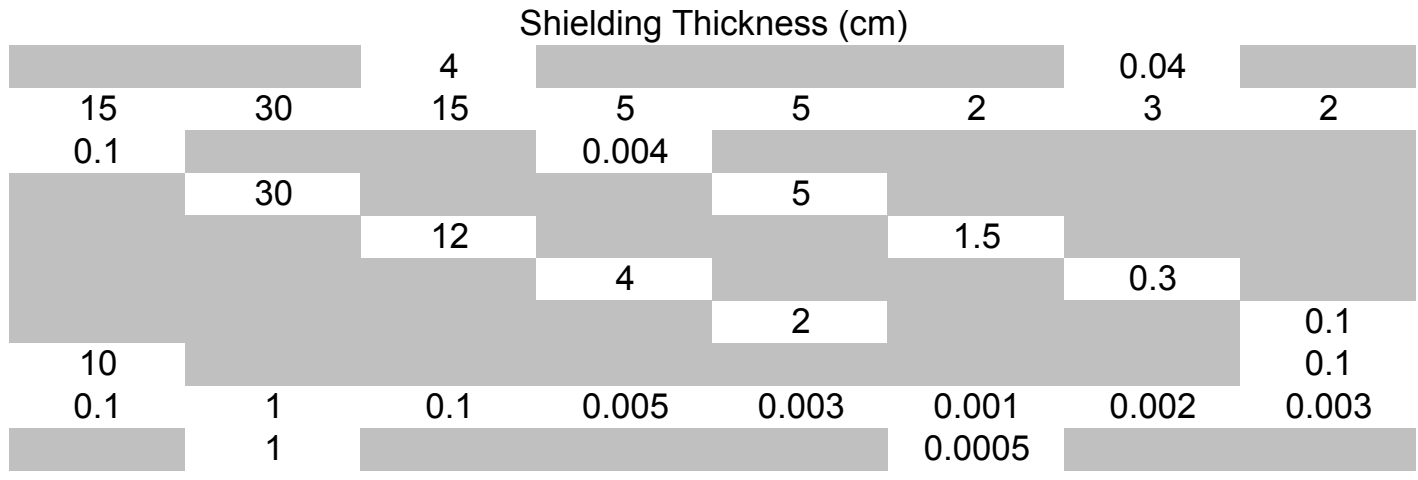

Volume

C-14

Co-60

$\mathrm{Sr}-90$

Ag- $110 \mathrm{~m}$

Cs-137

Ra-226

Th-228

Np-237

Pu-239

Cf-252

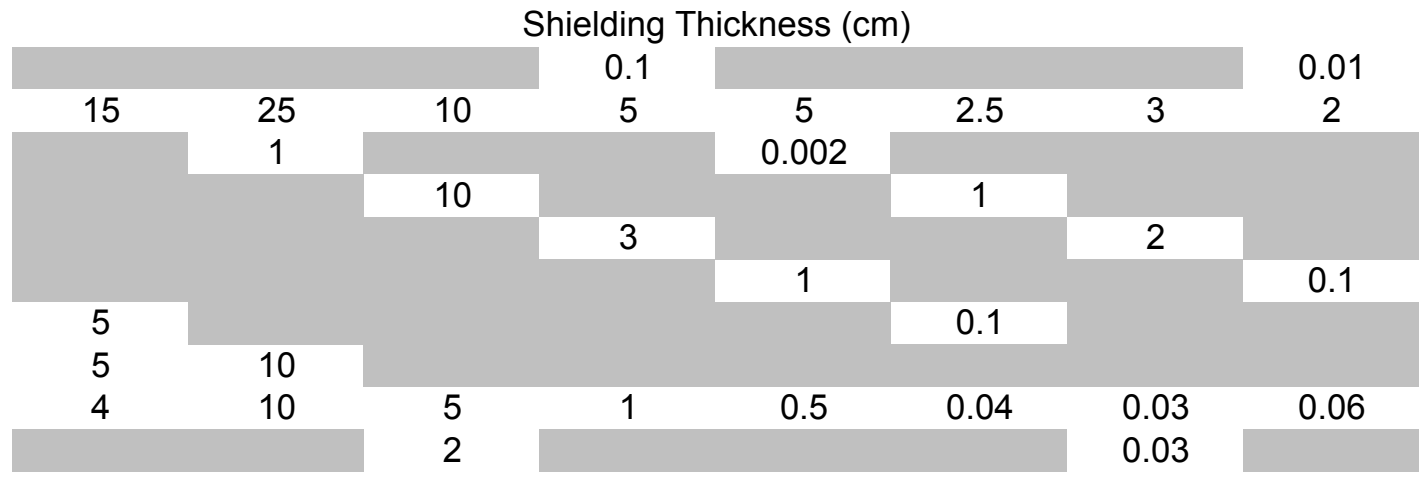




\section{Dosimetric and Buildup Factor Considerations}

MicroShield calculates several different dosimetric quantities applicable to external gamma exposure scenarios. In RESRAD-BUILD a single direct external dose is reported, but the user's manual does not specify the type of dose quantity used by the code. The effective dose equivalent for a whole body rotational exposure with photon buildup calculated by MicroShield was used for dose comparison purposes, as it appeared to be the dosimetric quantity that best represented the doses calculated in RESRAD-BUILD for simple point sources.

Equation F.7 in Appendix F of the RESRAD-BUILD user's manual indicates that thicknessweighted buildup factors for the air between the source and receptor, the source material (volume sources only) and the shield material (if applicable) are all used in determining a "composite" buildup factor. This is one limitation identified in the MicroShield code, which allows only the use of a single material to calculate buildup factors. The impact of this limitation is most apparent for a shielded volume source. Therefore, in these cases, two MicroShield runs were made when two different materials were used for the source and shield to bound the results.

Air is not expected to have a large effect on buildup and attenuation for high-energy photon emitters located close to the receptor. However, this can be a significant source of discrepancies between MicroShield and RESRAD-BUILD for low energy photon emitters located at distance that result in substantial air attenuation and buildup. It is not possible to view or change the properties of air (density) in either code, or the buildup factor coefficients for air are not contained in any of the RESRAD-BUILD data files. It is therefore assumed that such properties are contained in the source code.

\section{Criteria for Evaluating Results}

As indicated above, there are several sources of discrepancies that could affect the results calculated by either code. Therefore, no single factor was applicable to all cases. Such criteria would be highly dependent on the specific source/shield/receptor geometry and the photon energies. Any significant deviations between RESRAD-BUILD and MicroShield results, and their possible reason, are discussed qualitatively.

\section{Results - Unshielded Cases}

Table 2-7 shows the ratio between the of RESRAD-BUILD and MicroShield results for an unshielded point source. All of the ratios are within 20 percent, and the greatest deviations are noted for radionuclides with relatively low energies. Since MicroShield was set up to use the RESRAD-BUILD energy groups to calculate point source doses, the major contributors to any discrepancies are likely to be factors affecting attenuation and buildup in air. 
Table 2-7. Ratio of RESRAD-BUILD Results to MicroShield Results for Point Source

\begin{tabular}{lcccc} 
& \multicolumn{5}{c}{ Receptor Coordinates } \\
Radionuclide & $1(1,0,0)$ & $2(10,0,0)$ & $3(1,1,0)$ & $4(10,10,0)$ \\
\hline C-14 & 1.03 & 1.11 & 1.04 & 1.09 \\
Co-60 & 1.00 & 1.00 & 1.00 & 1.00 \\
Sr-90 & 1.16 & 0.99 & 1.15 & 0.92 \\
Ag-110m & 1.00 & 1.00 & 1.00 & 1.00 \\
Cs-137 & 0.99 & 1.00 & 1.00 & 1.00 \\
Ra-226 & 1.00 & 1.00 & 1.00 & 1.00 \\
Th-228 & 1.04 & 1.05 & 1.04 & 1.05 \\
Np-237 & 1.02 & 1.01 & 1.02 & 1.01 \\
Pu-239 & 1.19 & 1.00 & 1.17 & 0.96 \\
Cf-252 & 1.01 & 1.07 & 1.02 & 1.08
\end{tabular}

Table 2-8 shows the ratio between the of RESRAD-BUILD and MicroShield results for an unshielded line source. With the exception of the distant receptors for the Pu-239 and Sr-90 sources, all of the ratios are again within 20 percent, and the greatest deviations are noted for radionuclides with relatively low energies. At large distances, RESRAD reports extremely low or zero doses from $\mathrm{Pu}-239$ and $\mathrm{Sr}-90$ sources. A low dose is not unexpected from two radionuclides with low photon energies and yields. However, it is surprising considering that doses from point source with the same total activity as the line source yielded slightly higher doses for the receptor located a 1 meter, but much higher results for the receptor at 10 meters. If anything, a 1-m line source should be approximated by a point source much better at 10 meters distance. Thus, there appears to be a problem in the way RESRAD-BUILD calculates doses from low energy line sources at large distances. For high-energy photon emitters such as Co-60, the results that were calculated by RESRAD-BUILD for line source and point source at 10 meters are almost identical, as is expected.

Table 2-8. Ratio of RESRAD-BUILD Results to MicroShield Results for Line Source

\begin{tabular}{lcccc} 
& \multicolumn{5}{c}{ Receptor Coordinates } \\
Radionuclide & $1(1,0,0)$ & $2(10,0,0)$ & $3(1,1,0)$ & $4(10,10,0)$ \\
\hline C-14 & 1.03 & 1.11 & 1.01 & 0.92 \\
Co-60 & 1.00 & 1.00 & 0.99 & 0.98 \\
Sr-90 & 1.16 & $\mathbf{0 . 0 0}$ & 1.13 & $\mathbf{0 . 0 0}$ \\
Ag-110m & 1.00 & 0.99 & 0.99 & 0.97 \\
Cs-137 & 1.00 & 1.00 & 1.00 & 0.97 \\
Ra-226 & 1.00 & 1.00 & 0.99 & 0.97 \\
Th-228 & 1.00 & 0.99 & 1.00 & 0.93 \\
Np-237 & 1.01 & 0.97 & 1.01 & 0.83 \\
Pu-239 & 1.18 & $\mathbf{0 . 0 0}$ & 1.16 & $\mathbf{0 . 0 0}$ \\
Cf-252 & 1.01 & 1.07 & 1.00 & 0.91
\end{tabular}

As discussed earlier, three steps were required to evaluate unshielded area and volume sources. In the first step, "absolute" dose results were compared for infinite sources. In the second step, "absolute" dose results were compared for finite sources. The default MicroShield energy groups were used for all radionuclides except for C-14 and Sr-90, which are not in the MicroShield database. The energy groups from the COEFF_BD file were used for these two radionuclides, 
despite that fact that these are not used directly by RESRAD-BUILD in calculating the doses from area and volume sources. RESRAD-BUILD uses approximations based on the dose conversion factors in FGR12 for a volume source of infinite extent.

Tables 2-9 and 2-10 show the ratio between the RESRAD-BUILD and MicroShield results for infinite and finite area sources, respectively. Very large discrepancies were found for Th-232 doses and lesser discrepancies for Np-237. The reason for the large difference in the Th-232 calculations cannot be readily explained, since Th-232 does not have any short lived daughters that might be contributing to the much higher dose calculated by RESRAD-BUILD. Most likely this is due to differences between the MicroShield data library and the FGR12 database. In addition, the dose ratios fluctuated between higher in MicroShield and higher in RESRADBUILD for Sr-90 and Pu-239 sources at different distances. As with the point and area sources, higher energy photon emitters such as Co-60, Ag-110m and Cs-137 yielded the closest results.

Table 2-9. Ratio of RESRAD-BUILD Results to MicroShield Results for Infinite Area Source

\begin{tabular}{lcccc} 
& \multicolumn{5}{c}{ Receptor Coordinates } \\
Radionuclide & $1(1,0,0)$ & $2(10,0,0)$ & $3(1,1,0)$ & $4(10,10,0)$ \\
\hline C-14 & $\mathbf{0 . 0 0}$ & $\mathbf{0 . 0 0}$ & $\mathbf{0 . 0 0}$ & $\mathbf{0 . 0 0}$ \\
Co-60 & 0.93 & 0.99 & 0.94 & 0.99 \\
Sr-90 & $\mathbf{0 . 7 8}$ & $\mathbf{0 . 7 7}$ & $\mathbf{0 . 7 9}$ & $\mathbf{0 . 7 7}$ \\
Ag-110m & 0.95 & 1.01 & 0.96 & 1.01 \\
Cs-137 & 0.91 & 0.97 & 0.92 & 0.97 \\
Ra-226 & $\mathbf{0 . 0 1}$ & $\mathbf{0 . 0 1}$ & $\mathbf{0 . 0 1}$ & $\mathbf{0 . 0 1}$ \\
Th-228 & $\mathbf{5 0 8 . 9 1}$ & $\mathbf{5 5 9 . 3 7}$ & $\mathbf{5 1 2 . 4 5}$ & $\mathbf{5 5 9 . 9 3}$ \\
Np-237 & $\mathbf{6 . 9 9}$ & $\mathbf{7 . 5 2}$ & $\mathbf{7 . 1 0}$ & $\mathbf{7 . 5 3}$ \\
Pu-239 & $\mathbf{1 . 4 5}$ & $\mathbf{0 . 5 2}$ & $\mathbf{1 . 4 6}$ & $\mathbf{0 . 5 2}$ \\
Cf-252 & $\mathbf{1 . 6 3}$ & $\mathbf{1 2 . 9 2}$ & $\mathbf{1 . 6 6}$ & $\mathbf{1 2 . 8 2}$
\end{tabular}

Table 2-10. Ratio of RESRAD-BUILD Results to MicroShield Results for Finite Area Source

\begin{tabular}{lcccc} 
& \multicolumn{5}{c}{ Receptor Coordinates } \\
Radionuclide & $1(1,0,0)$ & $2(10,0,0)$ & $3(1,1,0)$ & $4(10,10,0)$ \\
\hline C-14 & $\mathbf{0 . 0 0}$ & $\mathbf{0 . 0 0}$ & $\mathbf{0 . 0 0}$ & $\mathbf{0 . 0 0}$ \\
Co-60 & 0.98 & 0.98 & 0.98 & 0.98 \\
Sr-90 & 1.02 & 0.86 & 1.00 & $\mathbf{0 . 7 9}$ \\
Ag-110m & 1.01 & 1.01 & 1.01 & 1.01 \\
Cs-137 & 0.96 & 0.96 & 0.96 & 0.96 \\
Ra-226 & $\mathbf{0 . 0 1}$ & $\mathbf{0 . 0 1}$ & $\mathbf{0 . 0 1}$ & $\mathbf{0 . 0 1}$ \\
Th-228 & $\mathbf{4 8 3 . 0 6}$ & $\mathbf{6 0 7 . 6 6}$ & $\mathbf{4 8 9 . 1 9}$ & $\mathbf{6 1 2 . 3 8}$ \\
Np-237 & $\mathbf{7 . 1 3}$ & $\mathbf{7 . 6 5}$ & $\mathbf{7 . 1 6}$ & $\mathbf{7 . 6 2}$ \\
Pu-239 & $\mathbf{3 . 2 2}$ & $\mathbf{0 . 6 4}$ & $\mathbf{2 . 7 9}$ & $\mathbf{0 . 5 8}$ \\
Cf-252 & $\mathbf{0 . 6 2}$ & $\mathbf{3 . 2 1}$ & $\mathbf{0 . 6 6}$ & $\mathbf{6 . 5 8}$
\end{tabular}

Tables 2-11 and 2-12 show similar results for the infinite and finite volume sources, respectively, but here the discrepancies are slightly higher (except for the very large difference for Sr-90). In some cases, such as Ra-226, the ratio is now more than two hundred times greater than one, 
whereas it was on the order of one hundred times smaller than one for the area source. Again, the ratios for the three high-energy gamma emitters are all within five-percent agreement.

Table 2-11. Ratio of RESRAD-BUILD Results to MicroShield Results for Infinite Volume Source

\begin{tabular}{lcccc} 
& \multicolumn{5}{c}{ Receptor Coordinates } \\
Radionuclide & $1(1,0,0)$ & $2(10,0,0)$ & $3(1,1,0)$ & $4(10,10,0)$ \\
\hline C-14 & $\mathbf{6 . 6 2}$ & $\mathbf{6 . 1 1}$ & $\mathbf{6 . 7 0}$ & $\mathbf{6 . 1 1}$ \\
Co-60 & 1.03 & 1.04 & 1.03 & 1.05 \\
Sr-90 & $\mathbf{1 . 0 4 E + 0 6}$ & $\mathbf{7 . 4 4 E + 0 5}$ & $\mathbf{3 . 0 2 E + 0 6}$ & $\mathbf{1 . 5 5 E + 0 6}$ \\
Ag-110m & 1.04 & 1.05 & 1.04 & 1.05 \\
Cs-137 & 0.99 & 1.00 & 0.99 & 1.00 \\
Ra-226 & $\mathbf{3 5 0 . 0 4}$ & $\mathbf{3 5 3 . 6 1}$ & $\mathbf{3 4 9 . 9 4}$ & $\mathbf{3 5 4 . 1 0}$ \\
Th-228 & $\mathbf{1 3 6 8 . 9 8}$ & $\mathbf{1 4 0 5 . 9 2}$ & $\mathbf{1 3 7 1 . 1 0}$ & $\mathbf{1 4 0 5 . 3 2}$ \\
Np-237 & $\mathbf{1 4 . 7 4}$ & $\mathbf{1 5 . 3 5}$ & $\mathbf{1 4 . 7 8}$ & $\mathbf{1 5 . 3 7}$ \\
Pu-239 & $\mathbf{1 . 2 4}$ & 1.12 & $\mathbf{1 . 2 9}$ & 1.13 \\
Cf-252 & $\mathbf{2 . 4 0}$ & $\mathbf{3 . 3 9}$ & $\mathbf{3 . 2 6}$ & $\mathbf{3 . 5 5}$
\end{tabular}

Table 2-12. Ratio of RESRAD-BUILD Results to MicroShield Results for Finite Volume Source

\begin{tabular}{lcccc} 
& \multicolumn{5}{c}{ Receptor Coordinates } \\
Radionuclide & $1(1,0,0)$ & $2(10,0,0)$ & $3(1,1,0)$ & $4(10,10,0)$ \\
\hline C-14 & $\mathbf{6 . 3 5}$ & $\mathbf{6 . 2 0}$ & $\mathbf{6 . 3 5}$ & $\mathbf{6 . 1 5}$ \\
Co-60 & 0.95 & 0.94 & 0.95 & 0.95 \\
Sr-90 & $\mathbf{8 . 8 5 E + 0 5}$ & $\mathbf{7 . 5 1 E + 0 5}$ & $\mathbf{1 . 9 8 E + 0 6}$ & $\mathbf{1 . 6 9 E + 0 6}$ \\
Ag-110m & 0.97 & 0.97 & 0.98 & 0.98 \\
Cs-137 & 0.94 & 0.94 & 0.95 & 0.94 \\
Ra-226 & $\mathbf{2 6 3 . 6 9}$ & $\mathbf{2 6 2 . 9 3}$ & $\mathbf{2 8 2 . 7 6}$ & $\mathbf{2 9 4 . 9 7}$ \\
Th-228 & $\mathbf{9 2 5 . 6 4}$ & $\mathbf{9 4 2 . 3 6}$ & $\mathbf{1 0 2 6 . 5 1}$ & $\mathbf{1 1 0 4 . 3 1}$ \\
Np-237 & $\mathbf{1 2 . 8 1}$ & $\mathbf{1 2 . 9 7}$ & $\mathbf{1 3 . 6 4}$ & $\mathbf{1 4 . 4 0}$ \\
Pu-239 & $\mathbf{1 . 2 8}$ & 1.04 & $\mathbf{1 . 3 2}$ & 1.10 \\
Cf-252 & $\mathbf{1 . 9 6}$ & $\mathbf{3 . 1 1}$ & $\mathbf{2 . 9 6}$ & $\mathbf{3 . 6 0}$
\end{tabular}

An effective area factor can be calculated when the dose from a finite source is divided by the dose from an infinite source located at the same distance from the receptor. These ratios for area and volume sources were calculated for each radionuclide in both MicroShield and RESRADBUILD. The ratios of area factors for area and volume sources are presented in Tables 2-12 and 2-14, respectively, and they provide an indication of how accurately RESRAD-BUILD is able to estimate this parameter. Ratios that deviate from unity by more than $20 \%$ are highlighted in boldface. 
Table 2-13. Ratio of RESRAD-BUILD to MicroShield Area Factors for Area Source

\begin{tabular}{lcccc} 
& \multicolumn{5}{c}{ Receptor Coordinates } \\
Radionuclide & $1(1,0,0)$ & $2(10,0,0)$ & $3(1,1,0)$ & $4(10,10,0)$ \\
\hline C-14 & 1.03 & 1.08 & 1.02 & 1.06 \\
Co-60 & 1.06 & 0.99 & 1.05 & 1.00 \\
Sr-90 & $\mathbf{1 . 3 1}$ & 1.11 & $\mathbf{1 . 2 7}$ & 1.02 \\
Ag-110m & 1.06 & 1.00 & 1.04 & 1.00 \\
Cs-137 & 1.05 & 0.99 & 1.04 & 0.99 \\
Ra-226 & 1.14 & 1.11 & 1.13 & 1.08 \\
Th-228 & 0.95 & 1.09 & 0.95 & 1.09 \\
Np-237 & 1.02 & 1.02 & 1.01 & 1.01 \\
Pu-239 & $\mathbf{2 . 2 2}$ & $\mathbf{1 . 2 4}$ & $\mathbf{1 . 9 1}$ & 1.12 \\
Cf-252 & $\mathbf{0 . 3 8}$ & $\mathbf{0 . 2 5}$ & $\mathbf{0 . 4 0}$ & $\mathbf{0 . 5 1}$
\end{tabular}

Table 2-14. Ratio of RESRAD-BUILD to MicroShield Area Factors for Volume Source

\begin{tabular}{lcccc} 
& \multicolumn{4}{c}{ Receptor Coordinates } \\
Radionuclide & $1(1,0,0)$ & $2(10,0,0)$ & $3(1,1,0)$ & $4(10,10,0)$ \\
\hline C-14 & 0.96 & 1.02 & 0.95 & 1.01 \\
Co-60 & 0.92 & 0.91 & 0.92 & 0.91 \\
Sr-90 & 0.85 & 1.01 & $\mathbf{0 . 6 6}$ & 1.09 \\
Ag-110m & 0.94 & 0.92 & 0.94 & 0.93 \\
Cs-137 & 0.96 & 0.94 & 0.96 & 0.94 \\
Ra-226 & $\mathbf{0 . 7 5}$ & $\mathbf{0 . 7 4}$ & 0.81 & 0.83 \\
Th-228 & $\mathbf{0 . 6 8}$ & $\mathbf{0 . 6 7}$ & $\mathbf{0 . 7 5}$ & $\mathbf{0 . 7 9}$ \\
Np-237 & 0.87 & 0.84 & 0.92 & 0.94 \\
Pu-239 & 1.03 & 0.93 & 1.03 & 0.97 \\
Cf-252 & 0.82 & 0.92 & 0.91 & 1.01
\end{tabular}

As expected, the ratios are much more consistent than the ratios for absolute doses from finite sources. However, some significant deviations in the relative dose reduction from infinite to finite source are evident. The most significant deviation is reported for the Pu-239 and $\mathrm{Cf}-252$ area factors for the finite area source, which in some cases exceeded a factor of two. It is also interesting to note that RESRAD-BUILD calculates a higher area factor for $\mathrm{Pu}-239$, whereas MicroShield calculates a higher area factor for Cf-252. Finally, when observing the area-factor ratios calculated for area and volume sources, it is apparent that RESRAD-BUILD calculates higher area factors than MicroShield for the majority of the area sources, while the opposite appears to be the case for volume source area factors. As expected, the best agreements are obtained for the three high-energy gamma emitters identified previously.

The final tests performed on unshielded sources were done to determine the differences between the RESRAD-BUILD and MicroShield results due to source material selection. These tests involved two steps. First, the absolute doses were calculated with each code for the selected source material/radionuclide combinations. This first step had already been performed for concrete, since this is the default material used in previous unshielded volume source tests. Additional tests were conducted for all the other 7 material types. The second step involved taking the direct ratio of the RESRAD-BUILD and MicroShield results for each source material/radionuclide combination. 
The results of the second step are presented in Table 2-15. Note that the ratios for the concrete volume source in Table 2-15 are the same as those reported in Table 2-12.

Table 2-15. Ratio of RESRAD-BUILD to MicroShield Source-Material-Dependent Doses

\begin{tabular}{|c|c|c|c|c|c|}
\hline \multirow[b]{2}{*}{$\begin{array}{l}\text { Shield } \\
\text { Material }\end{array}$} & \multirow[b]{2}{*}{ Radionuclide } & \multicolumn{4}{|c|}{ Receptor Coordinates } \\
\hline & & $1(1,0,0)$ & $2(10,0,0)$ & $3(1,1,0)$ & $4(10,10,0)$ \\
\hline Concrete & $\begin{array}{l}\text { Co-60 } \\
\text { Pu-239 } \\
\text { Th-228 } \\
\text { Np-237 }\end{array}$ & $\begin{array}{c}0.95 \\
1.28 \\
925.64 \\
12.81 \\
\end{array}$ & $\begin{array}{c}0.94 \\
1.04 \\
\mathbf{9 4 2 . 3 6} \\
\mathbf{1 2 . 9 7}\end{array}$ & $\begin{array}{c}0.95 \\
1.32 \\
1026.51 \\
13.64\end{array}$ & $\begin{array}{c}0.95 \\
1.10 \\
1104.31 \\
14.40\end{array}$ \\
\hline Water & $\begin{array}{l}\text { Co-60 } \\
\text { Pu-239 } \\
\text { Np-237 } \\
\text { Sr-90 }\end{array}$ & $\begin{array}{c}0.40 \\
0.89 \\
3.05 \\
275405.26\end{array}$ & $\begin{array}{c}0.40 \\
0.46 \\
3.03 \\
235988.20\end{array}$ & $\begin{array}{c}0.40 \\
0.75 \\
3.08 \\
274271.84 \\
\end{array}$ & $\begin{array}{c}0.40 \\
0.41 \\
3.10 \\
218639.80\end{array}$ \\
\hline Aluminum & $\begin{array}{l}\text { Co-60 } \\
\text { Pu-239 } \\
\text { Cf-252 } \\
\text { Ag-110m }\end{array}$ & $\begin{array}{l}1.06 \\
1.40 \\
2.23 \\
1.09\end{array}$ & $\begin{array}{l}1.06 \\
1.16 \\
3.45 \\
1.08 \\
\end{array}$ & $\begin{array}{l}1.06 \\
1.46 \\
3.39 \\
1.09\end{array}$ & $\begin{array}{l}1.06 \\
1.21 \\
3.97 \\
1.09\end{array}$ \\
\hline Iron & $\begin{array}{l}\text { Co-60 } \\
\text { Pu-239 } \\
\text { C-14 } \\
\text { Cs-137 }\end{array}$ & $\begin{array}{c}2.78 \\
6.26 \\
20.64 \\
2.77\end{array}$ & $\begin{array}{c}2.76 \\
6.06 \\
20.35 \\
2.75\end{array}$ & $\begin{array}{c}2.77 \\
6.29 \\
39.51 \\
2.75\end{array}$ & $\begin{array}{c}2.77 \\
6.13 \\
41.28 \\
2.76\end{array}$ \\
\hline Copper & $\begin{array}{l}\text { Co-60 } \\
\text { Pu-239 } \\
\text { Sr-90 } \\
\text { Ra-226 }\end{array}$ & $\begin{array}{c}3.22 \\
7.38 \\
1.61 \mathrm{E}+08 \\
2597.65 \\
\end{array}$ & $\begin{array}{c}3.20 \\
7.15 \\
3.25 E+12 \\
2769.58 \\
\end{array}$ & $\begin{array}{c}3.21 \\
7.30 \\
4.31 \mathrm{E}+28 \\
2710.52 \\
\end{array}$ & $\begin{array}{c}3.21 \\
7.21 \\
4.47 E+27 \\
2907.09 \\
\end{array}$ \\
\hline Tungsten & $\begin{array}{l}\text { Co-60 } \\
\text { Pu-239 } \\
\text { Ag-110m } \\
\text { Th-228 }\end{array}$ & $\begin{array}{c}6.13 \\
39.16 \\
6.47 \\
145722.61\end{array}$ & $\begin{array}{c}6.10 \\
19.72 \\
6.47 \\
160611.26\end{array}$ & $\begin{array}{c}6.13 \\
9729.33 \\
6.51 \\
315832.65\end{array}$ & $\begin{array}{c}6.11 \\
10892.56 \\
6.46 \\
374309.25\end{array}$ \\
\hline Lead & $\begin{array}{l}\text { Co-60 } \\
\text { Pu-239 } \\
\text { Cs-137 } \\
\text { Cf-252 }\end{array}$ & $\begin{array}{c}3.58 \\
15.23 \\
3.64 \\
18.55\end{array}$ & $\begin{array}{c}3.56 \\
7.74 \\
3.64 \\
18.47\end{array}$ & $\begin{array}{c}3.58 \\
123.19 \\
3.65 \\
589.86\end{array}$ & $\begin{array}{c}3.57 \\
78.39 \\
3.65 \\
870.73\end{array}$ \\
\hline
\end{tabular}


Table 2-15. Ratio of RESRAD-BUILD to MicroShield Source-Material-Dependent Doses (Cont'd)

\begin{tabular}{|c|c|c|c|c|c|}
\hline \multirow[b]{2}{*}{$\begin{array}{l}\text { Shield } \\
\text { Material }\end{array}$} & \multirow[b]{2}{*}{ Radionuclide } & \multicolumn{4}{|c|}{ Receptor Coordinates } \\
\hline & & $1(1,0,0)$ & $2(10,0,0)$ & $3(1,1,0)$ & $4(10,10,0)$ \\
\hline Uranium & Co-60 & 587 & & 590 & 588 \\
\hline & Pu-239 & 13.44 & 7.43 & 72.54 & 49.75 \\
\hline & Ra-226 & 31341.99 & 33739.20 & 230878.19 & 314075.63 \\
\hline & C-14 & 680.11 & 2683.36 & $2.55 E+13$ & $4.78 \mathrm{E}+15$ \\
\hline
\end{tabular}

A very large range of results can be observed in Table 2-15, with the greatest discrepancies observed in radionuclides with lower photon energy emissions. The greatest observed difference was a RESRAD-BUILD dose 28 orders of magnitude higher than MicroShield for Sr-90 in copper.

There are known (reported) problems with the MicroShield code under certain conditions, which could possibly be responsible for the observed discrepancies in source-material-dependent doses. Another possible reason for such large differences is that RESRAD-BUILD calculates multiple material buildup factors based on a thickness-weighted average of air and source material buildup. Therefore, especially for distant receptors and relatively thin sources of high-atomicnumber material, RESRAD may overestimate the external gamma dose compared to MicroShield, where the buildup is calculated only from the source material properties. Equation F.7 of Appendix F in the RESRAD-BUILD user's manual does not appear to consider the degree of attenuation in each material traversed, only the absolute distance through the material. Since the buildup factors in air are significantly higher than the buildup factors in high-atomic-number materials such as uranium, RESRAD-BUILD will significantly overestimate the external dose from these sources, especially for low energy photon emitters with multiple mean-free-paths in the source material.

\section{Results - Shielded Cases}

Multiple tests of shielded point, line, area and volume sources were conducted by the including the external shields defined in Table 2-6. The first set of tests was done by specifying that the buildup factor properties used by MicroShield were those of air. A second set of tests was conducted by specifying the buildup factor properties of the shield material. A third set of tests, valid only for the volume sources, was conducted by specifying the buildup factor properties of the source material.

Table 2-16 lists the ratios between RESRAD-BUILD and MicroShield for a point source by shield material, radionuclide, receptor location and buildup material. It appears that, in general, the best matches were obtained for point sources shielded by low-atomic number materials.

There appears to be a significant difference in the way the shield is configured in RESRADBUILD and in MicroShield. The offset receptor doses calculated by RESRAD-BUILD are consistently higher than the offset doses calculated by MicroShield. The reason for this is due to the fact that a shielding thickness is specified in RESRAD-BUILD, and the shield thickness is taken along line-of-sight trajectory between the source and receptor. In MicroShield the shielding material has a specific orientation relative to the source, not the receptor. While the sourceshield-receptor geometries are identical for the receptors located on the $\mathrm{x}$-axis, for off-set receptors the "effective shielding thickness" in MicroShield is approximately 1.4 times higher 
than in the equivalent RESRAD-BUILD case due to the 45-degree angle of incidence through the shield material. Therefore, greater attenuation is expected in the offset MicroShield cases.

Table 2-16. Ratio of RESRAD-BUILD to MicroShield Doses for Shielded Point Source

\begin{tabular}{|c|c|c|c|c|c|c|c|c|c|}
\hline \multirow{6}{*}{$\begin{array}{l}\text { Shield } \\
\text { Material } \\
\text { Concrete }\end{array}$} & \multirow{6}{*}{\begin{tabular}{|l|} 
Radionuclide \\
Co-60 \\
Pu-239 \\
C-14 \\
Cs-137
\end{tabular}} & \multicolumn{8}{|c|}{ Receptor Coordinates } \\
\hline & & \multicolumn{4}{|c|}{$\begin{array}{c}(1,0,0)(10,0,0) \quad(1,1,0) \quad(10,10,0) \\
\text { Air Buildup Factors }\end{array}$} & \multicolumn{4}{|c|}{$\begin{array}{c}(1,0,0) \quad(10,0,0) \quad(1,1,0) \quad(10,10,0) \\
\text { Shield Buildup Factors }\end{array}$} \\
\hline & & 0.90 & 0.90 & 1.51 & 1.52 & 0.98 & 0.98 & 1.70 & 1.71 \\
\hline & & 0.76 & 0.73 & 0.75 & 0.73 & 1.01 & 0.99 & 1.03 & 1.04 \\
\hline & & 0.12 & 0.11 & 0.34 & 0.32 & 0.76 & 0.75 & 2.95 & 2.91 \\
\hline & & 0.81 & 0.81 & 1.63 & 1.64 & 0.99 & 0.99 & 2.09 & 2.11 \\
\hline \multirow[t]{4}{*}{ Water } & & & & & & & & & \\
\hline & $\begin{array}{l}\text { Co-60 } \\
\text { Рu-239 }\end{array}$ & $\begin{array}{l}0.99 \\
101\end{array}$ & $\begin{array}{l}0.99 \\
0.93\end{array}$ & $\begin{array}{l}1.58 \\
1.46\end{array}$ & $\begin{array}{l}1.59 \\
1.08\end{array}$ & $\begin{array}{l}0.99 \\
100\end{array}$ & 0.98 & $\begin{array}{l}1.57 \\
1.44\end{array}$ & $\begin{array}{l}1.58 \\
107\end{array}$ \\
\hline & Sr-90 & 1.00 & 0.84 & $\begin{array}{l}1.40 \\
1.64\end{array}$ & 1.29 & 0.99 & 0.82 & 1.61 & 1.26 \\
\hline & Ra-226 & 1.00 & 0.99 & 1.68 & 1.69 & 0.99 & 0.98 & 1.67 & 1.68 \\
\hline \multirow[t]{5}{*}{ Aluminum } & & & & & & & & & \\
\hline & Co-60 & 0.90 & 0.89 & 1.60 & 1.61 & 0.98 & 0.98 & 1.80 & 1.81 \\
\hline & Pu-239 & 0.76 & 0.73 & 0.75 & 0.74 & 1.00 & 0.99 & 1.03 & 1.04 \\
\hline & Ag-110m & 0.85 & 0.85 & 1.72 & 1.72 & 0.99 & 0.99 & 2.06 & 2.07 \\
\hline & Th-228 & 0.90 & 0.91 & 1.55 & 1.55 & 1.01 & 1.01 & 1.70 & 1.70 \\
\hline \multirow[t]{5}{*}{ Iron } & & & & & & & & & \\
\hline & Co-60 & 0.80 & 0.80 & 1.37 & 1.37 & 0.98 & 0.98 & 1.75 & 1.76 \\
\hline & Pu-239 & 0.45 & 0.41 & 0.47 & 0.43 & 0.92 & 0.92 & 1.28 & 1.30 \\
\hline & Cs-137 & 0.62 & 0.61 & 1.28 & 1.28 & 0.97 & 0.97 & 2.24 & 2.26 \\
\hline & Cf-252 & 0.01 & 0.01 & 0.05 & 0.05 & 0.48 & 0.47 & 3.52 & 3.47 \\
\hline \multirow[t]{5}{*}{ Copper } & & & & & & & & & \\
\hline & Co-60 & 0.81 & 0.81 & 1.58 & 1.58 & 1.03 & 1.03 & 2.12 & 2.12 \\
\hline & Pu-239 & 0.87 & 0.31 & 0.38 & 0.34 & 0.87 & 0.87 & 1.36 & 1.36 \\
\hline & Ra-226 & 0.73 & 0.74 & 1.52 & 1.53 & 1.04 & 1.04 & 2.17 & 2.17 \\
\hline & C-14 & 0.03 & 0.03 & 0.11 & 0.10 & 0.54 & 0.54 & 3.39 & 3.32 \\
\hline \multirow[t]{5}{*}{ Tungsten } & & & & & & & & & \\
\hline & Co-60 & 0.48 & 0.48 & 0.83 & 0.82 & 0.89 & 0.89 & 1.79 & 1.80 \\
\hline & Pu-239 & 0.80 & 0.87 & 1.27 & 1.09 & 1.00 & 1.21 & 1.60 & 1.70 \\
\hline & Th-228 & 0.61 & 0.61 & 1.04 & 1.04 & 0.95 & 0.95 & 1.66 & 1.66 \\
\hline & Np-237 & 0.11 & 0.11 & 0.19 & 0.18 & 0.76 & 0.76 & 2.14 & 2.14 \\
\hline \multirow[t]{5}{*}{ Lead } & & & & & & & & & \\
\hline & Co-60 & 0.46 & 0.45 & 0.75 & 0.73 & 0.87 & 0.87 & 1.71 & 1.71 \\
\hline & Pu-239 & 0.64 & 0.72 & 0.64 & 0.74 & 1.00 & 1.29 & 1.09 & 1.48 \\
\hline & Np-237 & 0.05 & 0.05 & 0.14 & 0.13 & 0.66 & 0.66 & 3.10 & 3.11 \\
\hline & Sr-90 & 1.39 & 1.51 & 2.61 & 2.73 & 1.81 & 2.14 & 3.56 & 4.06 \\
\hline \multirow[t]{5}{*}{ Uranium } & & & & & & & & & \\
\hline & & 0.36 & & 0.67 & 0.66 & 0.82 & 0.82 & 1.92 & 1.93 \\
\hline & Pu-239 & 0.57 & 0.61 & 0.88 & 0.75 & 0.75 & 0.92 & 1.24 & 1.27 \\
\hline & Cf-252 & 0.01 & 0.01 & 0.03 & 0.03 & 0.39 & 0.39 & 3.19 & 3.15 \\
\hline & $\mathrm{Ag}-110 \mathrm{~m}$ & 0.27 & 0.26 & 0.52 & 0.50 & 0.85 & 0.85 & 2.21 & 2.22 \\
\hline
\end{tabular}


Another observation that was made is that the use in MicroShield of the shield material buildup factors, rather than the air buildup factors, results in somewhat higher doses for low atomic number material and significantly lower doses for high atomic number materials. This is expected, but adds another level of complexity to the evaluation of the results.

Table 2-17 lists the ratios between RESRAD-BUILD and MicroShield for a line source by shield material, radionuclide, receptor location and buildup material. The results are similar to those for the point source, with two important differences. First, the cases with Sr-90 and Pu-239 exhibited problems similar to those that were encountered in the unshielded line sources when the receptor is at larger distances from the source. Second, the differences in the dose ratios for the offset receptors are less pronounced than for the point source. The reason for this is that the incident angles through the shield in the MicroShield cases are closer to 90 degrees for the portions of the line source closest to the receptor. Therefore, these parts of the line source contribute disproportionably more to the dose than the distant portions. RESRAD-BUILD uses a shield thickness that is the same for all parts of the line source. Geometrically, this is equivalent to saying that the receptor is located on the longitudinal axis of a cylindrical shield of the specified thickness.

Table 2-18 lists the ratios between RESRAD-BUILD and MicroShield for an area source by shield material, radionuclide, receptor location and buildup material. Differences were much more pronounced than for the point and line sources. However, unlike the case with the point and line sources, the dose ratios for the offset receptors are very similar to the dose ratios for on-axis receptors. The reason for this is that RESRAD-BUILD appears to consider the area sources and volume sources to be shielded by a layer of material whose surface is parallel to the source surface. This is the same geometry used in the MicroShield cases.

Table 2-19 lists the ratios between RESRAD-BUILD and MicroShield for a volume source by shield material, radionuclide, receptor location and buildup material. The ratios for the source as the buildup material are presented separately in Table 2-20. In Table 2-20, the values for concrete shield are the same as in Table 2-19, with concrete as the buildup material for both shield and source. The results in Table 2-19 follow a pattern that is similar to what is seen in Table 2-20 for the area source. As with the area source, similar patterns can be observed with how the two codes calculate the results.

A final test was performed to verify that RESRAD-BUILD calculates consistent results when the shielding material is external to a volume source or when it is part of the source. The latter requires that a 2-region volume source be defined with essentially the same geometry and source/shielding properties as the single-region volume source with external shielding. The receptor coordinates were adjusted to compensate for the thickness of the first region (which was made to be the shield region in the two-region volume source) making it equivalent to a singleregion volume source with external shielding. The test was done for Co-60 and Pu-239 using a concrete layer, with receptors at the 4 locations previously specified. For most cases, the 2-region volume source results indicated good agreement (deviations of less than $5 \%$ ) with the previous RESRAD-BUILD calculations using an equivalent external shield. The only exception to this was the case for the 2-region source containing Co-60 and a receptor at one meter from the source, where the dose from the source with an internal shield layer was $25 \%$ higher than the source with an equivalent external source. The cause for this discrepancy was investigated, but could not be ascertained. 
Table 2-17. Ratio of RESRAD-BUILD to MicroShield Doses for Shielded Line Source

\begin{tabular}{|c|c|c|c|c|c|c|c|c|c|}
\hline \multirow{6}{*}{$\begin{array}{l}\text { Shield } \\
\text { Material } \\
\text { Concrete }\end{array}$} & \multirow{6}{*}{$\begin{array}{l}\text { Radionuclide } \\
\text { Co-60 } \\
\text { Pu-239 } \\
\text { Cf-252 } \\
\text { Ag-110m }\end{array}$} & \multicolumn{8}{|c|}{ Receptor Coordinates } \\
\hline & & \multicolumn{4}{|c|}{$\begin{array}{c}(1,0,0)(10,0,0) \quad(1,1,0) \quad(10,10,0) \\
\text { Air Buildup Factors }\end{array}$} & \multicolumn{4}{|c|}{$\begin{array}{c}(1,0,0) \quad(10,0,0) \quad(1,1,0) \quad(10,10,0 \\
\text { Shield Buildup Factors }\end{array}$} \\
\hline & & 0.94 & 0.90 & 1.40 & 1.50 & 1.03 & 0.99 & 1.56 & 1.69 \\
\hline & & 0.87 & 0.36 & 1.19 & 0.00 & 1.04 & 0.44 & 1.43 & 0.00 \\
\hline & & 0.11 & 0.10 & 0.26 & 0.32 & 0.79 & 0.69 & 2.31 & 3.34 \\
\hline & & 0.90 & 0.85 & 1.44 & 1.58 & 1.05 & 0.99 & 1.71 & 1.90 \\
\hline \multirow[t]{4}{*}{ Water } & Co-60 & 1.03 & 0.99 & 1.48 & 1.57 & 1.02 & 0.99 & 1.47 & 1.57 \\
\hline & Pu-239 & 1.04 & 0.17 & 1.37 & 0.00 & 1.03 & 0.16 & 1.35 & 0.00 \\
\hline & C-14 & 1.03 & 0.93 & 2.20 & 2.69 & 0.93 & 0.85 & 1.97 & 2.38 \\
\hline & Cs-137 & 1.05 & 1.00 & 1.67 & 1.84 & 1.04 & 0.99 & 1.64 & 1.80 \\
\hline \multirow[t]{5}{*}{ Aluminum } & & & & & & & & & \\
\hline & Co-60 & 0.94 & 0.90 & 1.46 & 1.59 & 1.03 & 0.98 & 1.63 & 1.79 \\
\hline & Pu-239 & 0.84 & 0.41 & 1.17 & 0.00 & 1.01 & 0.50 & 1.40 & 0.00 \\
\hline & Sr-90 & 0.91 & 0.00 & 1.15 & 0.00 & 1.07 & 0.00 & 1.38 & 0.00 \\
\hline & Ra-226 & 0.90 & 0.85 & 1.46 & 1.60 & 1.04 & 0.99 & 1.71 & 1.88 \\
\hline \multirow[t]{5}{*}{ Iron } & & & & & & & & & \\
\hline & Co-60 & 0.83 & 0.80 & 1.26 & 1.36 & 1.03 & 0.98 & 1.60 & 1.75 \\
\hline & Pu-239 & 0.84 & 0.45 & 1.18 & 0.00 & 1.04 & 0.59 & 1.45 & 0.00 \\
\hline & Ag-110m & 0.75 & 0.71 & 1.22 & 1.34 & 1.05 & 0.99 & 1.79 & 2.01 \\
\hline & Th-228 & 0.82 & 0.79 & 1.12 & 1.19 & 1.02 & 0.99 & 1.38 & 1.45 \\
\hline \multirow[t]{5}{*}{ Copper } & & & & & & & & & \\
\hline & Co-60 & 0.86 & 0.81 & 1.41 & 1.57 & 1.10 & 1.03 & 1.86 & 2.10 \\
\hline & Pu-239 & 0.77 & 0.70 & 1.07 & 0.10 & 0.95 & 0.92 & 1.30 & 0.14 \\
\hline & Cs-137 & 0.65 & 0.60 & 1.25 & 1.46 & 1.12 & 1.03 & 2.34 & 2.86 \\
\hline & Cf-252 & 0.01 & 0.01 & 0.03 & 0.03 & 0.41 & 0.35 & 1.49 & 2.50 \\
\hline \multirow[t]{5}{*}{ Tungsten } & & & & & & & & & \\
\hline & Co-60 & 0.51 & 0.47 & 0.77 & 0.81 & 0.94 & 0.89 & 1.60 & 1.79 \\
\hline & Pu-239 & 0.84 & 0.00 & 1.17 & 0.00 & 1.05 & 0.00 & 1.47 & 0.00 \\
\hline & Ra-226 & 0.55 & 0.52 & 0.85 & 0.91 & 1.01 & 0.96 & 1.62 & 1.78 \\
\hline & C-14 & 0.04 & 0.03 & 0.09 & 0.10 & 0.73 & 0.63 & 2.12 & 3.05 \\
\hline \multirow[t]{5}{*}{ Lead } & & & & & & & & & \\
\hline & Co-60 & 0.48 & 0.45 & 0.70 & 0.73 & 0.93 & 0.88 & 1.53 & 1.69 \\
\hline & Pu-239 & 1.37 & 0.00 & 1.88 & 0.00 & 1.71 & 0.00 & 2.37 & 0.00 \\
\hline & Th-228 & 0.62 & 0.60 & 0.90 & 0.96 & 0.99 & 0.95 & 1.47 & 1.58 \\
\hline & Np-237 & 0.11 & 0.10 & 0.16 & 0.16 & 0.83 & 0.75 & 1.77 & 2.20 \\
\hline \multirow[t]{5}{*}{ Uranium } & & & & & & & & & \\
\hline & Co-60 & 0.38 & 0.35 & 0.61 & 0.66 & 0.88 & 0.82 & 1.65 & 1.92 \\
\hline & Pu-239 & 0.59 & 0.38 & 0.82 & 0.00 & 0.79 & 0.57 & 1.15 & 0.00 \\
\hline & Np-237 & 0.12 & 0.11 & 0.17 & 0.17 & 0.85 & 0.78 & 1.74 & 2.11 \\
\hline & Sr-90 & 0.72 & 0.00 & 0.95 & 0.00 & 0.89 & 0.00 & 1.21 & 0.00 \\
\hline
\end{tabular}


Table 2-18. Ratio of RESRAD-BUILD to MicroShield Doses for Shielded Area Source

\begin{tabular}{|c|c|c|c|c|c|c|c|c|c|}
\hline \multirow{2}{*}{$\begin{array}{l}\text { Shield } \\
\text { Material } \\
\text { Concrete }\end{array}$} & \multirow{2}{*}{\begin{tabular}{|l|} 
Radionuclide \\
Co-60 \\
Pu-239 \\
Cf-252 \\
Ag-110m
\end{tabular}} & $(1,0,0)$ & $\begin{array}{l}(10,0,0) \\
\text { Air Buildu }\end{array}$ & $\begin{array}{l}(1,1,0) \quad( \\
\text { up Factors }\end{array}$ & $(10,10,0)$ & \multicolumn{4}{|c|}{$\begin{array}{c}(1,0,0)(10,0,0) \quad(1,1,0) \quad(10,10,0) \\
\text { Shield Buildup Factors }\end{array}$} \\
\hline & & $\begin{array}{l}0.53 \\
2.05 \\
5.19 \\
6.86\end{array}$ & $\begin{array}{l}0.65 \\
1.93 \\
5.73 \\
5.53\end{array}$ & $\begin{array}{l}0.61 \\
1.97 \\
7.28 \\
6.35\end{array}$ & $\begin{array}{l}0.64 \\
1.87 \\
8.28 \\
4.53\end{array}$ & $\begin{array}{c}0.58 \\
2.33 \\
22.13 \\
8.55\end{array}$ & $\begin{array}{c}0.71 \\
2.19 \\
24.13 \\
7.33\end{array}$ & $\begin{array}{c}0.69 \\
2.20 \\
34.69 \\
8.12\end{array}$ & $\begin{array}{c}0.73 \\
2.06 \\
42.06 \\
6.28\end{array}$ \\
\hline Water & $\begin{array}{l}\text { Co-60 } \\
\text { Pu-239 } \\
\text { C-14 } \\
\text { Cs-137 }\end{array}$ & $\begin{array}{l}0.53 \\
1.32 \\
0.08 \\
0.52\end{array}$ & $\begin{array}{l}\mathbf{0 . 7 7} \\
1.14 \\
\mathbf{0 . 3 1} \\
\mathbf{0 . 7 5}\end{array}$ & $\begin{array}{l}0.70 \\
1.25 \\
0.14 \\
0.69\end{array}$ & $\begin{array}{l}0.80 \\
0.98 \\
\mathbf{0 . 6 5} \\
\mathbf{0 . 7 9}\end{array}$ & $\begin{array}{l}0.53 \\
1.31 \\
0.08 \\
0.51\end{array}$ & $\begin{array}{l}\mathbf{0 . 7 7} \\
1.14 \\
\mathbf{0 . 3 1} \\
\mathbf{0 . 7 5}\end{array}$ & $\begin{array}{l}0.69 \\
1.24 \\
0.13 \\
0.68\end{array}$ & $\begin{array}{l}0.80 \\
0.98 \\
0.64 \\
0.78\end{array}$ \\
\hline Aluminum & $\begin{array}{l}\text { Co-60 } \\
\text { Pu-239 } \\
\text { Sr-90 } \\
\text { Ra-226 }\end{array}$ & $\begin{array}{l}0.49 \\
1.90 \\
0.00 \\
0.49\end{array}$ & $\begin{array}{l}0.59 \\
1.82 \\
0.00 \\
0.58\end{array}$ & $\begin{array}{l}0.57 \\
1.83 \\
0.00 \\
0.55\end{array}$ & $\begin{array}{l}0.59 \\
1.71 \\
0.00 \\
0.56\end{array}$ & $\begin{array}{l}0.54 \\
2.16 \\
0.00 \\
0.59\end{array}$ & $\begin{array}{l}0.65 \\
2.04 \\
0.00 \\
0.69\end{array}$ & $\begin{array}{l}0.63 \\
2.04 \\
0.00 \\
0.68\end{array}$ & $\begin{array}{l}0.66 \\
1.94 \\
0.00 \\
0.71\end{array}$ \\
\hline Iron & $\begin{array}{l}\text { Co-60 } \\
\text { Pu-239 } \\
\text { Ag-110m } \\
\text { Th-228 }\end{array}$ & $\begin{array}{l}\mathbf{0 . 5 1} \\
1.06 \\
1.07 \\
\mathbf{0 . 0 1}\end{array}$ & $\begin{array}{l}0.55 \\
1.02 \\
1.21 \\
0.01\end{array}$ & $\begin{array}{l}\mathbf{0 . 5 2} \\
1.01 \\
1.00 \\
\mathbf{0 . 0 2} \\
\end{array}$ & $\begin{array}{l}0.52 \\
0.97 \\
1.04 \\
0.02 \\
\end{array}$ & $\begin{array}{l}0.63 \\
1.82 \\
1.38 \\
0.10 \\
\end{array}$ & $\begin{array}{l}0.68 \\
1.48 \\
1.67 \\
0.10\end{array}$ & $\begin{array}{l}0.67 \\
1.52 \\
1.32 \\
0.21 \\
\end{array}$ & $\begin{array}{l}0.67 \\
1.39 \\
1.52 \\
0.31 \\
\end{array}$ \\
\hline Copper & $\begin{array}{l}\text { Co-60 } \\
\text { Pu-239 } \\
\text { Cs-137 } \\
\text { Cf-252 }\end{array}$ & $\begin{array}{c}\mathbf{0 . 4 7} \\
0.85 \\
\mathbf{0 . 3 9} \\
1339.67\end{array}$ & $\begin{array}{c}\mathbf{0 . 5 0} \\
0.83 \\
\mathbf{0 . 4 2} \\
\mathbf{1 3 4 4 . 0 0}\end{array}$ & $\begin{array}{c}0.49 \\
0.81 \\
0.40 \\
1743.60\end{array}$ & $\begin{array}{c}0.49 \\
0.81 \\
0.39 \\
1921.15\end{array}$ & $\begin{array}{c}\mathbf{0 . 6 0} \\
1.00 \\
\mathbf{0 . 5 8} \\
\mathbf{6 6 3 5 . 2 9}\end{array}$ & $\begin{array}{c}\mathbf{0 . 6 4} \\
1.06 \\
\mathbf{0 . 6 2} \\
\mathbf{6 5 9 4 . 7 0}\end{array}$ & $\begin{array}{c}\mathbf{0 . 6 5} \\
0.94 \\
\mathbf{0 . 6 2} \\
\mathbf{1 0 7 0 8 . 7 8}\end{array}$ & $\begin{array}{c}\mathbf{0 . 6 6} \\
1.11 \\
\mathbf{0 . 6 1} \\
\mathbf{8} \mathbf{1 3 2 0 1 . 9 7}\end{array}$ \\
\hline$n$ & $\begin{array}{l}\text { Co-60 } \\
\text { Pu-239 } \\
\text { Ra-226 } \\
\text { C-14 }\end{array}$ & $\begin{array}{l}0.32 \\
3.83 \\
0.17 \\
1.95 \\
\end{array}$ & $\begin{array}{l}0.34 \\
0.75 \\
0.19 \\
9.52 \\
\end{array}$ & $\begin{array}{l}0.28 \\
2.58 \\
0.14 \\
2.91 \\
\end{array}$ & $\begin{array}{c}0.27 \\
0.68 \\
0.12 \\
22.21 \\
\end{array}$ & $\begin{array}{l}0.60 \\
4.52 \\
0.61 \\
2.36 \\
\end{array}$ & $\begin{array}{c}0.62 \\
0.97 \\
0.64 \\
12.92 \\
\end{array}$ & $\begin{array}{l}0.60 \\
3.03 \\
0.60 \\
3.60 \\
\end{array}$ & $\begin{array}{c}0.59 \\
0.97 \\
0.59 \\
35.00 \\
\end{array}$ \\
\hline$\overline{\mathrm{L}}$ & $\begin{array}{l}\text { Co-60 } \\
\text { Pu-239 } \\
\text { Th-228 } \\
\text { Np-237 }\end{array}$ & $\begin{array}{l}0.33 \\
1.61 \\
0.02 \\
0.00\end{array}$ & $\begin{array}{l}0.35 \\
0.74 \\
0.02 \\
0.00\end{array}$ & $\begin{array}{l}\mathbf{0 . 2 9} \\
1.08 \\
\mathbf{0 . 0 3} \\
\mathbf{0 . 0 0}\end{array}$ & $\begin{array}{l}0.27 \\
0.71 \\
0.04 \\
0.00\end{array}$ & $\begin{array}{l}0.64 \\
1.93 \\
0.36 \\
0.00\end{array}$ & $\begin{array}{l}0.67 \\
0.97 \\
0.31 \\
0.00\end{array}$ & $\begin{array}{l}0.64 \\
1.30 \\
0.90 \\
0.00\end{array}$ & $\begin{array}{l}0.63 \\
1.01 \\
1.28 \\
0.00\end{array}$ \\
\hline Uranium & $\begin{array}{l}\text { Co-60 } \\
\text { Pu-239 } \\
\text { Np-237 } \\
\text { Sr-90 }\end{array}$ & $\begin{array}{c}0.24 \\
0.86 \\
1075.81 \\
6.35\end{array}$ & $\begin{array}{c}0.25 \\
0.88 \\
995.83 \\
5.71\end{array}$ & $\begin{array}{c}0.20 \\
0.81 \\
1637.78 \\
9.33\end{array}$ & $\begin{array}{c}0.19 \\
0.82 \\
1790.02 \\
10.02\end{array}$ & $\begin{array}{c}\mathbf{0 . 5 6} \\
1.03 \\
\mathbf{9 3 3 6 . 6 1} \\
\mathbf{1 4 5 . 5 7}\end{array}$ & $\begin{array}{c}0.58 \\
1.29 \\
8812.00 \\
129.02\end{array}$ & $\begin{array}{l}0.55 \\
1.00 \\
16996.40 \\
264.49\end{array}$ & $\begin{array}{c}0.53 \\
1.42 \\
021025.28 \\
324.40\end{array}$ \\
\hline
\end{tabular}


Table 2-19. Ratio of RESRAD-BUILD to MicroShield Doses for Shielded Concrete Volume Source (Air and Shield Material Buildup Factors)

\begin{tabular}{|c|c|c|c|c|c|c|c|c|c|}
\hline \multirow{2}{*}{$\begin{array}{l}\text { Shield } \\
\text { Material } \\
\text { Concrete }\end{array}$} & Radionuclide & $(1,0,0)$ & $\begin{array}{l}(10,0,0) \\
\text { Air Buildu }\end{array}$ & $\begin{array}{l}(1,1,0) \\
\text { up Factors }\end{array}$ & Receptor C & $\begin{array}{l}\text { Coordinates } \\
(1,0,0)\end{array}$ & eld Material & $\begin{array}{c}\quad(1,1,0) \\
\text { Buildup Fac }\end{array}$ & $\begin{array}{l}(10,10,0) \\
\text { ctors }\end{array}$ \\
\hline & $\begin{array}{l}\text { Co-60 } \\
\text { Pu-239 } \\
\text { Th-228 } \\
\text { Np-237 }\end{array}$ & $\begin{array}{c}0.44 \\
0.85 \\
\mathbf{6 1 7 . 5 6} \\
\mathbf{5 . 5 8}\end{array}$ & $\begin{array}{c}0.53 \\
0.82 \\
655.23 \\
5.89\end{array}$ & $\begin{array}{c}\mathbf{0 . 5 2} \\
1.03 \\
\mathbf{8 2 3 . 9 9} \\
\mathbf{6 . 6 2}\end{array}$ & $\begin{array}{c}\mathbf{0 . 5 3} \\
1.10 \\
961.88 \\
7.17\end{array}$ & $\begin{array}{c}0.49 \\
2.44 \\
1632.23 \\
19.90\end{array}$ & $\begin{array}{c}0.59 \\
2.37 \\
1744.77 \\
21.18\end{array}$ & $\begin{array}{c}0.59 \\
3.37 \\
2312.93 \\
26.28\end{array}$ & $\begin{array}{c}0.61 \\
3.90 \\
2805.49 \\
30.40\end{array}$ \\
\hline Water & $\begin{array}{l}\text { Co-60 } \\
\text { Pu-239 } \\
\text { Np-237 } \\
\text { Sr-90 }\end{array}$ & $\begin{array}{c}0.37 \\
0.86 \\
4.77 \\
6.99 E+08\end{array}$ & $\begin{array}{c}\mathbf{0 . 5 3} \\
0.82 \\
\mathbf{5 . 4 1} \\
\mathbf{5 . 7 2 E + 0 8}\end{array}$ & $\begin{array}{c}\mathbf{0 . 4 6} \\
1.05 \\
\mathbf{5 . 6 3} \\
\mathbf{1 . 3 5 E + 0 9}\end{array}$ & $\begin{array}{c}\mathbf{0 . 5 1} \\
1.11 \\
\mathbf{6 . 1 0} \\
\mathbf{1 . 1 1 E + 0 9} \\
\end{array}$ & $\begin{array}{c}\mathbf{0 . 3 7} \\
0.82 \\
\mathbf{4 . 4 8} \\
\mathbf{6 . 8 4 E + 0 8}\end{array}$ & $\begin{array}{c}0.53 \\
0.78 \\
5.07 \\
5.58 \mathrm{E}+08\end{array}$ & $\begin{array}{c}\mathbf{0 . 4 6} \\
0.99 \\
\mathbf{5 . 2 5} \\
1.31 \mathrm{E}+09\end{array}$ & $\begin{array}{c}\mathbf{0 . 5 0} \\
1.04 \\
\mathbf{5 . 6 6} \\
\mathbf{1 . 0 7 E + 0 9}\end{array}$ \\
\hline Aluminum & $\begin{array}{l}\text { Co-60 } \\
\text { Pu-239 } \\
\text { Cf-252 } \\
\text { Ag-110m }\end{array}$ & $\begin{array}{l}0.25 \\
1.06 \\
0.47 \\
0.54\end{array}$ & $\begin{array}{l}\mathbf{0 . 3 1} \\
1.00 \\
\mathbf{0 . 4 7} \\
\mathbf{0 . 6 1}\end{array}$ & $\begin{array}{l}0.25 \\
1.43 \\
0.43 \\
0.58\end{array}$ & $\begin{array}{l}0.24 \\
1.59 \\
0.40 \\
0.59\end{array}$ & $\begin{array}{l}0.27 \\
3.26 \\
1.87 \\
0.62\end{array}$ & $\begin{array}{l}0.33 \\
3.10 \\
1.92 \\
0.70\end{array}$ & $\begin{array}{l}0.27 \\
5.02 \\
1.94 \\
0.68\end{array}$ & $\begin{array}{l}0.27 \\
6.04 \\
1.96 \\
0.70\end{array}$ \\
\hline Iron & $\begin{array}{l}\text { Co-60 } \\
\text { Pu-239 } \\
\text { C-14 } \\
\text { Cs-137 }\end{array}$ & $\begin{array}{l}\mathbf{0 . 4 1} \\
1.16 \\
0.95 \\
\mathbf{0 . 5 6}\end{array}$ & $\begin{array}{l}\mathbf{0 . 4 4} \\
1.09 \\
0.91 \\
\mathbf{0 . 5 8} \\
\end{array}$ & $\begin{array}{l}0.43 \\
1.61 \\
0.80 \\
0.56\end{array}$ & $\begin{array}{l}0.42 \\
1.81 \\
0.69 \\
0.56 \\
\end{array}$ & $\begin{array}{c}0.53 \\
15.06 \\
9.97 \\
0.85 \\
\end{array}$ & $\begin{array}{c}0.56 \\
14.36 \\
10.10 \\
0.88 \\
\end{array}$ & $\begin{array}{c}0.56 \\
27.30 \\
9.96 \\
0.91 \\
\end{array}$ & $\begin{array}{c}0.56 \\
36.36 \\
10.03 \\
0.93 \\
\end{array}$ \\
\hline Copper & $\begin{array}{l}\text { Co-60 } \\
\text { Pu-239 } \\
\text { Sr-90 } \\
\text { Ra-226 }\end{array}$ & $\begin{array}{c}0.38 \\
0.84 \\
7.48 E+05 \\
221.06\end{array}$ & $\begin{array}{c}0.40 \\
0.80 \\
6.00 \mathrm{E}+05 \\
221.19\end{array}$ & $\begin{array}{c}\mathbf{0 . 4 0} \\
1.01 \\
1.43 E+06 \\
258.60\end{array}$ & $\begin{array}{c}0.40 \\
1.07 \\
1.18 E+06 \\
279.14\end{array}$ & $\begin{array}{c}0.50 \\
8.38 \\
9.94 \mathrm{E}+05 \\
1040.31\end{array}$ & $\begin{array}{c}0.53 \\
8.29 \\
8.54 \mathrm{E}+05 \\
1059.40\end{array}$ & $\begin{array}{c}0.54 \\
12.85 \\
2.09 E+06 \\
1491.47\end{array}$ & $\begin{array}{c}0.54 \\
16.11 \\
1.84 \mathrm{E}+06 \\
1821.82\end{array}$ \\
\hline Tungsten & $\begin{array}{l}\text { Co-60 } \\
\text { Pu-239 } \\
\text { Ag-110m } \\
\text { Th-228 }\end{array}$ & $\begin{array}{c}0.17 \\
1.31 \\
0.71 \\
1806.06\end{array}$ & $\begin{array}{c}\mathbf{0 . 1 8} \\
1.20 \\
\mathbf{0 . 7 2} \\
\mathbf{1 7 6 5 . 9 5}\end{array}$ & $\begin{array}{c}0.13 \\
1.89 \\
0.69 \\
2287.54\end{array}$ & $\begin{array}{c}0.12 \\
2.14 \\
0.68 \\
2522.70\end{array}$ & $\begin{array}{c}0.80 \\
16.91 \\
1.57 \\
15427.62 \\
\end{array}$ & $\begin{array}{c}0.79 \\
15.49 \\
1.58 \\
15507.03\end{array}$ & $\begin{array}{c}0.90 \\
31.72 \\
1.68 \\
25031.85\end{array}$ & $\begin{array}{c}0.92 \\
42.28 \\
1.73 \\
32497.91\end{array}$ \\
\hline$\overline{\text { Lead }}$ & $\begin{array}{l}\text { Co-60 } \\
\text { Pu-239 } \\
\text { Cs-137 } \\
\text { Cf-252 }\end{array}$ & $\begin{array}{l}0.24 \\
0.79 \\
0.13 \\
0.44 \\
\end{array}$ & $\begin{array}{l}0.25 \\
0.76 \\
0.14 \\
0.42 \\
\end{array}$ & $\begin{array}{l}0.22 \\
0.93 \\
0.11 \\
0.40\end{array}$ & $\begin{array}{l}0.20 \\
0.98 \\
0.09 \\
0.37\end{array}$ & $\begin{array}{l}0.53 \\
3.87 \\
0.58 \\
5.94\end{array}$ & $\begin{array}{l}0.55 \\
3.78 \\
0.60 \\
6.13\end{array}$ & $\begin{array}{l}0.54 \\
5.06 \\
0.57 \\
6.71\end{array}$ & $\begin{array}{l}0.53 \\
5.67 \\
0.55 \\
7.39 \\
\end{array}$ \\
\hline$m$ & $\begin{array}{l}\text { Co-60 } \\
\text { Pu-239 } \\
\text { Ra-226 } \\
\text { C-14 }\end{array}$ & $\begin{array}{c}0.17 \\
0.79 \\
490.29 \\
0.77\end{array}$ & $\begin{array}{c}0.18 \\
0.77 \\
464.15 \\
0.75\end{array}$ & $\begin{array}{c}0.15 \\
0.94 \\
803.47 \\
0.63\end{array}$ & $\begin{array}{c}0.14 \\
0.99 \\
980.14 \\
0.53\end{array}$ & $\begin{array}{c}0.47 \\
11.84 \\
6981.57 \\
11.56\end{array}$ & $\begin{array}{c}0.48 \\
12.03 \\
6511.63 \\
11.68\end{array}$ & $\begin{array}{c}0.45 \\
18.75 \\
15337.22 \\
11.45\end{array}$ & $\begin{array}{c}0.44 \\
24.03 \\
22491.52 \\
11.43\end{array}$ \\
\hline
\end{tabular}


Table 2-20. Ratio of RESRAD-BUILD to MicroShield Doses for Shielded Concrete Volume Source (Source Material Buildup Factors)

\begin{tabular}{|c|c|c|c|c|c|}
\hline \multirow[b]{2}{*}{$\begin{array}{l}\text { Source } \\
\text { Material }\end{array}$} & \multirow[b]{2}{*}{ Radionuclide } & \multicolumn{4}{|c|}{ Receptor Coordinates } \\
\hline & & \multicolumn{4}{|c|}{ Source Material Buildup Factors } \\
\hline Concrete & $\begin{array}{l}\text { Co-60 } \\
\text { Pu-239 } \\
\text { Th-228 } \\
\text { Np-237 }\end{array}$ & $\begin{array}{c}0.49 \\
2.44 \\
1632.23 \\
19.90\end{array}$ & $\begin{array}{c}0.59 \\
2.37 \\
1744.77 \\
21.18\end{array}$ & $\begin{array}{c}0.59 \\
3.37 \\
2312.93 \\
26.28\end{array}$ & $\begin{array}{c}0.61 \\
3.90 \\
2805.49 \\
30.40\end{array}$ \\
\hline Water & $\begin{array}{l}\text { Co-60 } \\
\text { Pu-239 } \\
\text { Np-237 } \\
\text { Sr-90 }\end{array}$ & $\begin{array}{c}0.41 \\
2.52 \\
15.80 \\
9.02 E+08\end{array}$ & $\begin{array}{c}0.59 \\
2.44 \\
18.15 \\
7.78 E+08\end{array}$ & $\begin{array}{c}0.52 \\
3.50 \\
20.94 \\
1.88 E+09\end{array}$ & $\begin{array}{c}0.57 \\
4.04 \\
24.43 \\
1.64 E+09\end{array}$ \\
\hline Aluminum & $\begin{array}{l}\text { Co-60 } \\
\text { Pu-239 } \\
\text { Cf-252 } \\
\text { Ag-110m }\end{array}$ & $\begin{array}{l}0.27 \\
3.47 \\
1.98 \\
0.62\end{array}$ & $\begin{array}{l}0.34 \\
3.30 \\
2.04 \\
0.70\end{array}$ & $\begin{array}{l}0.27 \\
5.38 \\
2.07 \\
0.69\end{array}$ & $\begin{array}{l}0.27 \\
6.50 \\
2.10 \\
0.71\end{array}$ \\
\hline Iron & $\begin{array}{l}\text { Co-60 } \\
\text { Pu-239 } \\
\text { C-14 } \\
\text { Cs-137 } \\
\end{array}$ & $\begin{array}{l}0.46 \\
3.90 \\
4.68 \\
0.68 \\
\end{array}$ & $\begin{array}{l}0.49 \\
3.69 \\
4.65 \\
0.70 \\
\end{array}$ & $\begin{array}{l}0.48 \\
6.25 \\
4.44 \\
0.70 \\
\end{array}$ & $\begin{array}{l}0.48 \\
7.67 \\
4.26 \\
0.70 \\
\end{array}$ \\
\hline Copper & $\begin{array}{l}\text { Co-60 } \\
\text { Pu-239 } \\
\text { Sr-90 } \\
\text { Ra-226 }\end{array}$ & $\begin{array}{c}0.43 \\
2.36 \\
9.50 \mathrm{E}+05 \\
407.47\end{array}$ & $\begin{array}{c}0.45 \\
2.28 \\
8.07 E+05 \\
410.65 \\
\end{array}$ & $\begin{array}{c}0.46 \\
3.21 \\
1.98 \mathrm{E}+06 \\
523.75\end{array}$ & $\begin{array}{c}0.46 \\
3.69 \\
1.72 E+06 \\
597.01\end{array}$ \\
\hline Tungsten & $\begin{array}{l}\text { Co-60 } \\
\text { Pu-239 } \\
\text { Ag-110m } \\
\text { Th-228 }\end{array}$ & $\begin{array}{c}0.39 \\
4.67 \\
0.81 \\
3191.95\end{array}$ & $\begin{array}{c}0.40 \\
4.27 \\
0.82 \\
3152.10\end{array}$ & $\begin{array}{c}0.41 \\
7.82 \\
0.81 \\
4322.01\end{array}$ & $\begin{array}{c}0.40 \\
9.66 \\
0.80 \\
4976.97\end{array}$ \\
\hline Lead & $\begin{array}{l}\text { Co-60 } \\
\text { Pu-239 } \\
\text { Cs-137 } \\
\text { Cf-252 } \\
\end{array}$ & $\begin{array}{l}0.27 \\
2.15 \\
0.16 \\
1.78 \\
\end{array}$ & $\begin{array}{l}0.28 \\
2.10 \\
0.17 \\
1.78 \\
\end{array}$ & $\begin{array}{l}0.24 \\
2.86 \\
0.14 \\
1.85 \\
\end{array}$ & $\begin{array}{l}0.23 \\
3.26 \\
0.12 \\
1.89 \\
\end{array}$ \\
\hline Uranium & $\begin{array}{l}\text { Co-60 } \\
\text { Pu-239 } \\
\text { Ra-226 } \\
\text { C-14 }\end{array}$ & $\begin{array}{c}0.20 \\
2.20 \\
1158.55 \\
4.45\end{array}$ & $\begin{array}{c}0.20 \\
2.18 \\
1090.56 \\
4.44\end{array}$ & $\begin{array}{c}0.17 \\
2.99 \\
2106.90 \\
4.15\end{array}$ & $\begin{array}{c}0.15 \\
3.42 \\
2729.41 \\
3.92\end{array}$ \\
\hline
\end{tabular}




\subsubsection{Submersion External Gamma Pathway}

Equation F.13 in Appendix F of the user's manual forms the basis for verifying the calculation of the submersion dose.

Five radionuclides were selected for these tests:

- H-3 (first radionuclide listed in the RESRAD-BUILD database and pure beta emitter)

- Co-60 (default radionuclide, strong gamma-emitter)

- $\mathrm{Sr}-90$ (strong beta-emitting radionuclide)

- Ra-226 (Rn-222 precursor, decay chain, alpha-gamma emitter)

- Cf-252 (last radionuclide listed in the RESRAD-BUILD database, decay chain, alpha-gamma emitter)

The components of this pathway were broken down into 4 sub modules tracking the movement from the source (injection), impact on indoor air quality (concentration in air), receptor characteristics (occupancy), and exposure point (dose).

Each individual module was set up as a spreadsheet linked to the other modules, each of which is described below.

\section{Source Injection Module}

Two source types, area and volume, were set up in the source injection module using the RESRAD-BUILD defaults. The verification was not extended to point and line sources since the transport mechanisms from these source types are the same as for the area source type. In fact, for all pathways except the direct external gamma pathway, the same results are obtained when running point, line, or area sources with equivalent radionuclide inventories and equivalent exposure conditions. With the exception of the tritium volume source, the injection rate for each radionuclide is independent of the properties of the radionuclide, but depends only on the properties of the source. For the line and area models, the spreadsheet results of $5.71 \mathrm{E}-8 \mathrm{pCi} / \mathrm{s}$ exactly matched the results listed in the DIAG.OUT file generated by RESRAD-BUILD. The same was true for the spreadsheet result of $2.40 \mathrm{E}-8 \mathrm{pCi} / \mathrm{s}$ generated for the non-tritium volume sources.

Since the injection of tritiated water vapor from a volume source into the building air flow affects only the inhalation dose from tritium, the special tritium volume source model is verified in Section 2.3.5. Similarly, a special model applies to the release of radon, which has a separate inhalation model that differs significantly from the particulate inhalation model. The source injection module for the radon pathway is verified in Section 2.3.4.

\section{Air Flow Module}

The indoor air quality model described in Appendix A of the user's manual was set up on a spreadsheet with the RESRAD-Build default parameters. This module receives the output of the source injection module as input and has a dependency on the half-life of each radionuclide. The output from this module is the concentration of the radionuclide in air. The results for both source types exactly matched the concentrations reported in the RESRAD-BUILD DIAG.OUT file, indicating that the code is correctly implementing the indoor air quality module for the one room model. 


\section{Receptor Module}

The receptor spreadsheet module incorporates the receptor-specific parameters in addition to the total exposure time and fraction indoors. It uses these parameters to calculate the occupancy factors (in exposure-years) used for the submersion and deposition external gamma pathway modules. It also is used calculates the volume of contaminated air inhaled by the receptor used by the inhalation module and the amount of ingested "area" used by the indirect ingestion pathway module. For the submersion pathway, the exposure factor was based on the product of the default exposure duration (365 d), indoor fraction (0.5), and receptor fraction (1), divided by a time conversion factor $(365 \mathrm{~d} / \mathrm{y})$, resulting in 0.5 exposure-years. These results are independent of the radionuclide.

\section{Submersion Module}

This module simply takes the output from the airflow module (concentration) and the receptor module (exposure-years) to calculate the dose from the submersion external gamma pathway using the DCF for submersion based on FGR 12.

Table 2-21 provides a comparison of the submersion dose calculated with RESRAD-BUILD and verified by the spreadsheet modules. The only discrepancy is the calculated value for the tritium area source. The reason for this difference is that RESRAD-BUILD uses a DCF of zero of submersion in tritium, whereas the submersion DCF in FGR 12 is a non-zero value, which likely takes into account dermal absorption (see also Section 2.3.5). RESRAD-BUILD takes into account dermal absorption of tritium by increasing the inhalation dose by $50 \%$. The calculated submersion dose for all other radionuclides and source types was an exact match with the results reported in the RESRAD-BUILD output files.

Table 2-21. Verification of Submersion Pathway Results

\begin{tabular}{|c|c|c|c|}
\hline & \multicolumn{2}{|c|}{ Dose (mrem) } & Ratio \\
\hline Radionuclide & RESRAD-BUILD & SS Verification & RB/SSV \\
\hline H-3 Area & $0.00 \mathrm{E}+00$ & $5.19 \mathrm{E}-14$ & 0.00 \\
\hline CO-60 Area & $1.83 \mathrm{E}-08$ & $1.83 \mathrm{E}-08$ & 1.00 \\
\hline CO-60 Volume & 7.69E-09 & 7.70E-09 & 1.00 \\
\hline SR-90 Area & $3.21 \mathrm{E}-11$ & $3.21 \mathrm{E}-11$ & 1.00 \\
\hline SR-90 Volume & 1.35E-11 & $1.35 \mathrm{E}-11$ & 1.00 \\
\hline RA-226 Area & $1.48 \mathrm{E}-08$ & $1.48 \mathrm{E}-08$ & 1.00 \\
\hline RA-226 Volume & 6.24E-09 & 6.22E-09 & 1.00 \\
\hline CF-252 Area & $6.53 \mathrm{E}-13$ & $6.52 \mathrm{E}-13$ & 1.00 \\
\hline CF-252 Volume & $2.75 \mathrm{E}-13$ & $2.74 \mathrm{E}-13$ & 1.00 \\
\hline
\end{tabular}

\subsubsection{Deposition External Gamma Pathway}

The user's manual does provide an explanation of how the RESRAD-BUILD code calculates the external gamma dose from deposited radionuclides. Tests were conducted on the same radionuclides and source types described in Section 2.3.2. This pathway depends on the source injection rate and indoor air concentrations, both of which were verified in Section 2.3.2, as well as the same receptor exposure time derived for the submersion external gamma pathway. In 
addition to these two modules, the spreadsheet verification included a deposition module and a groundshine module, which are discussed below.

\section{Deposition Module}

This spreadsheet module was developed to calculate the concentration on the room floor based on the concentration in the room air generated by the airflow module. The calculation of deposited activity is done by multiplying the deposition velocity by the room air concentration, taking into account resuspension by dividing by the sum of the radionuclide decay and resuspension rates. The resulting output is then used in the calculation of external gamma from an area source, as well as for the ingestion of deposited material (see Section 2.3.7).

Table 2-22 shows the room floor concentrations calculated using the deposition module. It was not possible to verify these intermediate results, as these are not available in any of the RESRADBUILD output files.

\section{Table 2-22. Floor Concentrations Calculated by the Deposition Module}

\begin{tabular}{lc} 
Radionuclide & $\begin{array}{c}\text { Concentration } \\
\mathrm{pCi} / \mathrm{m}^{2}\end{array}$ \\
\hline H-3 Area & $5.35 \mathrm{E}-02$ \\
CO-60 Area & $4.93 \mathrm{E}-02$ \\
CO-60 Volume & $2.07 \mathrm{E}-02$ \\
SR-90 Area & $5.55 \mathrm{E}-02$ \\
SR-90 Volume & $2.33 \mathrm{E}-02$ \\
RA-226 Area & $5.70 \mathrm{E}-02$ \\
RA-226 Volume & $2.40 \mathrm{E}-02$ \\
CF-252 Area & $4.34 \mathrm{E}-02$ \\
CF-252 Volume & $1.82 \mathrm{E}-02$
\end{tabular}

\section{Groundshine Module}

The groundshine module takes the floor concentration calculated by the deposition module and multiplies it by the exposure time from the receptor module. This product is then multiplied by the appropriate surface source DCF derived from FGR12. The results are presented in Table 2-23, where they are compared with the results calculated using RESRAD-BUILD.

With the exception of the tritium area source, all the other sources result in lower doses calculated by RESRAD-BUILD. These ratios are similar for different source types, but are not the same for different radionuclides, indicating that the differences are likely to be associated with parameters unique to each radionuclide. This could be the surface source DCF, an undocumented area factor calculation, or some other radionuclide-specific parameter used to by RESRAD-BUILD to calculate the external dose from deposited surface contamination. Appendix F of the user's manual does not provide any information on the possible use of an area factor for calculating external doses from deposited radionuclides.

It is unlikely that the problem lies with the calculation of the deposited floor concentrations, as these same concentrations were used to successfully verify the indirect ingestion pathway (see Section 2.3.7).

Table 2-23. Verification of Deposition External Gamma Pathway Results 


\begin{tabular}{lccc} 
& \multicolumn{2}{c}{ Dose (mrem) } & Ratio \\
Radionuclide & RESRAD-BUILD & SS Verification & RB/SSV \\
\hline H-3 Area & $0.00 \mathrm{E}+00$ & $0.00 \mathrm{E}+00$ & N/A \\
CO-60 Area & $1.60 \mathrm{E}-06$ & $6.77 \mathrm{E}-06$ & 0.24 \\
CO-60 Volume & $6.74 \mathrm{E}-07$ & $2.85 \mathrm{E}-06$ & 0.24 \\
SR-90 Area & $1.34 \mathrm{E}-08$ & $1.82 \mathrm{E}-08$ & 0.74 \\
SR-90 Volume & $5.64 \mathrm{E}-09$ & $7.65 \mathrm{E}-09$ & 0.74 \\
RA-226 Area & $1.32 \mathrm{E}-06$ & $5.54 \mathrm{E}-06$ & 0.24 \\
RA-226 Volume & $5.55 \mathrm{E}-07$ & $2.33 \mathrm{E}-06$ & 0.24 \\
CF-252 Area & $4.59 \mathrm{E}-10$ & $1.83 \mathrm{E}-09$ & 0.25 \\
CF-252 Volume & $1.93 \mathrm{E}-10$ & $7.70 \mathrm{E}-10$ & 0.25
\end{tabular}

\subsubsection{Radon Inhalation Pathway}

Appendix $\mathrm{C}$ of the user's manual provides a description of how the RESRAD-BUILD code calculates the inhalation dose from radon. The models for the release and inhalation of radon and its progeny differ significantly from the models for the release and inhalation of particulate radionuclides. This pathway depends on the indoor air concentrations and the receptor exposure time, both of which were verified in Section 2.3.2. Therefore, only the radon source injection and inhalation modules are verified separately in this section. In addition, the multi-region radon volume source injection module was verified for two, three, four, and five regions.

\section{Source Injection Module (Radon Source)}

Section C.1 in the user's manual provides the equations used to calculate injection (also called the flux) of radon from an indoor source. In the case of point, line, or area sources, the calculation of the radon injection rate is a straightforward application of Equation C.1 in the user's manual. This calculation was verified for an area source using the default parameters. The release rates of 4.49E-02 for Rn-220 and 7.55E-06 pCi/s for Rn-222 calculated by the spreadsheet model matched the results reported in the RESRAD-BUILD DIAG.OUT file, indicating that the code is correctly implementing the injection module for the radon area source. This verification extends in a similar manner to the point and line source models, since both implement the same equation for the injection rate as the area source.

Equations C. 2 through C. 17 of the user's manual are used to calculate the multi-region radon injection module for a volume source containing a radon parent within one of the regions. The approach to verifying the multi-region radon module was to first verify the calculations for a single-region volume source by implementing Equations C.2 through C.17 in a spreadsheet. The multi-region source was then verified by determining whether a multi-region source could be constructed to yield the same results as the single-region source.

Table 2-24 shows the results of the single-region calculations for Rn-220 and Rn-222 using default parameter values. In addition, all parameters affecting only the radon injection rate, such as source thickness, area, diffusion, porosity, and emanation fraction, were reduced by $10 \%$ to test whether small deviations from the default parameters would result in correct calculations of the radon flux. As can bee seen in Table 2-24, the results of the spreadsheet calculations match the results calculated and reported the RESRAD-BUILD DIAG.OUT file, indicating that the code is correctly implementing the injection module for the single-region radon volume source. 
Table 2-24. Verification of Single-Region Radon Volume Source Injection Module

\begin{tabular}{lcccc} 
& & \multicolumn{2}{c}{ Injection Rate (pCi/s) } & Ratio \\
& Radionuclide & RESRAD-BUILD & SS Verification & RB/ SSV \\
\hline Defaults & & & & \\
& Rn-222 & $5.44 \mathrm{E}+00$ & $5.44 \mathrm{E}+00$ & 1.00 \\
& $\mathrm{Rn}-220$ & $1.65 \mathrm{E}+04$ & $1.65 \mathrm{E}+04$ & 1.00 \\
90\% of Defaults & & & & \\
& $\mathrm{Rn}-222$ & $3.21 \mathrm{E}+00$ & $3.21 \mathrm{E}+00$ & 1.00 \\
& $\mathrm{Rn}-220$ & $1.01 \mathrm{E}+04$ & $1.01 \mathrm{E}+04$ & 1.00
\end{tabular}

Table 2-25 shows the results for the multi-region model compared with the single-region model. In this case, only Rn-220 was used due to the much shorter half-life, which in turn affects the amount of radon generated that is able to diffuse out of the source. The total source dimensions and all other parameters are the same as the single-region source, but the thickness of each region is calculated by taking the single-region source thickness and dividing it by the number of regions. For each multi-region volume, the source was alternately placed in each one of the regions, and the injection rate was calculated for each case. The injection rates for each multiregion volume source were then summed to obtain the total injection rate.

Table 2-25. Verification of Multi-Region Radon Volume Source Injection Module

\begin{tabular}{lccccc} 
& \multicolumn{5}{c}{ Selected Number of Regions in Source } \\
Region & 1 & 2 & 3 & 4 & 5 \\
\hline Region Thickness $(\mathrm{cm})$ & 15 & 7.5 & 5 & 3.725 & 3 \\
\hline Injection Rate 1 $(\mathrm{pCi} / \mathrm{s})$ & $1.65 \mathrm{E}+04$ & $8.23 \mathrm{E}+03$ & $6.51 \mathrm{E}+03$ & $5.41 \mathrm{E}+03$ & $4.67 \mathrm{E}+03$ \\
Injection Rate 2 $(\mathrm{pCi} / \mathrm{s})$ & $\mathrm{N} / \mathrm{A}$ & $8.23 \mathrm{E}+03$ & $3.45 \mathrm{E}+03$ & $2.81 \mathrm{E}+03$ & $2.57 \mathrm{E}+03$ \\
Injection Rate 3 $(\mathrm{pCi} / \mathrm{s})$ & $\mathrm{N} / \mathrm{A}$ & $\mathrm{N} / \mathrm{A}$ & $6.51 \mathrm{E}+03$ & $2.81 \mathrm{E}+03$ & $1.99 \mathrm{E}+03$ \\
Injection Rate 4 $(\mathrm{pCi} / \mathrm{s})$ & $\mathrm{N} / \mathrm{A}$ & $\mathrm{N} / \mathrm{A}$ & $\mathrm{N} / \mathrm{A}$ & $5.41 \mathrm{E}+03$ & $2.57 \mathrm{E}+03$ \\
Injection Rate 5 $(\mathrm{pCi} / \mathrm{s})$ & $\mathrm{N} / \mathrm{A}$ & $\mathrm{N} / \mathrm{A}$ & $\mathrm{N} / \mathrm{A}$ & N/A & $4.67 \mathrm{E}+03$ \\
\hline Total Injection Rate & & & & & \\
(pCi/s) & $1.65 \mathrm{E}+04$ & $1.65 \mathrm{E}+04$ & $1.65 \mathrm{E}+04$ & $1.64 \mathrm{E}+04$ & $1.65 \mathrm{E}+04$
\end{tabular}

The total injection rates for all of the multi-region models are effectively identical, and the intermediate results show how the contributions from each region change as a function of the source location within each volume. Since the totals match the result from the single-region source, using default values for $\mathrm{Rn}-220$, the multi-region model is validated. As expected, the flux profile in each of these volume sources exhibits symmetry about the volume mid-plane, with the regions closest to the exposed surfaces contributing more to the total flux than the centermost regions.

\section{Inhalation Module (Radon)}

The inhalation module takes the radon air concentration calculated by the airflow module and estimates the activity of radon progeny, expressed in units of working levels. The estimation of radon progeny concentrations are described in Section C. 2 and C. 3 of the user's manual.

Perhaps counter-intuitively, inhalation rates are not used to calculate radon inhalation doses. Rather, the radon inhalation model calculates dose from the receptor time parameters, coupled 
with factors used to convert from concentration to dose. This methodology is described in Sections C. 4 and C.5 of the user's manual.

Equations C.18 through C.39 in Appendix C of the user's manual were implemented in a spreadsheet model for both Rn-220 and Rn-222. In testing the radon inhalation model, the default parameter values were applied, except for the number of points for time integration, which was changed from 17 to 1 in order to simplify the calculations. However, the default values for two parameters, the attachment rate and the plate-out rate, which are required to calculate concentrations of radon progeny in two of the three possible states, are not listed in Table C.1 or elsewhere in the user's manual. In addition, these parameters are not directly accessible from the user interface. The values of the attachment rate and the plate-out rate used by RESRAD-BUILD were taken from Figure 5.3 of the internal RESRAD-BUILD verification report (Kamboj et al. 2001). In that figure, both values are listed as $108 / \mathrm{h}$, equivalent to $0.03 / \mathrm{s}$. This value is acceptable since it falls within the upper end of the range of values provided in Table C.1 of the user's manual.

Table 2-26 shows the results of this verification by comparing the concentrations calculated by RESRAD-BUILD and the spreadsheet model for Rn-220, Rn-222, and progeny, the total concentrations of progeny expressed as working levels, and the inhalation doses. The concentrations ( $\mathrm{pC} / \mathrm{m}^{3}$ and WL) calculated by RESRAD-BUILD are reported in the DIAG.OUT file. The only discrepancy between the spreadsheet implementation of the equations in the user's manual and the results reported by RESRAD-BUILD was the calculation of the Rn-220 progeny WL and dose. The source of this discrepancy was determined to be an error in Equation C-33 of the user's manual, where the correct coefficient for Bi-212 should be $1.17 \times 10^{-5}$, not $1.17 \times 10^{-4}$. After this correction, the ratio between RESRAD-BUILD and the spreadsheet model is one.

Table 2-26. Verification of the Radon Inhalation Module

\begin{tabular}{|c|c|c|c|}
\hline Radionuclide & RESRAD-BUILD & SS Verification & $\begin{array}{c}\text { Ratio } \\
\text { RB/SSV } \\
\end{array}$ \\
\hline \multicolumn{4}{|c|}{ Concentrations (pCi/m3 or WL) } \\
\hline $\mathrm{Rn}-220$ & $1.44 \mathrm{E}+04$ & $1.44 \mathrm{E}+04$ & 1.00 \\
\hline Po-216 & $1.43 E+04$ & 1.44E+04 & 1.00 \\
\hline $\mathrm{Pb}-212$ & $3.57 \mathrm{E}+01$ & $3.58 \mathrm{E}+01$ & 1.00 \\
\hline $\mathrm{Bi}-212$ & $1.47 \mathrm{E}+00$ & $1.47 \mathrm{E}+00$ & 1.00 \\
\hline Rn-220 Progeny WL & 4.42E-03 & $4.58 \mathrm{E}-03$ & 0.96 \\
\hline $\mathrm{Rn}-222$ & $2.70 \mathrm{E}+02$ & $2.69 \mathrm{E}+02$ & 1.00 \\
\hline Po-218 & 7.57E+01 & 7.57E+01 & 1.00 \\
\hline $\mathrm{Pb}-214$ & $6.87 \mathrm{E}+00$ & $6.87 \mathrm{E}+00$ & 1.00 \\
\hline $\mathrm{Bi}-214$ & 8.03E-01 & 8.02E-01 & 1.00 \\
\hline Rn-222 Progeny WL & 1.16E-04 & 1.16E-04 & 1.00 \\
\hline \multicolumn{4}{|c|}{ Radon Inhalation Dose (mrem) } \\
\hline Rn-220 & 1.67E+01 & $1.74 \mathrm{E}+01$ & 0.96 \\
\hline Rn-222 & $2.27 \mathrm{E}+00$ & 2.27E+00 & 1.00 \\
\hline
\end{tabular}

This pathway was verified with this limited set of input parameters. Verification of the model at extreme input parameters was not possible due to issues identified in Section 2.2 and detailed in Section 4.3.

Other Inhalation Pathway 
Appendix D of the user's manual provides a description of how the RESRAD-BUILD code calculates the inhalation dose from airborne radionuclides. Equation D.3 of the user's manual forms the basis for the verification of this pathway. Tests were conducted on the same radionuclides and source types described in Section 2.3.2. The particulate and tritium inhalation pathways depend on the source injection rate and indoor air concentrations, both of which were verified in Section 2.3.2. The source injection module for the tritium volume source model, which differs significantly from the particulate source injection module, is verified below. In addition, the spreadsheet verification for the inhalation pathway makes use of the receptor module and the inhalation module, which are also discussed below.

\section{Source Injection Module (Tritiated Volume Source)}

Section G.4 in Appendix G of the user's manual contains a detailed description of the tritium volume source transport model. Equations G.2 through G.13 in Appendix G were implemented in a spreadsheet to calculate the fraction of the tritium in a volume source that would be released to the room air. These calculations were performed using the default parameter values for the tritium volume source, but the exposure duration was made to range from 10 days to 160 days. The reason for choosing this range was due to the calculated time it would take to evaporate the entire tritium source, which was found to be just under 153 days when using the default parameters.

Table 2-27 lists the values for the fraction of source remaining as a function of time since the release starts, as calculated by the spreadsheet model. This time was also entered as the exposure duration in RESRAD; the dose to a receptor based on this exposure duration was calculated and presented in this table. The maximum dose corresponds to an exposure duration of 153 days, as expected from the spreadsheet model that implemented the equations in Appendix G of the user's manual. This maximum dose does not increase with exposure durations exceeding 153 days, due to the depletion of the tritium volume source.

The dose at times less than 153 days was divided by the maximum dose to estimate the fraction of the original source removed during that time. This fraction was then compared to the source fraction calculated using the spreadsheet model. The fact that the ratios are very close to unity verifies that the RESRAD-BUILD tritium volume source model is correctly implementing the equations in Appendix G of the user's manual.

Table 2-27. Verification of Tritium Source Injection Module

\begin{tabular}{ccccc}
$\begin{array}{c}\text { Exposure } \\
\begin{array}{c}\text { Duration } \\
\text { (days) }\end{array}\end{array}$ & $\begin{array}{c}\text { Fraction } \\
\text { Evaporated } \\
\text { (SS Verification) }\end{array}$ & $\begin{array}{c}\text { RESRAD-BUILD } \\
\text { Dose (mrem) }\end{array}$ & $\begin{array}{c}\text { Fraction of } \\
\text { Max. Dose }\end{array}$ & $\begin{array}{c}\text { Ratio of } \\
\text { Fractions } \\
\text { RB/SS }\end{array}$ \\
\hline 10 & 0.256 & $2.50 \mathrm{E}-03$ & 0.259 & 1.01 \\
50 & 0.573 & $5.58 \mathrm{E}-03$ & 0.578 & 1.01 \\
100 & 0.810 & $7.87 \mathrm{E}-03$ & 0.815 & 1.00 \\
150 & 0.992 & $9.61 \mathrm{E}-03$ & 0.995 & 1.00 \\
151 & 0.996 & $9.65 \mathrm{E}-03$ & 0.999 & 1.00 \\
152 & 0.999 & $9.66 \mathrm{E}-03$ & 1.000 & 1.00 \\
153 & 1.002 & $9.66 \mathrm{E}-03$ & 1.000 & $\mathrm{n} / \mathrm{a}$ \\
160 & 1.025 & $9.66 \mathrm{E}-03$ & 1.000 & $\mathrm{n} / \mathrm{a}$
\end{tabular}

Receptor Module 
The receptor spreadsheet module incorporates the receptor-specific parameters in addition to the total exposure time and fraction indoors. Another receptor parameter that is used in the calculations of inhalation dose is the breathing rate. The module uses these parameters to calculate the volume of inhaled air during the time spent at the receptor locations. For the inhalation pathway, the total inhaled volume of air was based on the product of the default exposure duration $(365 \mathrm{~d})$, indoor fraction $(0.5)$, receptor fraction $(1)$, and breathing rate $\left(18 \mathrm{~m}^{3} / \mathrm{d}\right)$ resulting in an inhaled volume of $3290 \mathrm{~m}^{3}$. These results are independent of the radionuclide.

\section{Inhalation Module}

The inhalation module takes the air concentration calculated by the airflow module and multiplies it by the inhaled volume from the receptor module. This product is then multiplied by the appropriate inhalation DCF derived from FGR11. The results are presented in Table 2-28, where they are compared with the results calculated using RESRAD-BUILD.

Table 2-28. Verification of Inhalation Pathway Results

\begin{tabular}{lccc} 
& \multicolumn{2}{c}{ Dose (mrem) } & Ratio \\
Radionuclide & RESRAD-BUILD & SS Verification & RB/SSV \\
\hline H-3 Area & $8.46 \mathrm{E}-10$ & $5.64 \mathrm{E}-10$ & 1.50 \\
CO-60 Area & $1.79 \mathrm{E}-06$ & $1.78 \mathrm{E}-06$ & 1.00 \\
CO-60 Volume & $7.51 \mathrm{E}-07$ & $7.50 \mathrm{E}-07$ & 1.00 \\
SR-90 Area & $1.20 \mathrm{E}-05$ & $1.19 \mathrm{E}-05$ & 1.01 \\
SR-90 Volume & $5.03 \mathrm{E}-06$ & $5.02 \mathrm{E}-06$ & 1.00 \\
RA-226 Area & $8.06 \mathrm{E}-05$ & $8.06 \mathrm{E}-05$ & 1.00 \\
RA-226 Volume & $3.39 \mathrm{E}-05$ & $3.39 \mathrm{E}-05$ & 1.00 \\
CF-252 Area & $1.14 \mathrm{E}-03$ & $1.14 \mathrm{E}-03$ & 1.00 \\
CF-252 Volume & $4.78 \mathrm{E}-04$ & $4.78 \mathrm{E}-04$ & 1.00
\end{tabular}

With the exception of the tritium area source, the results of the verification calculations and RESRAD-BUILD were perfect matches for all radionuclides and source types. As stated in Appendix $G$ of the user's manual in the case of tritium, the code is increasing the inhalation dose by $50 \%$ to account for dermal absorption.

\subsubsection{Direct Ingestion Pathway}

Section E.1 of Appendix E of the user's manual provides a description of how the RESRADBUILD code calculates the dose from the ingestion of radionuclides directly from a source. Equation E.1 of the user's manual forms the basis for the verification of this pathway. Tests were conducted on the same radionuclides and source types described in Section 2.3.2. RESRADBUILD sums the contributions from the direct and indirect ingestion pathways. Therefore, the indirect ingestion rate was set to zero so that the summed contribution of direct and indirect ingestion doses would only contain the direct component. The direct ingestion pathway does not depend on the source injection rate and indoor air concentrations, since the receptor must be in direct contact with the source. However, verification of the direct ingestion dose requires some of the source parameters specified in the source injection module, which is described in Section 2.3.2. In addition to this module, verification of the direct ingestion pathway makes use of the ingestion module, which is described below. 


\section{Source Injection Module}

Two source types, area and volume, and their respective ingestion rates, were set up in the source injection module using the RESRAD-BUILD defaults. However, the default direct ingestion rates were changed from zero to $0.01 \mathrm{~g} / \mathrm{h}$ (this corresponds roughly to $100 \mathrm{mg} / \mathrm{day}$ ) for the volume sources and to $0.0001 / \mathrm{h}$ for the area sources. The source injection module is then used to calculate the total activity. In the case of an non-volume source, the amount available for ingestion also depends on the removable fraction for that source. There are no such limitation for a volume source, all of which is available for ingestion even if the erosion rate of the source is set to zero.

\section{Ingestion Module}

The ingestion module consists of three sections: one used to calculate direct ingestion, the second to calculate indirect ingestion, and the third to sum the dose contributions from these two pathways. The section of the ingestion module used to calculate the dose from the direct ingestion pathway receives input from the source injection module in the form of ingestion rate, activity/concentration, and the removable fraction (non-volume sources only). It also receives the same input from the receptor module (exposure-years) that was used for the submersion and deposition external gamma pathways. The dose is obtained from the product of the source inventory (for area source) or concentration (for volume source), the applicable direct ingestion rate, the exposure years, and the removable fraction (set to 1 for a volume source). The resulting activity ingested is then multiplied by the appropriate ingestion DCF derived from FGR11 to obtain the dose. The results are presented in Table 2-29, where they are compared with the results calculated using RESRAD-BUILD.

Table 2-29. Verification of Direct Ingestion Pathway Results

\begin{tabular}{lccc} 
& \multicolumn{2}{c}{ Dose (mrem) } & Ratio \\
Radionuclide & RESRAD-BUILD & SS Verification & RB/SSV \\
\hline H-3 Area & $5.05 \mathrm{E}-07$ & $5.05 \mathrm{E}-07$ & 1.00 \\
CO-60 Area & $2.12 \mathrm{E}-04$ & $2.12 \mathrm{E}-04$ & 1.00 \\
CO-60 Volume & $1.18 \mathrm{E}-03$ & $1.18 \mathrm{E}-03$ & 1.00 \\
SR-90 Area & $1.21 \mathrm{E}-03$ & $1.21 \mathrm{E}-03$ & 1.00 \\
SR-90 Volume & $6.70 \mathrm{E}-03$ & $6.71 \mathrm{E}-03$ & 1.00 \\
RA-226 Area & $1.05 \mathrm{E}-02$ & $1.05 \mathrm{E}-02$ & 1.00 \\
RA-226 Volume & $5.83 \mathrm{E}-02$ & $5.81 \mathrm{E}-02$ & 1.00 \\
CF-252 Area & $8.51 \mathrm{E}-03$ & $8.55 \mathrm{E}-03$ & 1.00 \\
CF-252 Volume & $4.73 \mathrm{E}-02$ & $4.75 \mathrm{E}-02$ & 1.00
\end{tabular}

In all cases, the results of the verification calculations and RESRAD-BUILD were perfect matches for all radionuclides and source types. Additional runs were made to support the verification of the uncertainty module using the direct ingestion pathway. These tests are described in Section 3.3. The direct ingestion pathway is therefore considered fully verified.

\subsubsection{Indirect Ingestion Pathway}

Section E. 2 of Appendix E of the user's manual provides a description of how the RESRADBUILD code calculates the dose from the ingestion of deposited radionuclides. Equation E. 3 of 
the user's manual forms the basis for the verification of this pathway. Tests were conducted on the same radionuclides and source types described in Section 2.3.2. The direct ingestion rate was reset to the default of zero so that the summed contribution of direct and indirect ingestion doses would only contain the indirect component. As with other pathways that originate with the release of particulates to room air, the indirect ingestion pathway depends on the source injection rate and indoor air concentrations, both of which were verified in Section 2.3.2. This pathway also requires the floor surface concentrations calculated with the deposition module, which is described in Section 2.3.3. In addition to these three modules, the spreadsheet verification for the indirect ingestion pathway makes use of variations to the receptor module and the ingestion module, which are discussed below.

\section{Receptor Module}

The receptor spreadsheet module incorporates the receptor-specific parameters in addition to the total exposure time and fraction indoors. Another receptor parameter that is used in the calculations of inhalation dose is the breathing rate. The module uses these parameters to calculate the volume of inhaled air during the time spent at the receptor locations. For the inhalation pathway, the total inhaled volume of air was based on the product of the default exposure duration (365 d), indoor fraction (0.5), receptor fraction (1), indirect ingestion rate $(0.0001 / \mathrm{h})$, and time conversion factor $(24 \mathrm{~h} / \mathrm{d})$ resulting in an ingested "area equivalent" of $0.438 \mathrm{~m}^{2}$. These results are independent of the radionuclide.

\section{Ingestion Module}

One section of the ingestion module is used to calculate the dose from the indirect ingestion pathway. The dose is obtained from the product of the floor concentration (see Table 2-22), the ingested area equivalent calculated by the receptor module, and the appropriate ingestion DCF derived from FGR11. The results are presented in Table 2-30, where they are compared with the results calculated using RESRAD-BUILD.

Table 2-30. Verification of Indirect Ingestion Pathway Results

\begin{tabular}{lccc} 
& \multicolumn{2}{c}{ Dose (mrem) } & Ratio \\
Radionuclide & RESRAD-BUILD & SS Verification & RB/SSV \\
\hline H-3 Area & $1.50 \mathrm{E}-09$ & $1.50 \mathrm{E}-09$ & 1.00 \\
CO-60 Area & $5.81 \mathrm{E}-07$ & $5.81 \mathrm{E}-07$ & 1.00 \\
CO-60 Volume & $2.44 \mathrm{E}-07$ & $2.44 \mathrm{E}-07$ & 1.00 \\
SR-90 Area & $3.72 \mathrm{E}-06$ & $3.72 \mathrm{E}-06$ & 1.00 \\
SR-90 Volume & $1.56 \mathrm{E}-06$ & $1.57 \mathrm{E}-06$ & 1.00 \\
RA-226 Area & $3.32 \mathrm{E}-05$ & $3.31 \mathrm{E}-05$ & 1.00 \\
RA-226 Volume & $1.40 \mathrm{E}-05$ & $1.39 \mathrm{E}-05$ & 1.01 \\
CF-252 Area & $2.05 \mathrm{E}-05$ & $2.06 \mathrm{E}-05$ & 1.00 \\
CF-252 Volume & $8.62 \mathrm{E}-06$ & $8.66 \mathrm{E}-06$ & 1.00
\end{tabular}

In all cases, the results of the verification calculations and RESRAD-BUILD were perfect matches for all radionuclides and source types. The indirect ingestion pathway uses the same floor concentrations as the deposition external gamma pathway. Therefore, verification of this pathway also verifies that the floor concentrations in RESRAD-BUILD are being calculated correctly and that these are not the source of the significant errors found in verifying the deposition external gamma pathway. 


\section{Time Dependency Verification}

The RESRAD-BUILD code allows the user to enter multiple time steps to calculate the doses at times beyond time zero. In addition, the code also allows the user to enter different values for the time integration parameters applied to the exposure duration. It is important to verify that the code is correctly implementing radioactive decay and ingrowth models. In some cases, mechanical erosion or removal also contributes to the reduction of the radioactive source over time. Verification of the time-dependent calculations was accomplished in three separate steps.

The first step addressed the ability of the code to calculate radioactive decay and ingrowth. A test was run to compare the results obtained by a standard radioactive decay and ingrowth calculator available on the Internet (WISE 2000) and a RESRAD-BUILD source containing one curie (3.7E10 Bq) each of Cf-252, Cm-243, Am-243, Pu-242, and Pu-241. Erosion and removal were set to zero to focus only on radioactive decay and ingrowth. Decay and ingrowth were calculated over 100 years. The results for each of these radionuclide series were within a $1 \%$ error range, probably due to round-off error, except for the Cf- 252 series. Here the results calculated after U236 differed due to an incorrect half-life value for U-236 in the decay calculator database, not RESRAD-BUILD. This test covered the majority of radionuclides in RESRAD-BUILD that are part of large decay chains, and therefore serves to validate the process by which RESRADBUILD calculates the decay and ingrowth of radionuclides in a source.

A second test was done to ensure that all radionuclides in the RESRAD-BUILD database decayed correctly according to the half-lives listed in the database files. For each radionuclide, the exposure times were set to the half-life of each radionuclide whenever such half-life was less than the RESRAD-BUILD limit of 100,000 years. At an exposure time of one half-life, the concentration is expected to be one half of the original value. If the half-life was greater than the RESRAD-BUILD time limit, the decay up to 100,000 years was calculated and compared to the corresponding decay using the standard decay equation and the appropriate half-life for these longer lived radionuclides. In all cases, the RESRAD-BUILD results were found to be in perfect agreement with the expected results.

A third test was done to assess the accuracy of the concentration averaging routine described in Appendix H of the user's manual. This routine is used by RESRAD-BUILD to calculate the integrated doses when the user selects more than one integration point; the default is set to 257 points. Five radionuclides were selected for this test, based on increasing half-live values: Au195, Co-60, Bi-207, Am-241, and C-14. A volume and an area source were set up for each radionuclide, and the exposure duration was set to equal the half-life. While this is not realistic for Am-241 and C-14, the purpose of this exercise was to determine the mathematical implementation of this routine. The volume source was made sufficiently thick so that there would be no significant erosion over the exposure duration. In addition, the removal fraction for the area sources was set to 1 , but the lifetime was set to twice the half-life. Thus, at the end of each radionuclide's exposure duration, there would be one half the source left due to radioactive decay. In the case of the area source, another half would be gone due to the removal function. The doses from two pathways were reviewed: the direct external gamma pathway and the inhalation pathway, since different mechanisms affect how much of the source contributes to the receptor dose.

A spreadsheet formula was set up to test the number of integration points. For the 1-point integration, there is no actual integration, but the doses are based on the concentrations present in the source at time zero. A second time step (set at the time of each radionuclide's half-life) was 
selected to verify that the source had indeed decayed and been removed correctly. The dose from the second time step was also used to verify that RESRAD-BUILD correctly averaged the concentration when using the 2-step integration formula. For the 3-, 5-, and 9-step integration, Simpson's rule was implemented in the spreadsheet and was used to verify the correct integration of the RESRAD-BUILD code over each exposure duration. It was found that the code needed no more than 9 time steps to achieve convergence, even when a separate test was done for Au-195 over 7 half-lives. In all cases, the RESRAD-BUILD results exactly matched the expected results calculated by the spreadsheet formulas for both external gamma and inhalation pathways.

These three tests positively verify that RESRAD-BUILD is correctly implementing the timedependent calculations.

\subsection{Multiple-Room Model Verification}

Section 2.2.3 of this report describes the verification of parameters used by RESRAD-BUILD in defining one-, two-, or three-room models used in the indoor air flow calculations. Although the one-room air flow model was verified in Section 2.3, some problems were encountered with certain parameter values that prevented a full verification of the two- and three-room models, including the inability to properly set some of the air flow parameter values to zero.

However, it was still possible to perform a limited verification of the full indoor air flow models by using non-zero air flow parameter values. The strategy used to verify the two- and threeroom air flow models was to create a building model with two or three rooms that yielded equivalent results to those already verified for the one room model. This was accomplished by setting up a two- or three-room model so that it would have the same air flow properties as the one room model as follows:

- In the two-room model, the floor area in each room was reduced to one half of the floor area in the one-room model; in the three-room model, the floor area in each room was reduced by one third. In this way, the building's total floor area was equivalent to the floor area of the one-room model.

- The air flows between each room and the outside air were reduced by one half and one third for the two- and three-room models, respectively. This resulted in an equivalent building air exchange rate for the one-, two-, and three-room models.

- The net air flows between rooms (in the two- and three-room models) were set to zero, but the magnitude of the air flows in the positive and negative directions were increased each time by a factor of ten. Setting increasingly higher inter-room air exchange rates relative to the air exchange rate with outdoor air results in a better approximation to the perfect mixing that is assumed to occur within each room.

Table 2-31 provides a comparison of the air concentrations calculated by RESRAD-BUILD for each room, starting with the default parameter values for the one-room model and extending these parameters to equivalent two- and three-room models. The RESRAD-BUILD results for air concentrations in each room are reported in the DIAG.OUT file following each run.

It is apparent from the results presented in Table 2-31 that RESRAD-BUILD correctly implements the multiple-room models for cases in which the air-flow rates are non-zero. The average concentrations in the two- and three-room models are equal to the concentration in the one-room model, as expected, for all indoor air flow rates. In addition, as the air flow rate between rooms is increased, the concentration in all rooms tends to approach, as expected, the 
concentration in the one-room model. Similar observations would result by progressively reducing the outdoor air flow rate while holding constant the air flow between rooms.

Table 2-31. Verification of Multiple-Room Model Results

\begin{tabular}{lcccccc} 
& $\begin{array}{c}\text { Floor } \\
\text { Area } \\
\left(\mathrm{m}^{2}\right)\end{array}$ & $\begin{array}{c}\text { Room } \\
\text { Height } \\
(\mathrm{m})\end{array}$ & \multicolumn{2}{c}{ Outdoor Air Flow $\left(\mathrm{m}^{3} / \mathrm{r}\right)$} & $\begin{array}{c}\text { Bldg. } \\
\text { Exch. } \\
\text { Mate }(/ \mathrm{h})\end{array}$ \\
\hline One Room & 36 & 2.5 & Room 1 & Room 2 & Room 3 & Rat \\
Two Rooms & 18 & 2.5 & 72 & N/A & N/A & 0.8 \\
Three Rooms & 12 & 2.5 & 36 & 36 & N/A & 0.8 \\
\hline
\end{tabular}

\begin{tabular}{|c|c|c|c|c|c|c|c|}
\hline \multirow[b]{2}{*}{ Model } & \multicolumn{2}{|c|}{$\begin{array}{l}\text { Indoor Air Flow } \\
\qquad\left(\mathrm{m}^{3} / \mathrm{h}\right)\end{array}$} & \multicolumn{4}{|c|}{ Concentration in Air $\left(\mathrm{pC} / \mathrm{m}^{3}\right)$} & \multirow{2}{*}{$\begin{array}{c}\text { Relative } \\
\text { One } \\
\text { Room }\end{array}$} \\
\hline & $\begin{array}{l}\text { Room 1- } \\
\text { Room } 2\end{array}$ & $\begin{array}{l}\text { Room 2- } \\
\text { Room } 3\end{array}$ & Room 1 & Room 2 & Room 3 & Average & \\
\hline \multicolumn{8}{|c|}{ One Room } \\
\hline & $N / A$ & $N / A$ & $1.04 \mathrm{E}-06$ & $N / A$ & N/A & $1.04 \mathrm{E}-06$ & 1.00 \\
\hline \multicolumn{8}{|c|}{ Two Rooms } \\
\hline & 10 & N/A & 1.75E-06 & $3.40 \mathrm{E}-07$ & N/A & $1.05 E-06$ & 1.00 \\
\hline & 100 & $\mathrm{~N} / \mathrm{A}$ & $1.22 \mathrm{E}-06$ & 8.66E-07 & N/A & 1.04E-06 & 1.00 \\
\hline & 1000 & $N / A$ & 1.07E-06 & $1.02 \mathrm{E}-06$ & N/A & $1.05 \mathrm{E}-06$ & 1.00 \\
\hline \multicolumn{8}{|c|}{ Three Rooms } \\
\hline & 10 & 10 & 2.44E-06 & 5.44E-07 & $1.45 \mathrm{E}-07$ & 1.04E-06 & 1.00 \\
\hline & 100 & 100 & $1.43 \mathrm{E}-06$ & 9.57E-07 & 7.50E-07 & 1.05E-06 & 1.01 \\
\hline & 1000 & 1000 & 1.09E-06 & 1.04E-06 & 1.01E-06 & 1.05E-06 & 1.0 \\
\hline
\end{tabular}

\subsection{Multiple Pathways, Receptors, Sources, Times Verification}

The final step in verifying the deterministic RESRAD-BUILD calculations was to compile as comprehensive a scenario as possible. By combining scenarios and results from previous steps into a single run, this verification task incorporated as many radionuclides, receptor locations, source types, and time steps as possible. The goal of this exercise was to verify that summations over pathways, receptors and sources are properly executed by the code.

In practice, this task was accomplished by copying the individual values (by source/receptor/pathway/radionuclide) generated in the RESRAD-BUILD output file. These were then be tabulated and summed across receptors and pathways and compared to the summed dose contributions reported in the RESRAD-BUILD output report.

A test file was created, starting with the default, by following these steps:

- Add 10 receptors (all located at the default coordinates)

- Add 10 sources (all located at the default coordinates)

- Add 8 times (3, 10, 30, 100, 300, 1000, 3000, and 10000 years)

- Change the first three sources to point, line, and area, respectively 
- Add 10 radionuclides to each of the first nine sources (a unit activity/concentration), going down the entire list of radionuclides and repeating as necessary once having reached the last in the list of 67 radionuclides;

- Make the last source a tritium volume source

- $\quad$ Set the number of rooms to 3

- Set the room number for the first three sources and receptors to correspond to the source and receptor number, and then start the sequence over again for each additional source/receptor pair (i.e., Source 1 and Receptor 1 in Room 1, Source 2 and Receptor 2 in Room 2, Source 3 and Receptor 3 in Room 3, Source 4 and Receptor 4 in Room 1, etc.)

- Set the number of points for integration to 3 (done in an effort to speed up the calculations)

The code ran at a reasonable pace for the first evaluation until it appeared to stop progressing once it started processing the $10^{\text {th }}$ source. This was the single tritium volume source, and it took more than twice as long to process this source as the first nine sources combined, each of which had 10 radionuclides each. Subsequent evaluation times followed this same pattern.

As expected, this case took a very long time to run (over one hour on a Pentium III running at 700 $\mathrm{MHz}$ ), and yielded a very large output file (223 pages). The results were compiled and copied onto a spreadsheet, focusing on the results tabulated in RESRAD-BUILD and labeled as:

1. Source Contributions to Receptor Doses (Receptor/Source Dose Matrix)

2. Pathway Detail of Doses (Receptor/Pathway Dose Matrix - 10 tables by source for each time)

3. Nuclide Detail of Doses (Nuclide/Receptor Dose Matrix - 10 tables by source for each time)

4. Receptor Doses Received for the Exposure Duration (Receptor/Exposure Duration - 1 table)

The first set of tables was verified for all times, including time zero, whereas the next two sets of tables were verified for time zero and at 100 and 10,000 years. Item 4 is the last table in RESRAD-BUILD and represents a grand total summary over time and receptors that was compared with the totals reported in the first set of tables.

In all cases, the ratios between the totals calculated and reported by RESRAD-BUILD corresponded to the totals calculated independently by summing up the individual dose components (by columns and rows) on the spreadsheet. Minor deviations from a ratio of 1.00 were attributed to simple rounding errors.

In reviewing the cases at times beyond time zero, it was noted that RESRAD-BUILD does not consistently implement the methodology for reporting zero doses in the Pathway and Nuclide Details tables. For example, at time 100 years, the tenth source (tritium volume source) is reported to result in a zero dose to all receptors, whereas at time 10,000 years this table is actually omitted from the output report without notice. Also, while many nuclides that were originally present (but have since decayed and contribute zero dose) are not even listed in some of the Nuclide Details tables, in many cases a zero dose is in fact listed for a radionuclide even when it is zero for all receptors.

A unrelated problem that did not ultimately affect the ability to run this case was encountered after ten receptors and ten sources were entered and an attempt was made to view the Shielding Parameters table. After clicking on the "View Table" button, the code returned the following error message before crashing:

Run-time error '7': Out of memory 


\section{Verification of Uncertainty Model}

The RESRAD-BUILD uncertainty model was verified in three steps. The first step focused the response of the code to inputs made during the parameter verification phase. The second step was to verify that the input data sets produced by the Latin hypercube sampling (LHS) routine corresponded to the specified statistical distributions. The third step verified the correct distribution of output results following uncertainty simulations.

\subsection{Verification of Parameter Inputs}

As noted in Section 2.2, many errors were found in attempting to verify the response of the uncertainty analysis module to different parameter input distributions. These responses are described in the following sections, organized by the parameter groupings as listed in Appendix $\mathbf{J}$ of the user's manual.

The verification of the parameter input distributions is an extension of the parameter verification for the deterministic portion of the code, and the detailed results were documented on the Input Parameter Verification Checklist forms generated for each parameter. Unless otherwise specified in each of the following sections, the settings for the sample specification were kept at the defaults used by RESRAD-BUILD, namely Latin Hypercube method using a random seed of 1000, with 100 observations and 3 repetitions, uncorrelated or correlated groupings, for a total of 300 iterations. Where indicated (e.g., in Section 3.1.2), the number of observations was reduced from 100 to 10 in order to speed up some of the calculations. This also had the effect of verifying that it was possible to correctly change this parameter.

\subsubsection{Time Parameters}

The time parameters eligible for uncertainty analysis include TTIME and FTIN. A uniform distribution was assigned to TTIME, since the code does not provide a default for that parameter. The default values for the continuous distribution were used for FTIN. In both cases, no problems were encountered running the uncertainty analysis module under normal parameter ranges. However, tests for out-of-bounds conditions resulted in errors.

In the case of TTIME, the code correctly rejects entries for a uniform distribution in which the Min and Max are equal or when the Min is greater than the Max (by using a pink background in the input fields). However, the code does not reject a range of parameters in which $50 \%$ of the sampled values will yield incorrect results (values ranging from -1 to 1 ). After completing the runs for all 300 sampled values, the MC output reports the following doses at time zero:

Statistics of Dose (mrem) Summed over Radionuclide

$\begin{array}{ll}\text { Statistic } & \text { CO-60 } \\ \text { Minimum } & * * * * * * * * \\ \text { Maximum } & 1.34 \mathrm{E}-02 \\ \text { Average } & * * * * * * * \\ \text { Std.Dev } & 7.79 \mathrm{E}-03\end{array}$




\section{Percentile Distribution Table}

$\begin{array}{cc}\text { Statistic } & \text { CO-60 } \\ 5 \% & 0.00 \mathrm{E}+00 \\ 10 \% & 0.00 \mathrm{E}+00 \\ 15 \% & 0.00 \mathrm{E}+00 \\ 20 \% & 0.00 \mathrm{E}+00 \\ 25 \% & 0.00 \mathrm{E}+00 \\ 30 \% & 0.00 \mathrm{E}+00 \\ 35 \% & 0.00 \mathrm{E}+00 \\ 40 \% & 0.00 \mathrm{E}+00 \\ 45 \% & 0.00 \mathrm{E}+00 \\ 50 \% & 2.80 \mathrm{E}-05 \\ 55 \% & 1.35 \mathrm{E}-03 \\ 60 \% & 2.84 \mathrm{E}-03 \\ 65 \% & 4.12 \mathrm{E}-03 \\ 70 \% & 5.43 \mathrm{E}-03 \\ 75 \% & 6.75 \mathrm{E}-03 \\ 80 \% & 8.11 \mathrm{E}-03 \\ 85 \% & 9.45 \mathrm{E}-03 \\ 90 \% & 1.08 \mathrm{E}-02 \\ 95 \% & 1.22 \mathrm{E}-02 \\ 100 \% & 1.34 \mathrm{E}-02\end{array}$

These results clearly indicate a problem with the range of input values from a uniform distribution ranging from -1 to 1 , but the code does not warn the user that half of the values are invalid entries.

For the parameter FTIN, the extremes of -1 and 2 used to test the uniform distribution are outside the normal bounds of 0 to 1 and correspond to the extreme values used in the deterministic test. The code does not reject this range of parameters, but presents a mathematically correct result. After completing the runs for all 300 sampled values, the MC output reports the following doses at time zero:

Statistics of Dose (mrem) Summed over Radionuclide

Statistic CO-60

Minimum $* * * * * * * *$

Maximum 1.84E +01

Average $4.61 \mathrm{E}+00$

Std.Dev 7.99E+00 
Percentile Distribution Table

$\begin{array}{cc}\text { Statistic } & \text { CO-60 } \\ 5 \% & 0.00 \mathrm{E}+00 \\ 10 \% & 0.00 \mathrm{E}+00 \\ 15 \% & 0.00 \mathrm{E}+00 \\ 20 \% & 0.00 \mathrm{E}+00 \\ 25 \% & 0.00 \mathrm{E}+00 \\ 30 \% & 0.00 \mathrm{E}+00 \\ 35 \% & 5.01 \mathrm{E}-01 \\ 40 \% & 1.91 \mathrm{E}+00 \\ 45 \% & 3.29 \mathrm{E}+00 \\ 50 \% & 4.64 \mathrm{E}+00 \\ 55 \% & 6.01 \mathrm{E}+00 \\ 60 \% & 7.53 \mathrm{E}+00 \\ 65 \% & 8.84 \mathrm{E}+00 \\ 70 \% & 1.02 \mathrm{E}+01 \\ 75 \% & 1.15 \mathrm{E}+01 \\ 80 \% & 1.29 \mathrm{E}+01 \\ 85 \% & 1.43 \mathrm{E}+01 \\ 90 \% & 1.57 \mathrm{E}+01 \\ 95 \% & 1.71 \mathrm{E}+01 \\ 100 \% & 1.84 \mathrm{E}+01\end{array}$

These results clearly indicate a problem with the range of input values from a uniform distribution ranging from -1 to 2 but again the code does not warn the user that two thirds of the values are invalid entries.

\subsubsection{Building Parameters}

The building parameters that are eligible for uncertainty analysis include UD, DKSUS, H, AREA, and LAMBDAT. In all cases, no problems were encountered running the uncertainty analysis module under normal parameter ranges and default distributions. However, several errors were encountered when changing the distribution ranges to go out of the normal parameter ranges and/or selecting an alternative distribution.

Out of bounds tests were not possible with the default loguniform distributions assigned to UD and DKSUS or the truncated lognormal-n distribution assigned to LAMBDAT because this type of distribution does not allow the input of negative numbers, and there are no upper limits imposed on these three parameters. Negative numbers, zero, or a minimum value greater than a maximum value, are not accepted and are highlighted in red to warn the user. This is the correct response by the code to entries for a loguniform distribution. However, the use of a non-default distribution, such as uniform distribution, allows the acceptance of negative input values. These resulted in spurious results similar to those reported in Section 3.1.1.

In the case of LAMBDAT, a truncated lognormal-n distribution was tested with: $\mathrm{Mu}=+/-1 \mathrm{E} 4$; Sigma $=-1,0$, or $1 E 4 ; \mathrm{LQ}=-1,0 ; \mathrm{UQ}=1 ; \mathrm{LQ}>\mathrm{UQ}$. A large negative or positive mean $(\mathrm{Mu})$ of the underlying normal is accepted (as is a large positive value of Sigma), and the code will execute the uncertainty module. However, the uncertainty results are meaningless. A large value 
of $\mathrm{Mu}$ and/or Sigma cause an error to be reported in the LHS.ERR file, but there is no warning to the user of such error. Entering any of the other values above for Sigma, LQ and UQ is not accepted and the incorrect inputs are highlighted in red to warn the user. This is the correct response by the code.

The default distribution for the two remaining parameters, $\mathrm{H}$ and AREA, is triangular. No problems were encountered running the default cases.

For $\mathrm{H}$, a series of out-of-bounds test was made using the triangular distribution with the following parameter values: $\operatorname{Min}=-2.5, \operatorname{Mode}=0, \operatorname{Max}=2.5 ; \operatorname{Min}>\operatorname{Max} ; \operatorname{Mode}>\operatorname{Max} ; \operatorname{Mode}<\operatorname{Min}$. The code accepts the inappropriate negative/zero values in the input parameter range and appears to run the uncertainty module until reaching the final iteration. At that point, the code crashes with the following message:

\section{Run-time error '55': File already open}

It was not possible to determine which file was open.

Attempting to enter a Min $>$ Max, Mode $>$ Max, and/or Mode $<$ Min is not accepted by the code and the incorrect inputs are highlighted in red to warn the user. This is the correct response by the code.

For AREA, the same series of out-of-bounds tests was performed, but this time the following parameter values were used: $\operatorname{Min}=-36, \operatorname{Mode}=0, \operatorname{Max}=36$. This resulted in the same response as was found with $\mathrm{H}$, indicating that this is problem common to these two parameters.

One more issue was uncovered that is not addressed in the user's manual. Selecting a value of 2 or 3 for NROOM appears to disable the uncertainty module for $\mathrm{H}$ and/or AREA. However, if the user had previously selected uncertainty analysis for the height of Room 1 in the 1-room model, this is retained in the 2- or 3-room models. While the code appears to excecute the uncertainty analysis on the Room 1 height correctly in the 2- and 3-room models, it may not be apparent to the user that only the Room 1 height is subject to the uncertainty analysis. The solution to this is to enable uncertainty analysis of this parameter in the 2- and 3-room model independently of the Room 1 parameter values.

\subsubsection{Receptor Parameters}

Only two receptor parameters, BRTRATE and INGE2, are eligible for uncertainty analysis, although it is recommended that this feature be extended to the DX and TWGHT parameters. For both eligible parameters, no problems were encountered running the uncertainty analysis module under the default case with normal parameter ranges and default distributions. However, several errors were encountered when changing the distribution ranges to go out of the normal parameter ranges and/or selecting an alternative distribution.

In the case of BRTRATE, the default triangular distribution range was change to: $\operatorname{Min}=-1$, Mode $=0, \operatorname{Max}=1$. The code accepts the inappropriate negative values in the input parameter range. After running 10 observations and 3 repetitions, the minimum and average inhalation doses were reported as $" * * * * * * * * "$ and all inhalation doses up to the 50th percentile are reported as zero. As expected from the deterministic run, no variation in the radon inhalation dose is reported, despite the inclusion of a Ra-226 volume source. 
In the case of INGE2, the default loguniform distribution did not allow testing of out-of-bound values. However, replacing this distribution with a uniform distribution, and setting the minimum to a negative number, results in spurious results similar to those previously described for the BRTRATE parameter.

With both parameters, there is a problem in the way the uncertainty analysis module handles the addition and removal of receptors. To illustrate the problem, the following test sequence was followed for BRTRATE:

- Select uncertainty analysis for Receptor 1 breathing rate

- Add a receptor

- Select uncertainty analysis for Receptor 2 breathing rate

- Click on Receptor 1 and remove, leaving only Receptor 2

- View "Uncertainty Analysis Input Summary" window

When one of two receptors is removed (in this case, Receptor 1), both Receptor 1 and 2 still appear to be set up for uncertainty analysis. The code apparently does not automatically remove the selected receptor breathing rate from the uncertainty input screen, even though that receptor (and all associated receptor parameters) has been removed from the deterministic input screen. In fact, the code runs the uncertainty module and reports the input parameters for both Receptor 1 and 2, but calculates the uncertainty statistics for the receptor that was removed in the deterministic run. That is, the distribution/parameters originally assigned to Receptor 1, which was subsequently removed, are used to calculate the uncertainty analysis for the remaining receptor - Receptor 2. The same observations apply to the INGE2 parameter.

\subsubsection{Source Parameters}

Several source parameters, including SAREA, AIRFR, INGE1, RMVFR, RF0, RRF, THICK0, DENSI0, EROS0, POROS0, EFDIF0, and EMANA0 are eligible for uncertainty analysis. In addition, it is recommended that SX and RNUCACT be made eligible for uncertainty analysis in future versions of the code.

For eligible parameters, no problems were encountered running the uncertainty analysis module under the default case with normal parameter ranges and default distributions. However, several errors were encountered when changing the distribution ranges to go out of the normal parameter ranges and/or selecting an alternative distribution.

In the case of SAREA, no default distribution is assigned, so a test was made with the default case using a uniform distribution and the following bounds: with $\operatorname{Min}=-36$, Max $=36$. The negative minimum bound appears to be accepted in the uncertainty module. However, no uncertainty output is generated, and the uncertainty run is interrupted with the following error message:

Cannot Open Error file "F77L3.EER", error \# 94

A similar problem is encountered with the parameter EFDIF0. 
In the case of AIRFR, the default distribution is triangular, with: Min $=0.000001$, Mode $=0.07$, $\operatorname{Max}=1$. There is no good reason why the minimum default air release fraction cannot be set to zero. Since this is not a logarithmic distribution, and the maximum default is set to one, 0.000001 is essentially equal to zero and will result in the same uncertainty statistics being generated.

When the upper and lower bounds of the triangular distribution for AIRFR are set to -1 and 2, both of which are outside the range of 0 to 1 , the following inhalation doses are reported for the default case at time zero:

$\begin{array}{lr}\text { Statistic } & \text { Inhalation } \\ \text { Minimum } & * * * * * * * * \\ \text { Maximum } & 1.20 \mathrm{E}-05 \\ \text { Average } & 4.47 \mathrm{E}-06 \\ \text { Std.Dev } & 4.30 \mathrm{E}-06\end{array}$

Percentile Distribution Table

$\begin{array}{cc}\text { Statistic } & \text { Inhalation } \\ 5 \% & 0.00 \mathrm{E}+00 \\ 10 \% & 0.00 \mathrm{E}+00 \\ 15 \% & 0.00 \mathrm{E}+00 \\ 20 \% & 1.57 \mathrm{E}-07 \\ 25 \% & 8.38 \mathrm{E}-07 \\ 30 \% & 1.69 \mathrm{E}-06 \\ 35 \% & 2.73 \mathrm{E}-06 \\ 40 \% & 4.19 \mathrm{E}-06 \\ 45 \% & 4.20 \mathrm{E}-06 \\ 50 \% & 5.56 \mathrm{E}-06 \\ 55 \% & 5.61 \mathrm{E}-06 \\ 60 \% & 6.44 \mathrm{E}-06 \\ 65 \% & 6.63 \mathrm{E}-06 \\ 70 \% & 7.56 \mathrm{E}-06 \\ 75 \% & 7.65 \mathrm{E}-06 \\ 80 \% & 8.80 \mathrm{E}-06 \\ 85 \% & 9.13 \mathrm{E}-06 \\ 90 \% & 1.05 \mathrm{E}-05 \\ 95 \% & 1.09 \mathrm{E}-05 \\ 100 \% & 1.20 \mathrm{E}-05\end{array}$

The maximum inhalation dose reported above is almost twice as high as the maximum inhalation dose of 7.04E-06 calculated when the air release fraction is set to the upper bound of 1 . While the above results are mathematically correct, they are invalid since air release fractions of -1 and 2 are not meaningful. Similarly spurious results were obtained when entering out-of-bound ranges for INGE1, RMVFR, RF0, RRF, THICK0, DENSI0, EROS0, POROS0, and EMANA0.

The label for AIRFR in the "Uncertainty Analysis Input Summary" window is "Air fraction of i", where $i$ is the number of the source. The proper name for the parameter should be "Air release fraction" and the word "source" should follow the word "of". A more appropriate label would be "Air release fraction of source i". Similarly, the word "source" is missing in the label for all other source parameters eligible for uncertainty analysis. 
The label for RF0 in the "Uncertainty Analysis Input Summary" window is "Release time of i", where $i$ is the number of the source. The word "source" should follow the word "of". Also, the term "release time" is inconsistent with other names used for this parameter. The Help File uses the term "time of source removal" and the input field name for this parameter is "lifetime". This inconsistent terminology should be resolved. In the interest of brevity, it is recommended that the term "lifetime" be used in both the help and the uncertainty modules. A more appropriate label in the uncertainty summary for this parameter would therefore be "Lifetime of source $i$ ".

There is a general problem in how the uncertainty analysis module handles adding and removing sources. This is similar to the problem that was encountered with the addition and removal of receptors, discussed in the previous section. The following test sequence was followed starting with the default case, and using SAREA as an example:

- Select uncertainty analysis for Source 1 area

- Select Uniform distribution with $\operatorname{Min}=1$ and $\operatorname{Max}=2$

- Add a source

- Select uncertainty analysis for Source 2 area

- Select Uniform distribution with $\mathrm{Min}=2$ and $\mathrm{Max}=3$

- Add a source

- Select uncertainty analysis for Source 3 area

- Select Uniform distribution with $\operatorname{Min}=0$ and $\operatorname{Max}=1$

- Click on Source 2 and remove that source, leaving only Source 1 and 3

- View "Uncertainty Analysis Input Summary" window

When one of three sources is removed (in this case, Source 2), the area for Source 2 still appears to be set up for uncertainty analysis. The code does not automatically remove this source parameter from the uncertainty input screen, even though that source (and all associated source parameters) has been removed from the deterministic input screen. In fact, the code runs the uncertainty module and reports the uncertainty input parameters for the Source1, Source 2, and Source 3 area. However, the uncertainty statistics indicate that the doses from Source 3 (renumbered and identified as Source 2 in the output) are higher than the doses from Source 1. This can be very confusing, because the code is using the uncertainty input parameters for the area of the deleted source (formerly Source 2) instead of those for Source 3 (now renumbered as Source 2). The uncertainty input parameters for Source 3 are smaller than those for Source 1, so the dose from Source 3 should be lower, not higher.

Problems similar to the one reported above were encountered with AIRFR, INGE1, RMVFR, RF0, RRF, THICK0, DENSI0, EROS0, POROS0, EFDIF0, and EMANA0.

Another general problem occurs when changing from a non-volume source and to a volume source. To describe this problem, the following test sequence is followed starting with the default case, using RMVFR as an example:

- Change the source type to Area

- Select uncertainty analysis for Source 1 removable fraction

- Keep the default values for the triangular distribution

- Change the source type back to Volume

- View "Uncertainty Analysis Input Summary" window 
When a source is changed from a non-volume source to a volume source, the removable fraction is no longer available for the deterministic calculation. However, this parameter is not automatically removed from the uncertainty module. Even though this parameter is no longer used, the code will execute the uncertainty module. As expected, the results indicate no change in the receptor dose from all pathways.

Problems similar to the one reported above were encountered with RF0 and RRF, since they are also only available for non-volume sources.

A related problem occurs when switching from volume to non-volume sources for parameters only available in volume sources. To describe this problem, the following test sequence is followed starting with the default case, using THICK0 as an example:

- Select uncertainty analysis for Source 1 thickness

- Keep the default values for the triangular distribution

- Change the source type to Area

- View "Uncertainty Analysis Input Summary" window

When a source is changed from a volume source to a non-volume source, the source thickness is no longer available for the deterministic calculation. However, this parameter is not automatically removed from the uncertainty module. Even though this parameter is no longer used, the code will execute the uncertainty module. As expected, the results indicate no change in the receptor dose from all pathways.

Problems similar to the one reported above were encountered with THICK0, DENSI0, EROS0, POROS0, EFDIF0, and EMANA0.

One general problem was found to affect only the radon-specific volume source parameters POROS0 and EFDIF0, and EMANA0. This problem arises when one or more of these parameters is selected for uncertainty analysis and all radon precursors are subsequently removed from that source. The response of the code is similar to the case where a source is changed from volume to area.

The last general problem arises when multiple regions of a volume source are selected for uncertainty analysis, and the number of regions in that volume source is later reduced. The reduction in the number of regions does not automatically delete the uncertainty analysis for the multi-region volume source parameters of any regions that have been removed by such action. This problem was encountered with THICK0, DENSI0, EROS0, POROS0, EFDIF0, and EMANA0.

\subsubsection{Shielding Parameters}

Two shielding parameters, DSTH and DSDEN, are eligible for uncertainty analysis. For these parameters, no problems were encountered running the uncertainty analysis module under the default case with normal parameter ranges and default distributions. However, several errors were encountered when the distribution range exceeds the parameter bounds.

In the case of DSTH, as was the case for the deterministic test for negative shielding thickness, the code accepted and ran the uncertainty analysis with a distribution containing negative shielding thicknesses. While the deterministic run with a negative thickness resulted in error messages, the uncertainty run did not. In fact, the code calculated a maximum direct external 
dose at time zero that was greater than the dose without shielding, which is physically impossible. It appears that a negative shielding thickness produces the opposite effect of a positive shielding thickness.

In the case of DSDEN, as was the case for the deterministic test for negative shielding density, the code accepted and ran the uncertainty analysis with a distribution containing negative shielding densities. However, in this case, no uncertainty output was generated because the uncertainty run is interrupted with the following error message:

\section{Cannot Open Error file "F77L3.EER", error \# 94}

There is a problem in the uncertainty analysis module when more than one shield is selected between multiple receptors and/or sources. The following test sequence was followed, using DSTH as an example:

- Select uncertainty analysis for Receptor $1 /$ Source 1 shielding thickness

- Add a receptor

- Select uncertainty analysis for Receptor 2/Source 1 shielding thickness

- Add a source

- Select uncertainty analysis for Receptor $2 /$ Source 2 shielding thickness

- Click on Receptor 1 and remove that receptor, leaving only Receptor 2

- View "Uncertainty Analysis Input Summary" window

When one of two receptors is removed (in this case, Receptor 1), the shielding between Receptor 1 and Source 1 still appears to be set up for uncertainty analysis. The code apparently does not automatically remove the shielding thickness between Receptor 1 and any of the sources from the uncertainty input screen, even though that receptor (and all associated receptor parameters) has been removed from the deterministic input screen. In fact, the code runs the uncertainty module and reports the input parameters for Receptor 1/Source1, Receptor 2/Source 1, and Receptor 2/Source 2 shielding thickness. However the uncertainty statistics show no variation in the direct external dose to Receptor 2 (re-numbered and identified as Receptor 1 in the output) from Source 2, even though the distribution of shielding thicknesses should result in a range of direct external doses.

A similar problem occurs when one or more sources are removed. The above problem also applies to the uncertainty analysis for DSTH.

\subsubsection{Tritium Model Parameters}

The user's manual for one of the tritium model parameters, DRYTHICK, does not indicate whether this parameter is eligible for uncertainty analysis, and does not indicate any default distribution. However, the code allows uncertainty analysis on this and all the other tritium model parameters H3THICK, H3VOLFRACT, H3RMVF, and HUMIDITY. In addition, uncertainty analysis is enabled for two other tritium model parameters, H3POROSITY and WALL_DENSITY, which are not listed Appendix J of the user's manual.

For these parameters, no problems were encountered running the uncertainty analysis module under the default case with normal parameter ranges and default distributions, except for H3VOLFRACT, where the default uncertainty range overlaps the default value for 
H3POROSITY. In addition, several errors were encountered when the distribution range exceeds the parameter bounds or conflicts with other correlated parameters.

DRYTHICK and H3THICK are correlated and in the deterministic model, DRYTHICK cannot exceed H3THICK, or an error message will result. Therefore, the following test was conducted to determine how the code responded when the range of one or the other parameter violated this condition. The distribution for DRYTHICK was set as follows in two cases:

- Uniform with $\operatorname{Min}=5, \operatorname{Max}=15$, and Wet+Dry zone thickness = 10;

- Uniform with Min $=-10, \operatorname{Max}=10$, and Wet + Dry zone thickness $=10$

In the first test, the Dry zone thickness is greater than the Wet+Dry zone thickness in one out of two samples, resulting in the following output at time zero:

$$
\begin{array}{ll}
\text { Statistic } & \mathrm{H}-3 \\
\text { Minimum } & 0.00 \mathrm{E}+00 \\
\text { Maximum } & 5.31 \mathrm{E}-03 \\
\text { Average } & 1.51 \mathrm{E}-03 \\
\text { Std.Dev } & 1.85 \mathrm{E}-03
\end{array}
$$

Percentile Distribution Table

$$
\begin{array}{cc}
\text { Statistic } & \text { H-3 } \\
5 \% & 0.00 \mathrm{E}+00 \\
10 \% & 0.00 \mathrm{E}+00 \\
15 \% & 0.00 \mathrm{E}+00 \\
20 \% & 0.00 \mathrm{E}+00 \\
25 \% & 0.00 \mathrm{E}+00 \\
30 \% & 0.00 \mathrm{E}+00 \\
35 \% & 0.00 \mathrm{E}+00 \\
40 \% & 0.00 \mathrm{E}+00 \\
45 \% & 0.00 \mathrm{E}+00 \\
50 \% & 4.35 \mathrm{E}-04 \\
55 \% & 8.55 \mathrm{E}-04 \\
60 \% & 2.01 \mathrm{E}-03 \\
65 \% & 2.03 \mathrm{E}-03 \\
70 \% & 2.75 \mathrm{E}-03 \\
75 \% & 3.29 \mathrm{E}-03 \\
80 \% & 3.68 \mathrm{E}-03 \\
85 \% & 4.18 \mathrm{E}-03 \\
90 \% & 4.77 \mathrm{E}-03 \\
95 \% & 5.01 \mathrm{E}-03 \\
100 \% & 5.31 \mathrm{E}-03
\end{array}
$$

In the second test, the Dry zone thickness is negative in one out of two samples, resulting in the following output at time zero:
Statistic H-3
Minimum 6.45E-04
Maximum 9.55E-03
Average 5.44E-03
Std.Dev 2.93E-03 
Percentile Distribution Table

$\begin{array}{cc}\text { Statistic } & \text { H-3 } \\ 5 \% & 6.65 \mathrm{E}-04 \\ 10 \% & 1.25 \mathrm{E}-03 \\ 15 \% & 1.73 \mathrm{E}-03 \\ 20 \% & 1.97 \mathrm{E}-03 \\ 25 \% & 2.92 \mathrm{E}-03 \\ 30 \% & 3.02 \mathrm{E}-03 \\ 35 \% & 3.93 \mathrm{E}-03 \\ 40 \% & 4.68 \mathrm{E}-03 \\ 45 \% & 4.70 \mathrm{E}-03 \\ 50 \% & 5.77 \mathrm{E}-03 \\ 55 \% & 6.25 \mathrm{E}-03 \\ 60 \% & 6.77 \mathrm{E}-03 \\ 65 \% & 7.18 \mathrm{E}-03 \\ 70 \% & 7.56 \mathrm{E}-03 \\ 75 \% & 8.22 \mathrm{E}-03 \\ 80 \% & 9.10 \mathrm{E}-03 \\ 85 \% & 9.11 \mathrm{E}-03 \\ 90 \% & 9.51 \mathrm{E}-03 \\ 95 \% & 9.52 \mathrm{E}-03 \\ 100 \% & 9.55 \mathrm{E}-03\end{array}$

This result is statistically identical to the results from the "Reasonable Values Test" (i.e., uniform distribution ranging from 0 to 10 ), which are reported below:

$\begin{array}{ll}\text { Statistic } & \text { H-3 } \\ \text { Minimum } & 3.33 \mathrm{E}-04 \\ \text { Maximum } & 9.64 \mathrm{E}-03 \\ \text { Average } & 5.61 \mathrm{E}-03 \\ \text { Std.Dev } & 2.99 \mathrm{E}-03\end{array}$

Percentile Distribution Table

Statistic H-3

$5 \% \quad 7.68 \mathrm{E}-04$

$10 \% \quad 9.85 \mathrm{E}-04$

$15 \% \quad 1.86 \mathrm{E}-03$

$20 \% \quad 2.12 \mathrm{E}-03$

$25 \% \quad 3.14 \mathrm{E}-03$

$30 \% \quad 3.23 \mathrm{E}-03$

$35 \% \quad 4.19 \mathrm{E}-03$

$40 \% \quad 5.05 \mathrm{E}-03$

$45 \% \quad 5.20 \mathrm{E}-03$

$50 \% \quad 6.05 \mathrm{E}-03$

$55 \% \quad 6.46 \mathrm{E}-03$

$60 \% \quad 7.56 \mathrm{E}-03$

$65 \% \quad 7.58 \mathrm{E}-03$

$70 \% \quad 8.22 \mathrm{E}-03$ 
Percentile Distribution Table (cont'd)

Statistic H-3

$75 \% \quad 8.66 \mathrm{E}-03$

$80 \% \quad 8.94 \mathrm{E}-03$

$85 \% \quad 9.25 \mathrm{E}-03$

$90 \% \quad 9.52 \mathrm{E}-03$

$95 \% \quad 9.59 \mathrm{E}-03$

$100 \% \quad 9.64 \mathrm{E}-03$

The code apparently converted negative values of the Dry zone thickness to positive values. Similar problems were encountered when focusing on H3THICK using two test cases with the following distributions for H3THICK:

- Uniform with $\operatorname{Min}=5, \operatorname{Max}=30$, and Dry zone thickness = 10;

- Uniform with Min = -20, Max $=10$, and Dry zone thickness $=0$

In the first test, the Wet+Dry zone thickness is less than the Dry zone thickness in one out of five samples, resulting in the following output at time zero:

$\begin{array}{ll}\text { Statistic } & \mathrm{H}-3 \\ \text { Minimum } & 0.00 \mathrm{E}+00 \\ \text { Maximum } & 9.36 \mathrm{E}-03 \\ \text { Average } & 5.73 \mathrm{E}-03 \\ \text { Std.Dev } & 4.05 \mathrm{E}-03\end{array}$

Percentile Distribution Table

Statistic H-3

$5 \% \quad 0.00 \mathrm{E}+00$

$10 \% \quad 0.00 \mathrm{E}+00$

$15 \% \quad 0.00 \mathrm{E}+00$

$20 \% \quad 0.00 \mathrm{E}+00$

$25 \% \quad 2.47 \mathrm{E}-04$

$30 \% \quad 1.60 \mathrm{E}-03$

$35 \% \quad 3.40 \mathrm{E}-03$

$40 \% \quad 6.26 \mathrm{E}-03$

$45 \% \quad 6.27 \mathrm{E}-03$

$50 \% \quad 9.24 \mathrm{E}-03$

$55 \% \quad 9.36 \mathrm{E}-03$

$60 \% \quad 9.36 \mathrm{E}-03$

$65 \% \quad 9.36 \mathrm{E}-03$

$70 \% \quad 9.36 \mathrm{E}-03$

$75 \% \quad 9.36 \mathrm{E}-03$

$80 \% \quad 9.36 \mathrm{E}-03$

$85 \% \quad 9.36 \mathrm{E}-03$

$90 \% \quad 9.36 \mathrm{E}-03$

$95 \% \quad 9.36 \mathrm{E}-03$

$100 \% \quad 9.36 \mathrm{E}-03$ 
In the second test, the Wet+Dry zone thickness is negative in two out of three samples (with 15 observations), resulting in the following output at time zero:

$\begin{array}{ll}\text { Statistic } & \mathrm{H}-3 \\ \text { Minimum } & 1.24 \mathrm{E}-04 \\ \text { Maximum } & 1.48 \mathrm{E}-02 \\ \text { Average } & 7.76 \mathrm{E}-03 \\ \text { Std.Dev } & 4.69 \mathrm{E}-03\end{array}$

Percentile Distribution Table

$\begin{array}{cc}\text { Statistic } & \text { H-3 } \\ 5 \% & 5.72 \mathrm{E}-04 \\ 10 \% & 1.40 \mathrm{E}-03 \\ 15 \% & 3.05 \mathrm{E}-03 \\ 20 \% & 3.37 \mathrm{E}-03 \\ 25 \% & 3.66 \mathrm{E}-03 \\ 30 \% & 4.19 \mathrm{E}-03 \\ 35 \% & 5.13 \mathrm{E}-03 \\ 40 \% & 6.51 \mathrm{E}-03 \\ 45 \% & 6.70 \mathrm{E}-03 \\ 50 \% & 7.02 \mathrm{E}-03 \\ 55 \% & 8.21 \mathrm{E}-03 \\ 60 \% & 8.91 \mathrm{E}-03 \\ 65 \% & 9.21 \mathrm{E}-03 \\ 70 \% & 1.02 \mathrm{E}-02 \\ 75 \% & 1.16 \mathrm{E}-02 \\ 80 \% & 1.35 \mathrm{E}-02 \\ 85 \% & 1.48 \mathrm{E}-02 \\ 90 \% & 1.48 \mathrm{E}-02 \\ 95 \% & 1.48 \mathrm{E}-02 \\ 100 \% & 1.48 \mathrm{E}-02\end{array}$

The maximum dose is greater than the dose from the deterministic run (9.66E-03 mrem). The code appears to be converting negative values to positive values, since the deterministic dose for a 20 -cm Wet+Dry zone thickness is $1.48 \mathrm{E}-02$ mrem.

This hypothesis was tested by selecting a "Uniform*" distribution with 10 observations in the interval from 0 to 10 (equivalent to the range -10 to 10), and 5 observations in the interval from 10 to 20 (equivalent to the range from -20 to -10 ). This results in the following output at time zero:

$\begin{array}{ll}\text { Statistic } & \text { H-3 } \\ \text { Minimum } & 5.49 \mathrm{E}-04 \\ \text { Maximum } & 1.48 \mathrm{E}-02 \\ \text { Average } & 7.65 \mathrm{E}-03 \\ \text { Std.Dev } & 4.68 \mathrm{E}-03\end{array}$




\begin{tabular}{|c|c|}
\hline Statistic & H-3 \\
\hline $5 \%$ & $8.06 \mathrm{E}-04$ \\
\hline $10 \%$ & $1.63 \mathrm{E}-03$ \\
\hline $15 \%$ & $2.03 \mathrm{E}-03$ \\
\hline $20 \%$ & $2.89 \mathrm{E}-03$ \\
\hline $25 \%$ & $3.85 \mathrm{E}-03$ \\
\hline $30 \%$ & $4.57 \mathrm{E}-03$ \\
\hline $35 \%$ & $5.10 \mathrm{E}-03$ \\
\hline $40 \%$ & $5.94 \mathrm{E}-03$ \\
\hline $45 \%$ & $6.42 \mathrm{E}-03$ \\
\hline $50 \%$ & $7.04 \mathrm{H}$ \\
\hline $55 \%$ & $7.88 \mathrm{E}-03$ \\
\hline $60 \%$ & $8.72 \mathrm{E}-03$ \\
\hline $65 \%$ & $9.39 \mathrm{E}-03$ \\
\hline $70 \%$ & $1.02 \mathrm{E}-02$ \\
\hline $75 \%$ & $1.26 \mathrm{E}-02$ \\
\hline $80 \%$ & $1.34 \mathrm{E}-02$ \\
\hline $85 \%$ & $1.46 \mathrm{E}-02$ \\
\hline $90 \%$ & $1.48 \mathrm{E}-02$ \\
\hline $95 \%$ & $1.48 \mathrm{E}-02$ \\
\hline $100 \%$ & $1.48 \mathrm{E}-02$ \\
\hline
\end{tabular}

This distribution of results is statistically equivalent to that obtained in the second test.

Therefore, it is verified that the code uses the absolute value of negative thickness numbers.

In the case of H3VOLFRACT, the default distribution (uniform from 0.04 to 0.25 ) has been selected so that a sampled value will always exceed the default volumetric water content $(0.03)$. In addition, the sampled value will exceed the default porosity value $(0.1)$ more than $50 \%$ of the time, which is in conflict with the requirement that the volumetric water content be less than or equal to the porosity. Coincidentally, the default distribution for the volumetric water content is the same as the default distribution used for the porosity. A better default distribution of values for the volumetric water content would be $\operatorname{Min}=0$ and $\operatorname{Max}=0.1$.

Two test cases were run for H3VOLFRACT:

- Uniform with $\operatorname{Min}=0, \operatorname{Max}=2$;

- Uniform with $\operatorname{Min}=-1, \operatorname{Max}=0$

In the first test, one out of two sampled values of the volumetric water content exceeds the upper bound, resulting in the following output at time zero:

Statistic $\quad \mathrm{H}-3$

Minimum 3.29E-03

Maximum 9.69E-03

Average $\quad 4.28 \mathrm{E}-03$

Std.Dev 1.50E-03 
Percentile Distribution Table

Statistic H-3

$5 \% \quad 3.30 \mathrm{E}-03$

$10 \% \quad 3.30 \mathrm{E}-03$

$15 \% \quad 3.32 \mathrm{E}-03$

$20 \% \quad 3.33 \mathrm{E}-03$

$25 \% \quad 3.38 \mathrm{E}-03$

$30 \% \quad 3.38 \mathrm{E}-03$

$35 \% \quad 3.44 \mathrm{E}-03$

$40 \% \quad 3.52 \mathrm{E}-03$

$45 \% \quad 3.54 \mathrm{E}-03$

$50 \% \quad 3.65 \mathrm{E}-03$

$55 \% \quad 3.72 \mathrm{E}-03$

$60 \% \quad 4.00 \mathrm{E}-03$

$65 \% \quad 4.01 \mathrm{E}-03$

$70 \% \quad 4.29 \mathrm{E}-03$

$75 \% \quad 4.60 \mathrm{E}-03$

$80 \% \quad 4.91 \mathrm{E}-03$

$85 \% \quad 5.51 \mathrm{E}-03$

$90 \% \quad 6.90 \mathrm{E}-03$

$95 \% \quad 7.96 \mathrm{E}-03$

$100 \% \quad 9.69 \mathrm{E}-03$

Half of the doses are less than the minimum dose (3.59E-03 mrem) calculated using a volumetric water content of 1 . Since the dose is inversely proportional to this parameter, it appears that the code is using the higher values in a mathematically correct manner, but inconsistent with the parameter definition.

In the second test, the use of a negative volumetric water content causes the code to issue the following error message:

Cannot Open Error file "F77L3.EER", error \# 94

Similar problems were encountered when applying the same two tests to the parameter H3POROSITY, but with a slight variation in the results from the first test.

In the first test, one out of two sampled values of the porosity exceeds the upper bound, resulting in the following output at time zero:

Statistic $\quad \mathrm{H}-3$

Minimum 9.57E-03

Maximum 9.75E-03

Average $\quad 9.74 \mathrm{E}-03$

Std.Dev 3.54E-05 
Percentile Distribution Table

$\begin{array}{cc}\text { Statistic } & \text { H-3 } \\ 5 \% & 9.68 \mathrm{E}-03 \\ 10 \% & 9.70 \mathrm{E}-03 \\ 15 \% & 9.73 \mathrm{E}-03 \\ 20 \% & 9.74 \mathrm{E}-03 \\ 25 \% & 9.74 \mathrm{E}-03 \\ 30 \% & 9.74 \mathrm{E}-03 \\ 35 \% & 9.75 \mathrm{E}-03 \\ 40 \% & 9.75 \mathrm{E}-03 \\ 45 \% & 9.75 \mathrm{E}-03 \\ 50 \% & 9.75 \mathrm{E}-03 \\ 55 \% & 9.75 \mathrm{E}-03 \\ 60 \% & 9.75 \mathrm{E}-03 \\ 65 \% & 9.75 \mathrm{E}-03 \\ 70 \% & 9.75 \mathrm{E}-03 \\ 75 \% & 9.75 \mathrm{E}-03 \\ 80 \% & 9.75 \mathrm{E}-03 \\ 85 \% & 9.75 \mathrm{E}-03 \\ 90 \% & 9.75 \mathrm{E}-03 \\ 95 \% & 9.75 \mathrm{E}-03 \\ 100 \% & 9.75 \mathrm{E}-03\end{array}$

Since the dose approaches a maximum value of 9.75E-3 before the maximum porosity of 1 is reached, it appears that the code is using the higher values in a mathematically correct manner, but inconsistent with the parameter definition.

As with the previous two parameters, similar problems were encountered when applying the same two tests to the parameter H3RMVF, but with a slight variation in the results, as follows.

In the first test, one out of two sampled values of the fraction available for vaporization exceeds the upper bound, resulting in the following output at time zero:

$\begin{array}{ll}\text { Statistic } & \text { H-3 } \\ \text { Minimum } & 5.55 \mathrm{E}-04 \\ \text { Maximum } & 1.86 \mathrm{E}-02 \\ \text { Average } & 9.34 \mathrm{E}-03 \\ \text { Std.Dev } & 5.51 \mathrm{E}-03\end{array}$

Percentile Distribution Table

$\begin{array}{cc}\text { Statistic } & \text { H-3 } \\ 5 \% & 1.08 \mathrm{E}-03 \\ 10 \% & 1.49 \mathrm{E}-03 \\ 15 \% & 2.52 \mathrm{E}-03 \\ 20 \% & 3.39 \mathrm{E}-03 \\ 25 \% & 4.06 \mathrm{E}-03 \\ 30 \% & 4.98 \mathrm{E}-03 \\ 35 \% & 6.22 \mathrm{E}-03 \\ 40 \% & 8.21 \mathrm{E}-03 \\ 45 \% & 8.22 \mathrm{E}-03\end{array}$


Percentile Distribution Table (cont'd)

$\begin{array}{cc}\text { Statistic } & \text { H-3 } \\ 50 \% & 1.03 \mathrm{E}-02 \\ 55 \% & 1.04 \mathrm{E}-02 \\ 60 \% & 1.18 \mathrm{E}-02 \\ 65 \% & 1.21 \mathrm{E}-02 \\ 70 \% & 1.37 \mathrm{E}-02 \\ 75 \% & 1.39 \mathrm{E}-02 \\ 80 \% & 1.56 \mathrm{E}-02 \\ 85 \% & 1.60 \mathrm{E}-02 \\ 90 \% & 1.75 \mathrm{E}-02 \\ 95 \% & 1.79 \mathrm{E}-02 \\ 100 \% & 1.86 \mathrm{E}-02\end{array}$

Half of the doses are greater than the maximum dose (9.66E-03 mrem) calculated using the default evaporable water fraction of 1 . Since the dose is proportional to this parameter, it appears that the code is using the higher values in a mathematically correct manner, but inconsistent with the parameter definition. Note: after 1 year (when all the evaporable water has been removed), the doses are all from the particulate air pathway, and are summarized below:

$\begin{array}{ll}\text { Statistic } & \mathrm{H}-3 \\ \text { Minimum } & * * * * * * * * \\ \text { Maximum } & 8.55 \mathrm{E}-10 \\ \text { Average } & 2.79 \mathrm{E}-11 \\ \text { Std.Dev } & 5.21 \mathrm{E}-10\end{array}$

Percentile Distribution Table

$\begin{array}{cc}\text { Statistic } & \text { H-3 } \\ 5 \% & 0.00 \mathrm{E}+00 \\ 10 \% & 0.00 \mathrm{E}+00 \\ 15 \% & 0.00 \mathrm{E}+00 \\ 20 \% & 0.00 \mathrm{E}+00 \\ 25 \% & 0.00 \mathrm{E}+00 \\ 30 \% & 0.00 \mathrm{E}+00 \\ 35 \% & 0.00 \mathrm{E}+00 \\ 40 \% & 0.00 \mathrm{E}+00 \\ 45 \% & 0.00 \mathrm{E}+00 \\ 50 \% & 6.96 \mathrm{E}-11 \\ 55 \% & 1.37 \mathrm{E}-10 \\ 60 \% & 3.22 \mathrm{E}-10 \\ 65 \% & 3.25 \mathrm{E}-10 \\ 70 \% & 4.42 \mathrm{E}-10 \\ 75 \% & 5.28 \mathrm{E}-10 \\ 80 \% & 5.91 \mathrm{E}-10 \\ 85 \% & 6.72 \mathrm{E}-10 \\ 90 \% & 7.68 \mathrm{E}-10 \\ 95 \% & 8.06 \mathrm{E}-10 \\ 100 \% & 8.55 \mathrm{E}-10\end{array}$


In the second test, the use of a negative evaporable water fraction results in no doses from evaporation at time zero. The doses from particulate releases after one year are reported below (for comparison with the previous output):

$\begin{array}{ll}\text { Statistic } & \mathrm{H}-3 \\ \text { Minimum } & 9.33 \mathrm{E}-10 \\ \text { Maximum } & 1.79 \mathrm{E}-09 \\ \text { Average } & 1.37 \mathrm{E}-09 \\ \text { Std.Dev } & 2.60 \mathrm{E}-10\end{array}$

Percentile Distribution Table

$\begin{array}{cc}\text { Statistic } & \text { H-3 } \\ 5 \% & 9.68 \mathrm{E}-10 \\ 10 \% & 9.85 \mathrm{E}-10 \\ 15 \% & 1.06 \mathrm{E}-09 \\ 20 \% & 1.08 \mathrm{E}-09 \\ 25 \% & 1.16 \mathrm{E}-09 \\ 30 \% & 1.17 \mathrm{E}-09 \\ 35 \% & 1.24 \mathrm{E}-09 \\ 40 \% & 1.31 \mathrm{E}-09 \\ 45 \% & 1.32 \mathrm{E}-09 \\ 50 \% & 1.39 \mathrm{E}-09 \\ 55 \% & 1.43 \mathrm{E}-09 \\ 60 \% & 1.52 \mathrm{E}-09 \\ 65 \% & 1.52 \mathrm{E}-09 \\ 70 \% & 1.58 \mathrm{E}-09 \\ 75 \% & 1.62 \mathrm{E}-09 \\ 80 \% & 1.65 \mathrm{E}-09 \\ 85 \% & 1.70 \mathrm{E}-09 \\ 90 \% & 1.74 \mathrm{E}-09 \\ 95 \% & 1.76 \mathrm{E}-09 \\ 100 \% & 1.79 \mathrm{E}-09\end{array}$

The above output distribution appears to be a continuation of the previous output distribution. While mathematically correct, the use of a negative value for the evaporable water fraction to increase the dose from particulate releases is inconsistent with the definition of this parameter.

To test the HUMIDITY parameter, a single uniform distribution was selected, ranging from -1 to 1. In this case, one out of two sampled values of the humidity is negative, resulting in the following output at time zero:

Statistic $\quad \mathrm{H}-3$

Minimum $0.00 \mathrm{E}+00$

Maximum 9.73E-03

Average $\quad 9.02 \mathrm{E}-03$

Std.Dev 2.07E-03 


\begin{tabular}{|c|c|}
\hline Statistic & H-3 \\
\hline $5 \%$ & $4.07 \mathrm{E}-03$ \\
\hline $10 \%$ & $5.77 \mathrm{E}-03$ \\
\hline $15 \%$ & $9.56 \mathrm{E}-03$ \\
\hline $20 \%$ & $9.59 \mathrm{E}-03$ \\
\hline $25 \%$ & $9.66 \mathrm{E}-03$ \\
\hline $30 \%$ & $9.66 \mathrm{E}-03$ \\
\hline $35 \%$ & $9.68 \mathrm{E}-03$ \\
\hline $40 \%$ & $9.70 \mathrm{E}-03$ \\
\hline $45 \%$ & $9.70 \mathrm{E}-03$ \\
\hline $50 \%$ & $9.71 \mathrm{E}-03$ \\
\hline $55 \%$ & $9.71 \mathrm{E}-03$ \\
\hline $60 \%$ & $9.72 \mathrm{E}-03$ \\
\hline $65 \%$ & $9.72 \mathrm{E}-03$ \\
\hline $70 \%$ & $9.72 \mathrm{E}-03$ \\
\hline $75 \%$ & $9.72 \mathrm{E}-03$ \\
\hline $80 \%$ & $9.72 \mathrm{E}-03$ \\
\hline $85 \%$ & $9.73 \mathrm{E}-03$ \\
\hline $90 \%$ & $9.73 \mathrm{E}-03$ \\
\hline $95 \%$ & $9.73 \mathrm{E}-03$ \\
\hline $100 \%$ & $9.73 \mathrm{E}-03$ \\
\hline
\end{tabular}

The negative humidity values are accepted, but the resulting doses are reported as incorrectly calculated using negative values to increase the maximum dose. Since the dose is inversely proportional to humidity, the maximum dose of $9.70 \mathrm{E}-03$ can only occur at the minimum humidity of zero.

The test on WALL_DENSITY used the same distribution, but resulted in half the values (those less than 0 ) setting the lower $50 \%$ percentile of the dose distribution to zero.

There are common problems affecting all tritium parameters when multiple sources are involved or when removing a source, removing tritium from a source or changing the source type. An example of such problems is illustrated below, using DRYTHICK as an example.

Start with a single tritium volume source of unit concentration, and set the Dry zone thickness to a uniform distribution between 0 and 5 . The doses at time zero are summarized below:

Source 1

Statistic $\quad \mathrm{H}-3$

Minimum 5.79E-03

Maximum 9.66E-03

Average $\quad 8.15 \mathrm{E}-03$

Std.Dev 1.24E-03

Now add a second identical source, but set the Dry zone thickness for this source to a uniform distribution between 5 and 10. The doses for source 1 and 2 at time zero are summarized below: 
Source 1

Statistic H-3

Minimum 1.30E-04

Maximum 5.62E-03

Average 2.85E-03

Std.Dev 1.66E-03

Source 2

Statistic H-3

Minimum 1.23E-04

Maximum 5.59E-03

Average $\quad 2.83 \mathrm{E}-03$

Std.Dev 1.65E-03

Note that there is no significant difference in the statistics of Source 1 and 2 in the two-source run, despite the clear difference in the distribution of the Dry zone thickness. Note also that the results for Source 1 with and without Source 2 are significantly different, although they should be the same since the distribution of input values was not changed for Source 1. It appears that the code is applying the distribution defined for Source 2 to both sources.

Now click on Source 1 and remove it. View the "Uncertainty Analysis Input Summary" window; the code does not remove the Source 1 uncertainty analysis parameters. The doses from Source 2 (renamed Source 1 after the run) are summarized below:

$\begin{array}{ll}\text { Statistic } & \mathrm{H}-3 \\ \text { Minimum } & 5.79 \mathrm{E}-03 \\ \text { Maximum } & 9.66 \mathrm{E}-03 \\ \text { Average } & 8.14 \mathrm{E}-03 \\ \text { Std.Dev } & 1.23 \mathrm{E}-03\end{array}$

Note that the doses for this source are statistically equivalent to the doses reported above for Source 1 (single-source run), but Source 1 is the source that was removed. It appears that the code is assigning the distribution from Source 1 (the one that was removed prior to the uncertainty analysis run) to Source 2 .

Now remove the uncertainty parameters for Source 1 (the source that was removed from the deterministic run). The doses from Source 2 (renamed Source 1 after the run) are summarized below:

Statistic $\quad \mathrm{H}-3$

Minimum 9.66E-03

Maximum 9.66E-03

Average $\quad 9.66 \mathrm{E}-03$

Std.Dev $\quad 0.00 \mathrm{E}+00$

Note that there is no variation in the doses. This appears to be caused by an indexing problem, since the source is renumbered (from Source 2 to Source 1) in the deterministic input file, but the uncertainty parameter is not renumbered in the uncertainty input file, leading to a mismatch. 
Now change Source 2 to an area source. The code runs the uncertainty module, despite the fact that there are no volume sources and the fact that the area source does not use this parameter. No variation is observed in the reported doses, as expected.

Finally, change Source 2 back to a volume source, but replace the tritium in Source 2 with CO-60. The code runs the uncertainty module, despite the fact that there are no volume sources containing tritium. No variation is observed in the reported doses, as expected.

The above problems were encountered with H3THICK, H3VOLFRACT, H3RMVF, and HUMIDITY.

\subsection{Input Distribution Verification}

After the user enters a distribution and the associated statistics for a parameter, RESRAD-BUILD generates a file containing a set of parameter values from the specified distribution. The number of parameters generated will be the product of the selected number of repetitions and observations. One method for verifying that RESRAD-BUILD is generating a consistent set of parameter values is to generate a similar set of values using an industry-standard spreadsheet addin such as Crystal Ball, entering the same statistical distribution parameters specified in RESRAD-BUILD. The two independently generated data sets can then be tested to ensure that they are statistically equivalent. An alternate verification strategy that works well for common distributions is the use of the curve fitting routine in Crystal Ball to determine which distribution types most closely fit the data sets generated by the RESRAD-BUILD LHS routine. However, this alternate strategy can only be applied when the data sets have been generated from a continuous distribution. This process was repeated for five parameters for which uncertainty analysis is available and focused on the default or commonly used continuous distribution types available in both RESRAD-BUILD and Crystal Ball (uniform, triangular, normal, exponential, and lognormal). Unfortunately, the log-uniform distribution is not available in Crystal Ball.

\subsubsection{Selected Parameter Distributions}

Table 3-1 lists the selected parameters, distribution types, and values for which statistical tests were conducted. The range of values was selected to be consistent with the limits imposed by RESRAD-BUILD on these parameters.

Table 3-1. Parameters, Distributions, and Values Used in Uncertainty Analysis Input Tests

\begin{tabular}{llcccc} 
Parameter $($ Units $)$ & Distribution & $\begin{array}{l}\text { Min or } \\
0.1 \%\end{array}$ & $\begin{array}{c}\text { Most Likely } \\
\text { or Mean }\end{array}$ & $\begin{array}{c}\text { Std. Deviation } \\
\text { or Lambda }\end{array}$ & $\begin{array}{c}\text { Max or } \\
99.9 \%\end{array}$ \\
\hline DENSIO $(\mathrm{g} / \mathrm{cm}$ & Uniform & 2.2 & $\mathrm{~N} / \mathrm{A}$ & $\mathrm{N} / \mathrm{A}$ & 2.6 \\
BRTRATE $\left(\mathrm{m}^{3} / \mathrm{d}\right)$ & Triangular & 12 & 33.6 & $\mathrm{~N} / \mathrm{A}$ & 46 \\
AREA $(\mathrm{m})$ & Normal & $\mathrm{N} / \mathrm{A}$ & 36 & 3 & $\mathrm{~N} / \mathrm{A}$ \\
AIRFR $(-)$ & Exponential & $\mathrm{N} / \mathrm{A}$ & $\mathrm{N} / \mathrm{A}$ & 7 & $\mathrm{~N} / \mathrm{A}$ \\
LAMBDAT $(1 / \mathrm{h})$ & Lognormal-B & 0.15 & $\mathrm{~N} / \mathrm{A}$ & $\mathrm{N} / \mathrm{A}$ & 15.0
\end{tabular}




\subsubsection{Crystal Ball Results}

The RESRAD-BUILD file that generates the uncertainty analysis input values for each parameter, LHSBIN.DAT, was transferred to a spreadsheet. The five sets of parameter values generated by RESRAD-BUILD were then subjected to a Crystal Ball distribution fit test. This test compares each data set to a list of 11 continuous distributions. Three testing methods, chisquared, Kolmogorov-Smirnov, and Anderson-Darling, are used to determine the best fit among these 11 distribution types. All three techniques correctly determined the underlying distributions of the data sets generated by RESRAD-BUILD for DENSI0 and LAMDAT. The chi-squared technique also correctly determined the underlying distribution for AIRFR, while the AndersonDarling technique correctly determined the underlying distribution for BRTRATE. However, only the Kolmogorov-Smirnov technique correctly predicted the underlying distribution for all five parameters. Table 3-2 lists the distribution fits obtained by Crystal Ball using the Kolmogorov-Smirnov technique.

\section{Table 3-2. Distribution fits obtained by Crystal Ball using the Kolmogorov-Smirnov} Technique

\begin{tabular}{|c|c|c|c|c|c|}
\hline Parameter (Units) & Distribution & $\begin{array}{l}\text { Min or } \\
0.1 \%\end{array}$ & $\begin{array}{l}\text { Most Likely } \\
\text { or Mean }\end{array}$ & $\begin{array}{l}\text { Std. Deviation } \\
\text { or Lambda }\end{array}$ & $\begin{array}{l}\text { Max or } \\
99.9 \%\end{array}$ \\
\hline DENSI0 $(\mathrm{g} / \mathrm{cm}$ & Uniform & 2.199 & $\mathrm{~N} / \mathrm{A}$ & $\mathrm{N} / \mathrm{A}$ & 2.599 \\
\hline BRTRATE $\left(\mathrm{m}^{3} / \mathrm{d}\right)$ & Triangular & 12.269 & 33.185 & $\mathrm{~N} / \mathrm{A}$ & 46.342 \\
\hline AREA (m) & Normal & N/A & 35.997 & 2.989 & $\mathrm{~N} / \mathrm{A}$ \\
\hline AIRFR (-) & Exponential & $\mathrm{N} / \mathrm{A}$ & $\mathrm{N} / \mathrm{A}$ & 7.025 & $\mathrm{~N} / \mathrm{A}$ \\
\hline LAMBDAT $(1 / \mathrm{h})$ & Lognormal & $\mathrm{N} / \mathrm{A}$ & 1.973 & 1.685 & $\mathrm{~N} / \mathrm{A}$ \\
\hline
\end{tabular}

A comparison between Tables 3-1 and 3-2 verifies that the parameter distribution data sets generated by RESRAD-BUILD correctly represent the user-selected distribution and associated parameters.

\subsection{Output Distribution Verification}

The verification of the uncertainty analysis tests conducted for single parameters was extended by applying uncertainty analysis to multiple parameters in a pathway model. This was useful in understanding the impact from parameters that apply to only one pathway, compared to parameters that apply to all pathways and/or source types.

In verifying the deterministic results for most pathways, excluding the external gamma pathway, results were obtained by coding the pathway equations in an Excel spreadsheet. The deterministic spreadsheet model was extended by assigning distributions using the Excel uncertainty analysis add-on Crystal Ball. Distributions equivalent to those allowed in RESRADBUILD were defined for the appropriate input parameters, and the simulations were run under similar conditions (i.e., Latin Hypercube with 300 iterations). While results from Crystal Ball and RESRAD-BUILD simulations are not expected to be identical due to different randomnumber generation, tests on the output distributions were used to verify that any differences are only due to statistical chance.

The direct ingestion pathway was selected for the output distribution verification because it is relatively simple, but incorporates multiple parameters that are eligible for uncertainty analysis. Since the algorithms used in the uncertainty analysis module are independent of which pathway is 
selected, verifying the correct implementation of the uncertainty analysis module to a single pathway is sufficient to demonstrate verification for all pathways. This conclusion is subject to the limitations and errors noted in Section 3.1 that apply to individual parameters eligible for uncertainty analysis.

\subsubsection{Input Parameter Distributions}

The equation for the direct ingestion of removable material is provided in Appendix $\mathrm{E}$ of the user's manual for both volume (Equation E.1) and non-volume (Equation E.2) sources. Two tests were conducted, one for each equation, using the default parameters for each parameter eligible for uncertainty analysis. These parameters, distributions, and values are listed in Table 3-3. The distributions were selected to represent a number of the most popular distribution types likely to be used. With the exception of the air release fraction (and the source type in the second test), all deterministic parameter values were left as the default. To assess only the direct component of the ingestion dose, the value for the air removal fraction (AIRFR) was set to zero, effectively suppressing the air-dependent pathways. In addition, only time zero was assessed, and the number of integration points was set to 1 (no correction for decay and removal). The source concentration was set to $100 \mathrm{pCi} / \mathrm{g}$ of Co-60. In the second test, the default volume source was changed to an area source, and the source concentration was set to $100 \mathrm{pCi} / \mathrm{m}^{2}$. Of the parameters exercised in the uncertainty output tests, one parameter applies only to the direct ingestion pathway (INGE1), but is used differently in calculating volume or non-volume sources, another parameter applies to only non-volume sources (RMVFR) and the remaining parameters affected all pathways and sources (TTIME and FTIN).

Table 3-3. Parameters, distributions, and values used in uncertainty analysis output tests

\section{Volume Source}

\begin{tabular}{llllll} 
& & & Most Likely or & \\
Parameter/Units & Distribution & Min & Mean & Standard Deviation & Max \\
\hline INGE1 $(\mathrm{g} / \mathrm{h})$ & Normal & N/A & 0.01 & 0.001 & N/A \\
TTIME (d) & Triangular & 0 & 90 & N/A & 365 \\
FTIN (-) & Uniform & 0 & N/A & N/A & 1
\end{tabular}

Area Source

\begin{tabular}{llllll} 
& & & Most Likely or & Std. Deviation or & \\
Parameter/Units & Distribution & Min & Mean & Lambda & Max \\
\hline INGE1 (1/h) & Exponential & N/A & N/A & 10000 & N/A \\
TTIME (d) & Triangular & 0 & 90 & N/A & 365 \\
FTIN (-) & Uniform & 0 & N/A & N/A & 1 \\
RMVFR (-) & Bnd-Normal & 0 & 0.75 & 0.25 & 1
\end{tabular}

No correlation between variables was assumed in the first set of tests (all variables are independent). A second set of tests was conducted by positively and negatively correlating TTIME and FTIN with correlation coefficients of +0.99 and -0.99 , respectively.

\subsubsection{Uncertainty Output Tabular Results}

Table 3-4 summarizes the results obtained using Crystal Ball and RESRAD-BUILD. In general, the uncertainty analysis results obtained with Crystal Ball and RESRAD-BUILD were very 
similar, as indicated by ratio between statistical parameters very close to unity for the most important parameters, such as the mean (ratio within 6 percent), median (ratio within 16 percent) and standard deviation (ratio within 20\%). The ratio in the average deviation between the cumulative values (excluding the intervals containing the minima and maxima) was calculated for each $10^{\text {th }}$-percentile interval; this ratio indicates good agreement, within $10 \%$ or less, in the cumulative distribution for each result. The minimum and maximum values are single values out of 300 that are generated; therefore, they are subject to much greater variability than the mean or median values. Considering that the range of direct ingestion doses calculated by RESRADBUILD spanned 2-4 orders of magnitude for the volume source and 4-6 orders of magnitude for the area source, such close agreement indicates that the uncertainty module in RESRAD- BUILD is correctly calculating the distribution of doses.

Table 3-4. Ratio between RESRAD-BUILD and Crystal Ball Results for Statistical Parameters of Output Distributions

\begin{tabular}{lcccccc} 
& \multicolumn{2}{c}{ No Correlation } & \multicolumn{2}{c}{ Positive Correlation } & \multicolumn{2}{c}{ Negative Correlation } \\
Statistic & Volume & Area & Volume & Area & Volume & Area \\
\hline Minimum & 1.03 & 0.24 & 1.88 & 8.36 & 3.13 & 2.30 \\
Maximum & 0.65 & 0.84 & 0.65 & 0.75 & 0.89 & 1.09 \\
Mean & 0.99 & 1.06 & 1.00 & 1.04 & 1.00 & 0.96 \\
Median & 1.16 & 1.09 & 1.08 & 0.98 & 1.10 & 1.00 \\
Std. Dev. & 0.80 & 1.06 & 0.94 & 1.00 & 0.81 & 0.93 \\
Av. \%ile & 1.08 & 0.99 & 1.07 & 0.95 & 1.04 & 1.04
\end{tabular}

Deviation*

*This represents the average deviation in the 10-percentile cumulative distribution of results, excluding the upper and lower $10^{\text {th }}$ percentile, which contain the minima and the maxima.

The degree of dependency (sensitivity) of the results on each parameter can be determined by viewing the rank observations in RESRAD-BUILD (or the sensitivity chart in Crystal Ball). RESRAD-BUILD consistently ranked FTIN and TTIME as the most important parameters affecting the ingestion dose, regardless of whether these two parameters were correlated or not. RESRAD-BUILD also consistently ranked the direct ingestion rate for the volume source lower than the direct ingestion rate for the area source, despite the fact that the dose from the area source was typically two orders of magnitude lower than the dose from the volume source. Since most of the dose from the volume source is due to external gamma, whereas the ingestion pathway dominates the area source calculation, this is not unexpected; it is the relative change in the dose and not the magnitude of the dose that matters as far as sensitivity is concerned. Crystal Ball correctly identified FTIN and TTIME as important parameters, but also ranked the direct ingestion rate for the volume source among the top three parameters. In the case of negative correlation between FTIN and TTIME, Crystal Ball identified the opposite effects that these two parameters have on the dose, and ranked the direct ingestion rate for the volume source as the most important parameter, whereas RESRAD-BUILD did not. Because the variations in the total dose in the volume source is much greater than the ingestion dose, the regression and correlation coefficients of total dose against the ingestion rate indeed turn out to relatively unimportant for the volume source. These inconsistencies may be due in large part to differences in how Crystal Ball and RESRAD-BUILD report their correlation coefficients. 


\subsubsection{Uncertainty Output Graphic Results}

The primary objective in verifying the output distributions is the comparison of the tabulations of statistical properties generated by RESRAD-BUILD and Crystal Ball (i.e., minimum, maximum, mean, median and percentiles). An attempt was made to also compare the graphical output generated by RESRAD-BUILD with the graphical output from the Crystal Ball simulations to determine whether this component of the statistics package has been implemented correctly. Unfortunately, the graphic output from RESRAD-BUILD was not available. After running the uncertainty module, attempting to select "View, Uncertainty Graphics" from the main menu resulted in the following error message: "Component 'VCFI32.OCX' or one of its dependencies not correctly registered: a file is missing or invalid." This error was also duplicated on another computer and indicates a possible problem with the RESRAD-BUILD installation program. 


\section{Evaluation of Other Issues}

In addition to performing a strict verification of the deterministic and uncertainty calculations performed by RESRAD-BUILD, the following related tasks aimed at improving the code and supporting documentation were conducted in parallel:

- Review of the code, user's manual and other ancillary documentation for consistency.

- Review of the code functions that do not impact the calculations.

- Review of the calculation methodology.

In general, the user's manual was found to be very well written and easy to follow. Most of the time, what was written in the manual was reflected in the code. However, there are some areas, highlighted below, that could be improved to make the RESRAD-BUILD code and the user's manual a better product.

\subsection{Consistency}

The purpose of this task was to identify inconsistencies between what is stated in the code documentation and what is actually performed or described in the code. Potential issues included, but were not limited to, inconsistent information (parameter values/bounds/descriptions) in the user's manual and in the parameter help screens, omissions in the code and/or its documentation, and editorial changes. As such issues were uncovered, they were documented along with suggestions for possible resolutions. Most of these inconsistencies have already been addressed in Section 2.2 and 3.1 of this report. Additional minor typos and inconsistencies are addressed in the parameter-specific checklist reports included in the CD-ROM appendix included with this verification report.

Some issues that do not involve parameters or models were uncovered that may affect the ability of a user to take full advantage of the features described in the user's manual. These issues are described below.

\section{$\underline{\text { Installation Problems }}$}

The user's manual indicates that RESRAD-BUILD may be installed on a computer running one of the following operating systems: "Windows 95, 98, NT, 2000, or later versions." The code was successfully tested on a computer running Windows 2000 Professional and ME.

The code also appeared to install correctly under the Windows XP operating system. The graphical user interface is fully functional, and the user is able to create and save input files. However, requesting the code to run an input file results in the following error message:

\section{Abnormal program termination: Stack fault $C S: E I P=000 F h: 00001373 h$}

This problem, which prevents the code from performing any calculations, was reproduced on two different computers running the Windows XP Professional operating system. Even running RESRAD-BUILD under an emulation of an earlier version of Windows did not resolve this problem. Future releases of RESRAD-BUILD should be tested to ensure compatibility with the latest Windows operating system. 


\section{Graphical Problems}

After running the uncertainty module, attempting to select "View, Uncertainty Graphics" from the main menu resulted in the following error message: "Component 'VCFI32.OCX' or one of its dependencies not correctly registered: a file is missing or invalid." This was duplicated on two other computers.

\section{General Typos/lnconsistencies}

1. The error message that follows the input of an inappropriate value (e.g., alphanumeric or out of bounds) is " $X$ not set appropiately," where $X$ would be replaced by the code name of the parameters, such as AIRFR or UD. The word "appropiately" is an embedded typo; it should be corrected to "appropriately" in the error message.

2. There is a typo in the "Uncertainty Analysis Input Summary" window. Under "Sample specifications - Grouping of observations" the word "Uncorrlelated" is misspelled (should be changed to "Uncorrelated"). Also, a blank line should be inserted between paragraphs under "Information about current selection" for each applicable selection on this screen.

3. The capitalization of the tab headings in the "Uncertainty Analysis Input Summary" window is inconsistent. Either capitalize every word OR just capitalize the first word in each tab heading.

4. When no default distribution is available to conduct uncertainty analysis on certain parameters (e.g., source area), the "Parameter distributions" tab in the "Uncertainty Analysis Input Summary" window displays a paragraph requesting the user to select from the list of distributions. The second sentence in this paragraph contains a misspelled word, "distirbuition," which should be changed to "distribution". The word "inputs" in this sentence should also be changed to the singular "input".

\subsection{User Friendliness}

The purpose of this task was to consider those issues that do not impact the calculations, but should be addressed to improve the user-friendliness of the code. Potential issues include, but are not limited to, layout of input screens, organization of output reports, graphical or visual displays, and menu navigation. Many of the comments in this section have already been reported in previous sections of this report. Suggestions for improvements are provided when applicable.

\section{File Save}

1. When viewing the output file for a deterministic run, the "Save" command does not appear to be working. No file is saved under the filename specified by the user (in this case Titletest.txt).

2. When viewing the output file for a deterministic run, the first time a "Save All" command is issued following a run with no uncertainty analysis the code will rename any existing uncertainty input files (*.SAM, *.PRB) under the filename assigned to the current run.

3. Saving a file where the user has set up parameters with uncertainty analysis does not result in the uncertainty analysis parameters being saved along with the input file. If a file which had 
been previously run with some parameters selected for uncertainty analysis is saved and then opened at a later time, all previously "saved" uncertainty analysis settings are gone.

\section{Help Function}

1. Clicking on the Help Button [?] in the tool bar or the F2 function key (or selecting "Help, Index" from the main menu bar) when no parameter is highlighted does not work the first time it is attempted. Repeating this attempt, however, invokes the list of help topics. The general list of help topics should appear after the first time the Help Button or F2 function key is pressed, or the first time that "Help, Index" is selected.

2. The Help Screens, while now similar to those in the RESRAD code, are not as informative. In earlier versions of the RESRAD-Build code, the Help Screens for each parameter included the default and bounding values for that parameter. This provided some useful information for the user, especially when the default parameter was changed.

\section{Default Parameter Values}

1. To provide consistency with the treatment of parameters in RESRAD, the default parameter values should be on a yellow background, which changes to a white background after entering a non-default value. This is already implemented in the uncertainty module and should be extended to the deterministic input as well.

2. There should be a simple mechanism for resetting a single parameter to its default value. The code currently only allows the user to change ALL parameter to the default. In essence, this is just like starting a new input file.

\section{Multiple Screen Windows}

1. With the default input file in memory, the following actions were performed in the Building Parameters input panel: Press "Air Flow" button; Select 2 for "Number of Rooms"; Press "Air Flow" button; Select 3 for "Number of Rooms"; Press "Air Flow" button. This sequence of actions caused three "Room Details" windows to open up on the screen, one for the one-, one for the two-, and one for the three-room models. This has the potential to cause confusion, as the user may choose a different number of rooms, but may forget to cancel the inappropriate "Room Details" window. Inappropriate data may still be present on the screen, possibly covered by a larger sized window. Each of the three windows was found to accept user input even when only one would have been appropriate based on the current selection for the number of rooms.

2. It is possible to run the code with the "Room Details" window still open after changes have been entered, but the code will run using the previous values. Changes made to any of the parameters in this window will not be saved unless the window is closed by pressing either "OK" or "Cancel". This was also found to be the case for other windows that are accessed from the main input windows (e.g., Evaluation Times, Details for Source \#N, Wall Region Parameters, and Source Receptor Table). The code should request that the user either confirms or cancels any changes made in open windows prior to running the code. 


\section{Uncertainty Module}

1. While in the uncertainty analysis input window, clicking on the "Help" button will invoke a graphical display of the currently selected distribution and parameters. In most cases, entering an inappropriate parameter value causes the code to warn the user without crashing the code (by changing the input field background to red). However, some problems may arise with lognormal-type distributions. If the parameter value selected for the mean and/or standard deviations is inappropriately large (in either negative or positive direction), it may still be accepted and the code may run. However, if the user clicks on "Help" before running the code, the code crashes with one of the following messages: Runtime error '11' (division by zero) or ' 6 ' (overflow).

2. The order in which the pathways are listed differs in the deterministic and uncertainty output report. In the deterministic output report, the pathways are listed in the following order: External, Deposition, Immersion, Inhalation, Radon, and Ingestion. In the uncertainty output report, the pathways are listed in the following order: External, Inhalation, Deposition, Immersion, Ingestion, Radon, and Total. This different ordering has the potential to result in errors of transcription, but this can easily be remedied. Since the deterministic output report is the one that is most frequently viewed by typical users, it is recommended that the order of the pathway doses presented in the uncertainty output report be arranged to match the order of presentation in the deterministic output report.

3. The column listing the total dose in the uncertainty output report may not necessarily match the sum of the individual pathway doses listed on the same row. That is because some pathways may be sensitive or insensitive to one or more parameter that are the subject of the uncertainty analysis and some parameters may have opposite effects in different pathways. For example, the deposition and indirect ingestion pathway are directly proportional to the deposition velocity, but the inhalation and immersion are inversely proportional to this parameter. The opposite is true for the resuspension rate. This is a potential source of confusion and should be clarified.

\section{Miscellaneous Issues}

1. Changing the radiological units for activity and dose is effective only for the duration of the current RESRAD-BUILD session. Closing and then opening RESRAD-BUILD causes the units to revert to the defaults ( $\mathrm{pCi}$ and mrem). Having to reset the units can become tedious for users that run the code using exclusively SI units or units other than the defaults. Displaying a dialog box asking the user if he/she wishes to save the current units as the defaults (if these are different from the current saved defaults) upon exiting RESRADBUILD would resolve this issue.

\subsection{Calculation Methodology}

The purpose of this task was to review the calculation methodology to determine whether it is adequate for the intended purpose of the code. The primary focus of this review was on the following complex models:

- External Radiation Exposure

- Indoor Air Quality

- Deposition Model 
- Radon and Progeny Model

- Tritium Model

- Ingestion/Inhalation Models

The limitations of each of these models were identified, along with the availability of more appropriate models if applicable. Simpler calculation models were also reviewed to determine if they are adequate for the purpose of producing reasonable or conservative results. The results of this review are documented below.

It was understood that any computer model has to strike a balance between degree of model complexity, parameter availability, and computation time. Therefore, any suggestions for improvements in the calculation methodology were made in consideration of the intended applications.

\section{External Radiation Models}

The external radiation model is described in Appendix F of the user's manual and has already been extensively reviewed in Sections 2.3.1 through 2.3.3.

In assessing the methodology used by RESRAD-BUILD for direct gamma exposures, the MicroShield code was used as a benchmark. Several limitations were encountered in the RESRAD-BUILD methodology that have been overcome in MicroShield.

1. The point and line source models use a 4-group energy spectrum that may not adequately characterize the emissions from radionuclides with complex spectra. This problem is accentuated when shielding is applied due to differences in buildup and attenuation factors for different photon energies. The differences may not be conservative, depending on the radionuclide and shield material type.

2. The analytical line source model is adequate for the unshielded calculations, but yields unreliable results when shielding is added. This is due to the assumption that there is a constant shielding thickness between source and receptor. However, the specified thickness is only applicable to the radiation emitted from the line center point; for all other portions of the line, the "effective" shield thickness will be different depending on the geometry between the line and the receptor. This problem is accentuated for large line sources and may result in conservative doses. The differences may not be conservative, depending on the radionuclide and source-receptor geometry.

3. The area and volume sources are circular and cylindrical, respectively. This is not the normal geometry of most cases for which RESRAD-BUILD might be applied. Most contaminated surfaces and volumes will be rectangles or parallelepipeds (walls, floors, etc.). Use of a circular geometry will overestimate the doses from rectangular area or volume of the same size, as long as the receptor is located along the center point. However, this dose may not be conservative if the receptor is located near the corner of a rectangular source.

4. The use of a cover and depth factor, as well as an area and off-set factor, to adjust the doses from areas and volumes of infinite extent is useful in realistically modeling finite shielded sources. These area factors were derived based on point-kernel integration methodologies such as those used by MicroShield. Actual doses, however, are calculated using interpolation or coefficients derived from fitting a curve to the point-kernel results. As such, there is some loss of accuracy relative to direct application of a point-kernel code such as MicroShield. In addition, there is no flexibility in defining the shield geometry, and partial shields cannot be 
directly modeled in RESRAD-BUILD. These limitations may not lead to conservative results, depending on the radionuclide and source-shield-receptor geometry.

5. RESRAD-BUILD uses up to 3 materials to calculate an effective build-up factor (air, and/or source material, and/or shield material). Most point-kernel codes, such as MicroShield, attribute the buildup factor over the entire attenuation path to a single material. In shielding practice, this is usually the material in which the photons undergo the greatest attenuation, or the last material in the path between source and receptor. Therefore, RESRAD-BUILD results will always be inconsistent with results obtained by traditional point-kernel codes. These differences may not lead to conservative results, depending on the radionuclide and air/source/shield material properties and source-shield-receptor geometry.

6. The immersion external gamma dose model, as discussed in the user's manual, does not take any credit for a limited room size. This may significantly overestimate doses from highenergy emitters, but this conservative dose model will only have a significant impact on the total doses in limited cases. These cases may include receptors not located in the same room as the source and/or cases when the inhalation pathway is greatly reduced or eliminated, as might be the case for receptors using respirators.

7. The deposition external gamma model is not described in the user's manual, but presumably follows the same methodology as that for an unshielded area source. However, since there is no way to define the coordinates of the receptor with respect to this secondary source, the RESRAD-BUILD likely models this exposure pathway by assuming the floor to be a circular area source with the receptor located one meter above the center of the floor. The code is possibly applying an area factor to account for the finite dimensions of the floor. All of the above, however, is speculation. The verification of this pathway yielded results that appeared to underestimate the doses in all cases that were tested. Such results will not likely have significant impacts on the overall dose in most typical cases. However, calculated doses may not be insignificant when calculated for cases similar to those described for the submersion model.

\section{Indoor Air Quality Model}

The RESRAD-BUILD indoor air quality model is described in Appendix A of the user's manual. Its purpose is to calculate time dependent concentrations of radionuclides that are released from sources and transported in the air flow between one, two, or three rooms and the external environment.

The one-room model verification is documented in Section 2.3 of this report. However, while a partial verification of the two- and three-room models was performed in Section 2.5, it was not possible to fully verify the correct implementation of the two- and three-room model due to problems encountered with the input parameters for this model that govern the flow of air between multiple rooms and the outside. These problems are described in Section 2.2.3 of this report. In particular, the code does not appear to be capable of accommodating zero air flows at boundaries between adjacent rooms or between rooms and the outside air (such as might be the case in a basement).

One simplification of this model is the assumption of steady state concentrations and instantaneous mixing, although the concentrations are corrected for decay, ingrowth, and removal over the exposure duration. However, it is not possible to model any variability in the air exchange rates over time, and uncertainty analysis is not enabled for most parameters that go into the air quality model. For most applications, such simplifications will be adequate, but the 
limitations of the code in estimating air concentrations in the room air due to varying ventilation parameters should be addressed in the user's manual.

\section{Air Particulate Deposition Model}

The air particulate deposition model is described in Appendix B of the user's manual. This model is an integral part of the indoor air quality model and is the primary model used to estimate external gamma doses and ingestion doses from deposited material. The most significant observation is that the deposition of material on the floor is assumed to be in steady state with the resuspension of material, resulting in a concentration on the floor that is only a function of air concentration, deposition rate and resuspension rate. There is no consideration for the gradual change in concentration due to a buildup or depletion of material over time. In a real situation, the concentration on a previously uncontaminated floor will be zero at time zero and gradually build up until a steady state is reached between deposition and resuspension, after which the concentration will change as the room air concentration changes or the resuspension and deposition parameters change. This assumption leads to an overestimate of doses when the source is releasing contamination to the air, especially at time zero. However, the dose will be underestimated for those times when the initial source is no longer releasing material through mechanical erosion. In those cases, RESRAD-BUILD calculates a zero dose from deposited material, when in reality the deposited material is still contributing to the indirect ingestion and deposition external gamma doses as well as to the inhalation and submersion external gamma doses (from resuspended material). In most cases, the doses from these pathways will likely be small relative to the initial doses, but ingrowth from short-lived, less hazardous radionuclides (e.g. Pu-241 to Am-241) may actually result in higher doses over time from these secondary sources where the code calculates a zero dose.

\section{Radon Model}

The RESRAD-BUILD radon model is a complex model described in Appendix C of the user's manual. Some problems arose when attempting to verify the RESRAD-BUILD radon model. Several of these problems have been addressed in Section 2.2.5 with regards to the input parameters used by the volume source radon model. Other issues were identified in Section 2.3.4 of this report.

In particular, the current RESRAD-BUILD user's manual contains a typographical error in Equation C.33 on page C-21. The coefficient for Bi-212 used to calculate the Rn-220 progeny working levels was reported to be $1.17 \times 10^{-4}$. The correct value of $1.17 \times 10^{-5}$, as reported in the previous RESRAD-BUILD user's manual, should be used in the next revision of the RESRADBUILD user's manual. The user's manual should also cite the original source for these coefficients as well as the source for other factors used in the model, such as the radon inhalation $\mathrm{K}$ factors and the dose conversion factors.

In addition to the issues identified previously, the RESRAD-BUILD radon model appears to have the following limitations.

1. The volume source radon model assumes that diffusion is the dominant transport mechanism from source to the room air. This may underestimate the true concentration in the room air because it neglects the effects of advective transport mechanisms. Such mechanisms may dominate the transport pathways for certain porous materials or for rooms with changing 
pressure differentials over time, such as when a ventilation system alternates between on and off, as is the case in many residential settings.

2. The rate constants used in the RESRAD-BUILD radon progeny model in Table C. 1 of the user's manual. There is no way for the user to adjust the attached fractions for the radon progeny in the current version of the code. In addition, Table C.1 provides a range of values for attachment rate and the plate-out rate that span one and two orders of magnitude, respectively. The code uses only a single value from this range, but this value is not specified in Appendix C of the user's manual. The values of these parameters may be very different for the range of possible RESRAD-BUILD scenarios, ranging from demolition (high average dust loading and inhalation rates) to residential (low average dust loading and inhalation rates). Therefore, it is recommended that the user be given access to these parameters, and the user's manual expand on Table C.1 by providing default values for a representative range of scenarios.

3. The radon dosimetry is based on the concept of working level months (WLM), a measure of dose specific to radon exposures, and is not directly tied to the inhaled concentrations of radon progeny as might be calculated by an inhalation rate. According to Appendix $\mathrm{C}$ of the user's manual, some adjustment using a " $\mathrm{K}$ " factor and dose conversion factors is made to convert from WLM to standard dose units. This multiplication factor takes into consideration the different effects of indoor occupancy, typical dust loading, and inhalation rates relative to exposures in radon in mine workers. While the user's manual provides the default values for "K" used by the code, the user cannot change this factor. However, the RESRAD-BUILD radon model should be more flexible since it can apply to a large number of different exposure scenarios, ranging from demolition (high average dust loading and inhalation rates) to residential (low average dust loading and inhalation rates). Therefore, it is recommended that the user be given access to this parameter, and the user's manual be revised to include a table of default values of " $\mathrm{K}$ " for a representative range of scenarios.

\section{Tritium Model}

The tritium model, described in detail in Appendix G of the user's manual, was verified for all source types, but in greater detail for the volume source. There were some issues that arose with how RESRAD-BUILD calculates the tritium dose to an exposed individual. The methodology described in the user's manual, and verified in this report, is to account for the dose by dermal absorption by increasing inhalation dose by $50 \%$. This methodology suffers from an obvious flaw in those cases where the inhalation rate is set to zero for receptors assumed to be wearing respirators, resulting in an inhalation and dermal absorption dose of zero. One solution to this case is to include a parameter for the respiratory protection factor for tritiated water vapor (or other gases). This parameter could also be extended to account for respiratory protection from particulates only, so that radon and tritium inhalation doses might still be incurred by the receptor without having to set the inhalation rate to zero to model the use of respirators. Since only tritiated water vapor would contribute significantly to the dermal absorption dose, this solution would also more accurately model the contributions of tritium released as, or attached to, particulates.

Regarding the volume source model, the model considers only diffusion, rather than advection, possibly underestimating the release rate. In addition, the model does not consider adsorption/desorption, atomic exchanges with hydrogen, or isotopic effects. Some of these limitations are recognized in the user's manual, but the impacts of neglecting these effects are not quantified. 
Additional problems were identified when reviewing the tritium volume source parameters. These problems are described in Section 2.2.7 and prevented the full verification of the tritium volume source model. While there may be no need to increase the complexity of the tritium model, the problems identified in the existing model should be fixed. The current user's manual simply recommends that the vaporization model in RESRAD-BUILD be used for screening purposes only, but does not specify whether the calculated results are conservative. The manual should be updated to give the user a better sense of the tritium model's strengths or weaknesses in typical RESRAD-BUILD applications.

\section{Mass Balance Issues (Ingestion/Inhalation Models)}

The RESRAD-BUILD code does not check whether the amount of source intake exceeds the available source. It is possible to adjust parameters such as breathing and ingestion rates to far exceed the inventory of the source. While the user's manual provides a warning that the user needs to check the parameter values that are used, the code could do a better job at limiting inadvertent user errors. At a minimum, the code should limit the breathing and ingestion rates to physiologically realistic maxima. Another simple solution would be to compare the total activity intake summed over all the receptors against the source inventory for each radionuclide. Other more sophisticated diagnostic tests may be feasible, but these two methods would provide a simple first step towards warning to the user that there is a gross mass balance problem. 


\section{Documents Used for Verification}

The following list of reference documents includes all of those that were used to verify the RESRAD-BUILD code. There was some initial delay during the verification project in acquiring the main source document, the RESRAD-BUILD user's manual. This required that the verification tasks be suspended until this document became available. There were no other difficulties in obtaining the remaining documents.

Eckerman et al. 1988

K.F. Eckerman, A.B. Wolbarst, and A.C.B. Richardson, Limiting Values of Radionuclide Intake and Air Concentration and Dose Conversion Factors for Inhalation, Submersion, and Ingestion, EPA 520/1-88-020, Federal Guidance Report No. 11, U.S. Environmental Protection Agency.

Eckerman and Ryman 1993

Eckerman, K.F. and Ryman, J.C, External Exposure to Radionuclides in Air, Water, and Soil, EPA-402-R-93-081, Federal Guidance Report No. 12, Environmental Protection Agency.

Grove 1996

Grove Engineering, "MicroShield 5.0," Rockville, Maryland.

ICRP 1983

International Commission on Radiological Protection, Radionuclide Transformations, Energy and Intensity of Emissions, ICRP Publication 38, Annals of the ICRP, Pergamon Press.

Kamboj et al. 1998

S. Kamboj, C. Yu, and D.J. LePoire, External Exposure Model Used in the RESRAD Code for Various Geometries of Contaminated Soil, ANL/EAD/TM-84, Environmental Assessment Division, Argonne National Laboratory, September.

Kamboj et al. 2001

S. Kamboj, C. Yu, B.M Biwer, and T. Klett, RESRAD-BUILD Verification, ANL/EAD/TM-115, Environmental Assessment Division, Argonne National Laboratory, October.

Shleien 1992

B. Shleien, editor, The Health Physics and Radiological Health Handbook, Revised Edition, Scinta Publishers, Silver Springs, MD.

Trubey 1991

D.K. Trubey, New Gamma-Ray Buildup Factor Data for Point Kernel Calculations: ANS-6.4.3 Standard Reference Data, NUREG-5740, ORNL/RSIC-49, prepared by Oak Ridge National Laboratory, Oak Ridge, TN, for U.S. Nuclear Regulatory Commission, Washington, D.C., August. 
Verification of RESRAD-BUILD, Version 3.1

WISE 2000

WISE Uranium Project, Universal Decay Calculator, November 27. Available online at: http://www.antenna.nl/wise/uranium/rcc.html

Yu et al. 2001

C. Yu, D.J. LePoire, J.-J. Cheng, E. Gnanapragasam, S. Kamboj, J. Arnish, B.M. Biwer, A.J. Zielen, W.A. Williams, A. Wallo III, H. Peterson, Jr., User's Manual for RESRADBUILD Version 3, ANL/EAD-5, Environmental Assessment Division, Argonne National Laboratory, November. 